$$
\begin{aligned}
& \text { lemang Lle Testo } \\
& \text { A DIINITTRITEUR DES COLWNIES } \\
& -\infty \\
& \text { NOTES } \\
& \text { SIR LES } \\
& \text { 3. DINS LA }
\end{aligned}
$$

Circonscription de la Nyanga

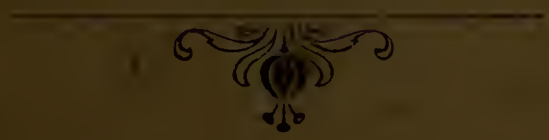

\footnotetext{
$(11 N$

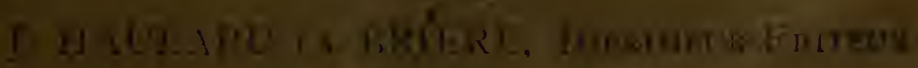

f. kine firingerthe =
} 




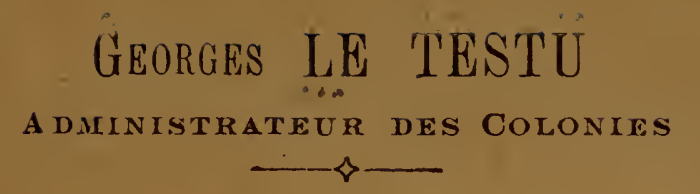

NOTES

\author{
SUR LES
}

\title{
COUTUMES BAPOUNOU
}

\author{
DANS LA
}

Circonscription de la Nyanga

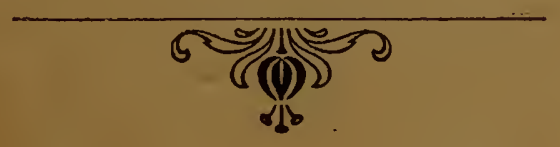

CAEN

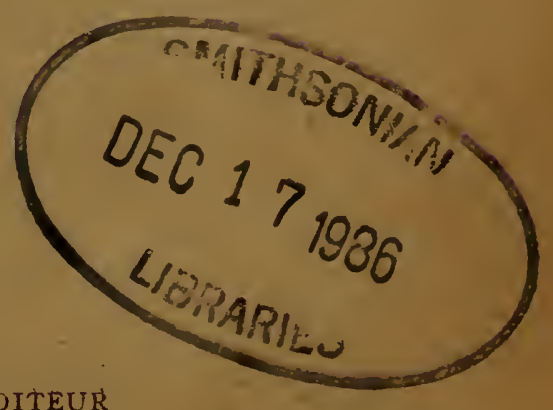

J. HAUİARD LA BRIERE, IMPRIMEUR-EDITEUR

6, Rue Branville 



\section{SỦR LA MANIĖRE DAPPLIQUER}

\section{LES COUTUMES INDIGĖNES}

\section{Conseils Préliminaires aux Chefs de Subdivision}

Les décrets qui ont successivement régi l'administration de la Justice en A. E. F., ont toujours prévu que les indigènes pourraient ou même devraient être jugés suivant leurs coutumes " en tout ce qui n'est pas contraire aux principes de la civilisation française ". (Décret du 16 avril 1913, art. 47).

Les Chefs de Subdivision ne conservent plus à présent que le rôle d'officiers de police judiciaire, auxiliaires du Procureur de la République, et celui d'arbitres dans les différends. Si le rôle de juges au civil et au criminel leur a été enlevé, leurs attributions n'en conservent pas moins au point de vue judiciaire une haute importance; e'est à eux que revient le soin d'empêcher que les " palabres " entre indigènes prennent assez de gravité pour nécessiter l'intervention de la Justice et leur entremise comme conciliateurs entre les parties présente un grand intérêt social. Ce dont les indigènes ont le plus besoin, en effet, c'est de la paix, mère de la stabilité, et la conciliation peut la leur procurer mieux encore que la Justice.

Quel que soit le rôle attribué aux Chefs des différentes divisions territoriales au point de rue judiciaire, la première qualité qu'ils doivent manifester, e'est la constance dans les opinions; la Justice doit être une. Il n'en est point ainsi à l'heure actuelle, et les indigènes auxquels ce manque d'uniformité n'a pas échappé, en profitent pour présenter leurs " palabres " à plusieurs "Commandants " successifs, risquant ainsi que l'un d'eux leur donne raison.

Ce défaut capital de notre Justice est imputable pour partie aux mutations fréquentes dans le per- 
sonnel, mutations qui nous empêchent de prendre assez de contact avec nos administrés pour bien connaître leurs coutumes.

Il faut incriminer également l'obscurité du texte: "Les indigènes seront jugés, dit l'art. 47 du décret du 16 avril 1913, suivant leurs coutumes en tout ce qui n'est pas contraire aux principes de la civilisation française "; ce sont termes bien vagues, et ils laissent le champ libre aux interprétations. La civilisation des indigènes est très primitive, ses principes opposés aux nôtres: filiation maternelle, mariage hors du consentement de l'épouse, successions collatérales, esclavage, ignorance des sanctions, etc., etc. Faut-il appliquer notre loi écrite? Faut-il s'en tenir aux principes de la morale naturelle la plus élémentaire? Les espèces ne manqueront pas où l'on ne saura à quoi se résoudre et en fait, j'ai constaté des divergences de principe entre des fonctionnaires très consciencieux, très soucieux de bien remplir leur rôle d'arbitres.

Dès le début de mon séjour dans la Nyanga, 1907, j'ai nourri l'intention de mettre un peu d'unité dans la manière d'appliquer les coutumes. Je suis resté longtemps, près de dix ans, dans le même poste; j'ai étudié avec soin les usages des indigènes, les ai recueillis par écrit; à ces titres, j'en puis parler.

Je ne m'illusionne cependant pas; mon étude présentera des lacunes, des inexactitudes. Il appartiendra à mes successeurs de la compléter, de la rectifier. Les Chefs des territoires voisins apprécieront dans quelle mesure les principes que je pose pourront être mis en vigueur dans leur région. De l'ensemble de ces travaux peut sortir la codification des coutumes du Gabon.

Tel qu'il est cependant, et en attendant mieux, le travail qui paraît aujourd'hui peut sans doute être appliqué. Il vaut mieux un règlement imparfait, mais uniforme et constant, que pas de règlement du tout. 
Faut-il appliquer les coutumes? - Evidemment, oui; toutes les relations entre les indigènes sont conclues sous l'empire de la coutume et il est de stricte équité d'admettre le principe que la convention fait loi entre les parties; en outre, le texte de 1913 le dit, il faut nous y conformer.

Faut-il les appliquer toujours? - Non. - Il faut cearter la coutume lorsquelle est contraire:

- à un réglement spécial et précis, exemple: dans les faits de traite;

- à l'équité, exemple: dans le cas d'épreuve judiciaire par le poison.

J'ajouterai, qu'il faut passer outre à la coutume lor'squ'elle est altentatoire au libre arbitre des personnes, lorsque sa conservation doit entraver le développement moral ou social de l'indigène et j'en citerai des exemples quand je parlerai du mariage.

Maintenant, dans quel esprit faut-il appliquer la coutume?

Au point de vue de l'Administration de la Justice Indigène, je veux dire, lorsqu'un acte commis sous l'empire de la coutume se trouve soumis aux Tribunaux Indigènes de la Circonscription, lexistence de la coutume doit ètre prise en considération et faire accorder les circonstances atténuantes, voire jusqu’à l'absolution complète, à l'indigène de bonne loi, habitant d'une région peu pénétrée, en dehors de l'action ordinaire de l'autorité.

-Dans le rôle d'arbitre réservé aux Chefs de Subdivision, un principe doit tout dominer; ce n'est point la préoccupation de la légalité, de l'équité mème qui doit prévaloir, c'est le souci de procurer, d'assurer, de maintenir la paix entre 'les indigènes, car la paix est la condition sine qua non de la stabilité, du travail, du développement social, du progrès moral des populations primitives que nous administrons.

En un mot, la Justice Indigène ne doit pas être son but à elle-même, elle ne doit être qu'un moyen, parmi les autres, d'amélioration, de civilisation.

Ceci dit, j’aborderai immédiatement l'étude des difiérentes parties de la coutume. 
PREMIERE PARTIE

\section{DES PERSONNES}

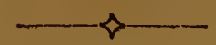

CHAPITRE I

\section{DE L'ÉTAT DES PERSONNES}

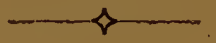

\section{$\S 1 .-$ De la Servitude}

Les indigènes sont libres ou ne le sont pas. Je n'hé. siterai pas à employer le mot d'esclave. L'autorité officielle, par une sorte de pudeur administrative, en proscrit l'usage. En employant ce mot prohibé, cependant, nous ne reconnaissons pas la légitimité de la servitude, nous en constatons seulement l'existence et celle-ci n'est pas niable. Les archives judiciaires de tous les postes sont pleines de procédures pour faits de traite, et les points d'aboutissement des esclaves, les endroits où se rencontrent en plus grand nombre les consommateurs de ce produit spécial qu'est l'esclave, sont génćralement les pays habités par les races les plus évoluées, c'est Libreville avec les Mpongwé, l'Ogooué avec les Galloa, Fernan-Vaz avec les Nkomi, Loango avec les Bavili.

N'ayons donc pas peur d'employer le mot esclave; constater lexistence de la servitude, étudier son origine, ses lois, ses conséquences, les règles qui gouvernent le trafic des esclaves, c'est le meilleur moyen de remédier à cette plaie sociale du pays et des peuples fiotes.

L'homme libre jouit de tous les droits que reconnaît la coutume; il a les obligations qu'elle impose. 
Lesclave a un peu plus de devoirs et un peu moins de droits et nous signalerons à chaque chapitre ce en quoi il se différencie de l'homme libre.

Il convient dajouter que rien dans la coutume n'assure le respect de ces droits, n'astreint à l'exécution de ces devoirs. -

\section{Comment devient=on esclave?}

1. Par la naissance, lorsque la mère est clle-même esclave;

$2^{\circ}$ Par accident: Il arrive fréquemment encore, il arrivait quotidiennement autrefois que des femmes, des enfants, même des hommes, rencontrés en petits groupes ou isolés, ou même en plein village étaient enlevés et vendus.

En général cet enlèvement constituait des représailles; on compensait ainsi la dette impayée d'un débiteur insolvable. Il n'ćtait d'ailleurs pas nécessaire que la personne enlevée fût parente ou alliée de celui-ci; il suffisait qu'elle fût du même village, ou d'un village voisin. Dans ce cas le créancier disait à haute voix: "Je prends cet homme (hom:me = être humain, de quelque sexe ou àge qu'il soit) à cause d'un tel qui me doit telle chose ".

3" Par frande: Les Chefs de Poste ont souvent entendu les femmes marićes se plaindre qu'on "les traitait comme esclaves "; leurs auteurs déposent souvent pour elles la même plainte. Cette phrase, pour quelqu'un de non prévenu, est dépourvue de sens.

La première question que nous posons dans ce cas est celle-ci: Voyons, qu'est-ce qu'on t'a fait? - On te maltraite? - On te prive de nourriture? de vêtements? - Nous sommes loin de compte. C'est une simple menace et qui ne peut toucher la femme personnellement. Elle ne peut lui inspirer de craintes que pour ses enfants et pour ses parents à elle; et voici le sens de la phrase, sens que j'ai mis fort longtemps à découvrir. Traiter sa femme comme esclave veut dire: la menacer de la considérer elle et ses enfants comme des esclaves. Sa situation, ses besognes d'épouse ne seront 
en rien changées et son mari prendra d'elle autant ou aussi peu de soin. Mais ses enfants seront réputés fils d'une esclave, c'est-à-dire non libres "'bifou la " (au singulier " tchifoula " en vili, "ifoula " en yaka) et lors du mariage des filles, la ligne paternelle seule recueillera toute la dot. Mais encore, lors du décès de son mari, s’il précède le sien, elle deviendra l'épouse du neveu ou du frère de celui-ci; nous verrons que, libre ou non libre, tel est le sort de la veuve; seulement, ses ayant-droit ne toucheront pas, pour cette mutation, l'indemnité fixée par l'usage : dix pièces.

On ne menace une épouse de la traiter comme esclave que lorsque, pour une raison quelconque, elle a perdu toute relation avec. sa famille, soit que celle-ci ait disparu, soit qu'elle se trouve trop éloignée.

Nous verrons qu'un des droits que les épouses maintiennent le plus jalousement, c'est celui de conserver des relations suivies avec leur famille. D'où les fréquents et longs séjours loin du village de leur mari. Ces séparations temporaires ont de graves inconvénients, mais on ne peut les empêcher. Elles sauvent. les femmes des abus de pouvoir de leur seigneur et maître.

$4^{\circ}$ - Par voie de justice. - Il s'agit éridemment de la justice spéciale aux indigènes.

Si un individu se rend coupable dun fait criminel grave, ou plus souvent, si la décision du sorcier lui impute la responsabilité, par exemple, d'un décès, d'une suite de décès, d'un simple accident, l'arbitre indigènê qui règle la compensation, attribue le coupable ou supposé tel à la partie plaignante. Cela a pu se faire pour les hommes, je ne l'ai pas observé; cela se fait surtout pour les femmes et je citerai le cas suivant: un honme au cours d'une chasse fut grièvement blessé par l'éclatement de son fusil et mourut. On trouva la cause de l'accident dans un adultère, non prouvé ou supposé, de l'épouse et on la réduisit en esclavage.

Il fut un temps où l'esclavage par condamnation 
était courant. Le meurtre d'un chat, par exemple, entraînait l'obligation de payer une pièce par poil; l'amende était impossible à liquider, on réduisait en servitude toute la famille du meurtrier.

Un Chef important, ayant besoin d'esclaves, arrêtait des passants chez lui, les accusait de l'avoir insulté, alors qu'un chant de coq, simplement, s'était fait entendre; - ou bien, à l'un de ces passants, on offrait à boire dans un récipient déjà brisé, mais recollé légèrement; au moindre attouchement non combiné, le vase se brisait de nouveau. Pour ces injures supposées, pour ce rase soi-disant brisé, on réduisait un ou plusieurs de ces passants en servitude.

$5^{\circ}$ - Par suite de la mort des parents proches. Nos indigènes ignorent la charité; lorsque le père et la mère décèdent laissant des enfants en bas âge, s'il n'y a pas de parents très proches pour en prendre soin, il ne se trouve personne disposé à en assumer la charge et on les vend pour s'en débarrasser.

La situation d'esclave attaché à la famille n’a rien de pénible; au point de vue matériel, elle est mème enviable. Jeune ou vieux, l'esclave, dans ce cas, est considéré comme un enfant de la maison; son maître lui donne d'ailleurs ce nom: " mwana ". enfant, le mème qu'il donne à son fils, et l'esclave le traite de père. La fanille a vis-à-vis de lui les nêmes obligations qu'envers les enfants du sang; on doit assurer sa nourriture, son vêtement, son mariage même quelquefois. En principe, ce qu'il peut posséder appartient à son maître, mais rien ne l'empêche de disposer luimême de ce qu'il a pu gagner. Il n'y a pas de sanctions contre lui. Bien plus, un homme qui traiterait mal ses esclaves serait mal vu de sa propre famille.

S'il s'agit d'une femme, elle ne fera pas souche d'hommes libres, cela est vrai; mais, dans la pratique, son importance dans la famille ne sera pas diminuée, et, dans le mariage de ses filles, par exemple, on tiendra toujours compte de son opinion. 
Si le maître lui-même épouse une femme achetée, il devra en payer la dot à sa propre famille à lui.

La descendance d'une femme esclave, tout en continuant à former une famille subordonnée, peut constituer une vraie famille, avec un nom, et, l'autorité de chef de village ou de terre peut très bien passer d'un homme libre à un ifoula.

Si je voulais résumer en quelques mots quelle est la condition de l'esclave de famille, je dirais qu'il reste toute sa vie vis-à-vis de son maître, dans la situation d'un enfant à l'égard de ses auteurs, père et oncles maternels. L'un et l'autre ont des obligations; la coutume leur en impose, mais elle ne prévoit pas de sanctions s'ils lui désobéissent. L'enfant est nourri, il n'est pas éduqué; l'esclave insoumis n'encourt pas de punition.

\section{$\therefore$}

La situation d'esclave-marchandise est moins bonne sans être pénible. Elle est caractérisée par ceci qu’il passe de main en main avec la plus grande rapidité; il ne séjourne dans aucune famille. S'il s'y attardait, en effet, la coutume l'y attacherait définitivement, et la famille chercherait noise au maître s'il venait à s'en défaire. Il finit toujours d'ailleurs par faire partie de quelque famille et, étant donné le peu de distance du pays d'origine au point d'aboutissement, les mutations ne sont pas très nombreuses.

Quand j’aurai ajouté que la servitude est perpétuclle et qu'elle se transmet par les femmes jusqu'à la plus lointaine génération, j'aurai à peu près épuisé le sujet.

\section{Conséquences sociales de la servitude}

J'avoue n'en point voir de regrettables. L'esclave n'est ni moins ni plus libre que son maître. Homme, il peut s'enrichir, il peut commander et j'en ai sonnu qui violentaient leur maitre. - Femme, elle a autant 
de droits qu'une épouse quelconque, elle a les mêmes devoirs et on n'a pas moins d'égards pour elle que pour une femme libre. En fait, on ne mariera pas ses filles autrement qu'elle ne le voudra et elle aura également dans la dot la petite part attribuée à la mère.

En somme, la condition matérielle de l'esclave n'a rien de pénible: il est à peu près aussi considéré qu'un homme libre. Il a des droits et rien ne l'oblige à s'astreindre à des devoirs. Il ne faut donc pas s'étonner que la liberté, à notre sens, n'ait point d'attraits pour lui. Il est excessivement rare, on le sait, qu'un esclave vienne demander au poste sa liberté; je ne l'ai, pour ma part, vu qu'une ou deux fois.

Ce qui m'étonne davantage, c'est que, dans les cas où la coutume n'attribue à l'esclave ou à l'ifoula que des avantages pécuniaires restreints par rapport à ceux des hommes libres, il ne vienne pas demander à l'autorité qu'il lui soit attribué une part entière. Il y a cependant une évolution de ce côté et j'ai déjà vu quelques fils d'esclaves réclamer d'être considérés pratiquement comme étant de souche libre.

Une question subsidiaire se pose: étant donné le peu d'avantages pratiques rapportés au maître par la possession d'un ou de plusieurs esclaves, comment se fait-il que le commerce en soit aussi tenace, persiste aussi longtemps malgré les pénalités sévères encourues? - Jaai souvent posé la question aux indigènes, aux non civilisés, et à ceux qu'un peu d'instruction nous a fait prendre comme auxiliaires. On m'a toujours fait la même réponse et je la crois en définitive exacte.

Les indigènes recherchent les esclaves pour se créer une famille, une société, pour aroir, comme ils le disent eux-mêmes, beaucoup de gens autour d'eux, à eux. Nous verrons, en effet, que la famille indigène n'est pas constituée comme la nôtre. Un homme étant donné, son individualisme incapable de concessions, sa crainte des sorts et des périls suscités à ses yeux par une imagination désordonnée, l'amèneront à s’isolẹr avec sa ou ses épouses, quelquefois son frère, quel- 
quefois son ou ses neveux, mais tout ce monde peut le quitter un beau matin. Ses enfants sont pour lui des étrangers. Le lien familial est très ténu et le lien social moins solide encore. Pour éviter la solitude, pour se créer une famille à notre sens ou mieux au sens latin du mot, il arrive à s'entourer d'esclaves. Ceux-là, surtout s’il les a élevés, ne se sauveront pas et ils sont bien plus ses enfants que ceux qu'il a engendrés.

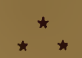

\section{Conséquences morales de Ia servitude}

Nous avons vu combien peu la servitude dans notre région porte effectivement atteinte à la liberté de l'individu. Il ne faut pas entourer l'esclavage de cette auréole d'inhumanité que la tradition nous a transmise. L'esclave dans nos régions est moins assujetti qu'un domestique et est l'objet de plus d'égards. C'est ailleurs qu'il faut chercher pour justifier la réprobation dont la servitude doit être l'objet.

J'ai exposé que l'esclave a des droits, ou plutôt que la coutume impose au maître vis-à-vis de son esclave les mèmes devoirs que vis-à-vis de ses enfants. Cette obligation a pour sanction les dissensions familiales éventuelles, choses bcaucoup plus graves assurément que ces termes ne peuvent l'indiquer.

La coutume impose également des devoirs à l'esclave envers son maitre. Seulement ces devoirs n'ont aucune sanction. Souvent, très souvent, l'esclave abuse de la bénignité de la contume. Il vole, il tue, il comnet l'adultère et le moins qu'on puisse lui reprocher, c'est d'incarner la paresse.

Qui doit alors pourvoir à ses besoins sans espoir de rétribution? - Le maître.

De tous ses méfaits, qui est pécuniairement responsable? - Encore le maître.

Bien heureux est-il, s'il n'est pas la première victime.

A mon sens, l'esclavage, tẹl que je le vois pratiquer, 
est cause qu'il se perpétue une classe d'individus, sans loi et sans aveu et ceci doit être réprimé avec la dernière énergie.

Si primitive, si élémentaire que puisse être la morale d'un être humain, il en a toujours une: l'esclave n'en a pas. Il s'est abaissé au rang de l'animal qui satisfait ses instincts par tous les moyens possibles; il faut s'opposer à de pareilles mœurs et les faire disparaitre.

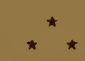

\section{Quel compte tenir de la coutume}

\section{en matière d'esclavage ?}

J'attirerai d'abord l'attention sur ceei, que nous ne devons pas inquiéter les gens qui possèdent des esclaves. Aucun texte ne nous l'impose, et s'il fallait en croire l'autorité de la Colonie, nous devrions l'ignorer.

Je conseille au contraire de les rechercher avec soin et de les noter sur les recensements. Un esclave peut être vendu, il peut demander à retourner dans son pays, sa qualité d'esclave lui impose des obligations. lui donne des droits déterminés. Constater le fait n'est point en reconnaître la légitimité, comme je le disais plus haut. Mais la connaissance du statut personnel d'un individu donné nous permettra de rendre des jugements ou des sentences arbitrales en connaissance de cause et, sinon de les faire admettre, il n'y faut pas songer cncore, du moins de les faire comprendre des parties.

Je n'ai eu à observer que quatre sortes de cas où l'intervention de l'autorité se justifiait ou était sollicitée.

$1^{\circ}$ Faits de traite proprement dits. - Le décret du 12 décembre 1905 régit la matière et sa portée est absolument générale. Il frappe "tout acte accompli avec l'intention de disposer de la liberté d'un individu contrairement à sa volonté ", il faut ajouter: même en dehors de sa volonté. Les pénalités qu’il prévoit, bien 
qu'élevées, ne seront efficaces qu'à la longue, tant il est difficile de faire disparaître des coutumes consacrées par un usage immémorial.

La grande difficulté que nous rencontrons vient de ce que nous luttons seuls contre les intéressés, sans l'appui d'une contre-partie à intérêts opposés.L'esclave adulte est rarement négocié; l'objet du trafic est très généralement un enfant; il n'a aucune affection pour sa famille et il lui importe peu de vivre avec elle ou avec des étrangers.

Les faits de traite doivent être réprimés sévèrement, j'ai expliqué pourquoi, mais il faut cependant être équitable. Il est juste d'infliger le maximum de la peine, par exemple, aux habitants de la côte, point d'aboutissement habituel des esclaves; ils sont en effet inexcusables, ayant été depuis longtemps en contact avec notre civilisation, n'ayant pas à exciper d'une ignorance improbable de ce qui est permis et de ce qui ne l'est pas.

Il faut au contraire être indulgent pour les habitants de l'intérieur, chez qui la coutume est toute puissante et que notre action civilisatrice a encore à peine effleurés.

Il y a place pour tous les degrés de peine et j'imagine sans effort des cas oì les circonstances atténuantes pourront être admises jusqu'a l'absolution complète.

$2^{\circ}$ - Un esclave est réclamé par son maître. - Il ne s'agit pas en général d'esclave prenant véritablement sa liberté, mais bien d'un esclave quittant son maître pour un autre maître de son choix.

Nous ne pouvons pas imposer à l'esclave fugitif de retourner chez son maître. Ce serait attenter à sa liberté.

Nous ne pouvons davantage imposer au nouveau maître choisi par l'esclave de dúdomimager l'ancien, bien que sa conduite lui cause un réel préjudice; nous semblerions ainsi reconnaître la légitimité de la convention par laquelle un homme a acheté un autre homme, convention nulle puisqu'elle a un objet illicite. 
En droit strict, nous ne devrions pas intervenir. Mais notre abstention laisserait place libre aux représailles de la part du maître lésé et, pour l'esclave fugitif, il peut $y$ avoir risque de mort: mort violente, mort par le poison.

Notre rôle, dans ce cas, consistera à conseiller au maitre de l'esclave d'abandonner sa plainte, à tâcher de lui faire reconnaitre le droit d'un homme à disposer de sa personne et de sa liberté, à lui dire que nous ne pouvons contraindre son esclave à revenir, mais que nous serions forcés de le punir s'il usait de violences vis-à-vis de lui ou du noureau maître.

A l'esclave, nous rappellerons que son maître a pris soin de lui, qu'il l'a traité comme son fils, que, maître pour maitre, autant vaut celui qu'on connaît que celui qu'on ne connaît pas. A lui et au nouveau maître de son choix, il faut faire prévoir les représailles possibles, représailles que nous pouvons réprimer, mais que nous sommes dans l'impossibilité de prévenir et d'empècher. Si notre éloquence n'a pas d'effet persuasif, il faut laisser l'affaire suivre son cours naturel, elle peut n'avoir pas de conséquence.

$3^{\circ}$ - Un esclave réclame sa liberté complète. - Le cas est encore très rare. Je ne l'ai observé que deux fois: un adulte, banzabi, a voulu retourner dans son pays; - un jeune garçon est venu déclarer son intention de retourner chez son oncle.

Dans les deux cas, il est indispensable d'assurer l'arrivée de l'esclave qui se libère au point qu'il a choisi; il faut veiller à sa sécurité dans la route. Les races ide l'intérieur, banzabi, mitsogho, portent des tatouages qui les font reconnaitre et un esclave de ces races retournant dans son pays serait arrêté en route et remis en serviturde. Il faut l'envoyer de poste en poste muni d'une feuille de route explicative, ou même le faire accompagner par un garde.

S'il s'agit d'un homme ou 'd'un enfant de la région, il est indispensable de faire venir au poste le parent, père, oncle, frère de qui il se réclame et le leur remettre en mains propres. 
Il ne sera pas inutile de s'assurer si cette prétendue réclamation de liberté ne dissimule pas une vente du maitre au soi-disant parent, vente que l'on voudrait effectuer sous le couvert de notre autorité.

$4^{\circ}$ - Un esclave ou un homme non libre réclame des droits égaux à ceux des hommes libres. - Le cas se présente, en particulier, lors du paiement des dots. Normalement, la dot payée pour un mariage est partagée entre le père, et les frères de la mère de la fenme, entre la branche paternelle et la branche maternelle. S'il s'agit d'une fille de femme esclave, la idot revient tout entière à la tige paternelle. L'espèce que j'ai eue à juger est la suivante :

Un homme épousa une esclave achetée, en eut des garçons et des filles; son neveu (fils de la sœur utérine), après sa mort, prétendit toucher seul la dòt entière de ces filles. Suivant la coutume il avait raison.

Sur la réclamation des frères rle la future, j’imposai le partage de la dot entre le neveu et les frères réclamants.

L'esclavage est d'autant plus difficile à faire disparaître que l'esclave ne voit pas qu'il a intérêt à ne pas rester escllave, ne serait-ce qu'un intérêt de dignité. Il faut saisir toutes les occasions qui permettent de lui faire trouver un intérêt à se libérer; celles où on peut lui montrer un intérêt immédiat et matériel sont les meilleures.

\section{$\S 2 .-$ De l'origine ethnique des esclaves}

\section{et spécialement des Babongo}

Les indigènes eschaves re notre région appartien. nent aux races les plus diverses, ainsi que l'origine de la servitude peut le faire prévoir.

J'ai rencontré des Mitsoghø à Mayumba, un Batéké à Mongonyanga, des Banzabi, Bavoumba, Echira, Masango, etc, partout; j'ai même vu un Bavili à Mocabe. Ils portent généralement des noms particuliers: Bambatama, Barondi, Barombiyaya, Bambéna, Bicouciala, Baranguémina, Bingana, etc., etc., sont des noms d'es- 
claves. A défaut du nom, les tatouages de race permettent de les reconnaître à premier examen; tel est le cas des Mitsogho et des Banzabi, qui portent sur l'abdomen des figures formées presque exclusivement de lignes droites.

Les femmes esclaves se reconnaissent plus difficílement; aucun signe extérieur, le plus souvent, n'indique leur situation.

Mais il existe une race distincte dont tous les individus sont esclaves, je veux parler des Babongo ou Barimba.

Quiconque à parcouru l'intérieur du Gabon a remarqué assurément ces hommes, souvent de petite taille, au teint clair, au regard fuyant, à l'aspect craintif. Ils fréquentent peu les postes, n'y portent autant dire jamais leur impôt; au moins ne viennent-ils pas euxmêmes pour cela. On les voit cependant, dans les subdivisions de Moabi et Tchibanga, assez nombreux dans les équipes de travailleurs présentés pour être engagés.

Le type de leur visage est variable, quelques-uns sont notablement prognathes, ont le nez largement épaté; d'autres, au contraire, ont la figure presque fine. C'est qu'ils ne sont pas de race pure, mais bien le résultat de métissages successifs.

Le mode de vie des Babongo est très différent de celui de nos administrés Bayaka, Bavili, Baloumbo (1). Ils ne construisent pas de villages; à peine font-ils,

(1) L'emploi de l'article français concurremment avec le préfixe personnel pluriel $\mathrm{BA}$, constitue en quelque manière un pléonasme. On derrait, ce me semble, dire : les Yakas, les Loumbos les Vilis. L'usage s'est établi cependant de dire : les Bayaka, etc Nous nous y sommes conformés.

Autre reflexion : Nous emploierons indifféremment les mots Bapounou et Bayaka, pour désigner les populations habitant sur la rive droite de la Moyenne-Nyanga. Ces deux mots sontils exactement synonymes? Les Bapounou, au contraire, ne sont ils qu'une espèce da Bayalia, et en existe-t-il d'autres dénommés d fféremment? Ou Jien. enfin, le vraı nom de la race est-il Bapounou, le mot Bayaka étant une sorte d'épithète dénigrante ayant un peu lesens de "sauvages". attribuée aux indigènes de l'intérieur par ceux de la còte? Nous n'arons pu nous former une opinion présentant quelque chance de certitude. 
en saison des pluies, quelques abris dans le canton de forêt où ils nomadisent. Ils n'ont point de cultures, vivent ,des fruits de la brousse, des produits de la pêche et de la chasse, et ils échangent ces produits, surtout le gibier, soit contre des bananes ou du manioc, soit contre les produits manufacturés européens, machetes, pagnes, etc. Encore, bien souvent, n'entrent-ils pas en relations directes avec les indigènes; ils arrivent de la forêt subrepticement dans les plantations, déposent à un endroit donné ce qu'ils se proposent d'échanger et se retirent; ils reviendront plus tard prendre livraison de ce qu'ils auront demandé. Voilà ce que sont les vrais Babongo. Mais beaucoup d'entre eux, surtout dans les subdivisions où il n'en existe pas de groupe organisé, vivent comme les autres indigènes, ont leur case, leur plantation, mais ils conservent un grand fond d'indépendance, un goût prononcé pour le vagabondage et on les aperçoit rarement.

Que sont ces hommes ? - D'où viennent-ils ? - Ils n'appartiennent assurément à aucune des races de la région, ne sont ni Bavili, ni Baloumbo, ni Bayaka. Je les ai, par hypothèse, rattachés aux négrilles, et, des résurgences assez fréquentes du type se rencontrent, attirant l'attention par l'exiguïté de la taille.

Comme toutes les races qui peuplent la Nyanga, je les crois étrangers; attachés, nous le verrons tout à l'heure, à une famille par les liens de la servitude, ils sont venus avec elle et l'ont accompagnée dans ses migrations. Je laisse à d'autres le soin de rechercher si les Bavili et les Baloumbo possèdent des groupes de Babongo et quelle est leur origine.

Ceux possédés par les Bayaka, sont venus avec les Bayaka de la Haute-Nyanga, et, par rapport à Tchibanga, de l'Est et du Sud-Est. C'est un fait constant, et $\mathrm{j}$ 'ai vu des indigènes faire la distinction entre leurs Babongo à eux et ceux venant du pays Nzabi, car les Banzabi en possèdent également.

Ces petits hommes existent encore dans d'autres 
endroits du Gabon et je pense que les Bécu du pays pahouin, les Akoa de l'Ogooué appartiennent à la même race.

Le statut social de ces indigènes est un peu différent de celui des autres races, Ils sont tous esclaves, ai-je dit, mais ce sont des esclaves ayant quelques droits spéciaux, et je vais, pour les faire connaître, expliquer comment se constitue à l'heure actuelle un groupe de Babongo. Il est vraisemblable que les groupes présentement établis depuis plusieurs générations n'ont pas une origine différente.

Lorsqu'un indigène veut se créer un groupe de Babongo, il achète une femme de cette race, la met en dépôt dans un groupe déjà constitué; elle s'y mariera et aura des enfants. Le premier de ses enfants mâles sera le chef idu groupe qui se formera ainsi peu à peu. Il aura sur les individus les pouvoirs et l'autorité du chef de famille, touchera une partie des dots. Comme lui et tous les siens sont esclaves d'une tribu, il sera bien obligé de temps en temps de laisser vendre quelqu'un des membres de sa bande; n'oublions pas toutefois que les Babongo sont des esclaves de famille et qu'on ne les vend, en somme, guère plus souvent que les enfants libres du sang, et seulement en cas de nécessité. Toutefois, le propriétaire de la bande de $\mathrm{Ba}$ bongo devra en consulter le chef au préalable, et c'est ce chef qui décidera soit l'individu qui sera vendu, soit la famille où il faudra le prendre, soit enfin qui laissera explicitement au propriétaire la liberté de choisir à son gré.

Il y a quelques tribus qui ont un nom, mais le plus sourent, je crois, elles n'en ont pas qui les distingue et on les désigne par le nom de la famille du propriétaire; on dit, par exemple, les Babongo des Liaba, des Bacambo, des Bavéla, des Youngou. Ce sont à ma connaissance les quatre familles les plus riches à ce point de vue. 
Avec des gens aussi peu saisissables que les Babongo, quelle politique tenir ? - C'est une situation difficile. $\mathrm{Si}$, d'une part, on n'a de relations avec eux que par l'intermédiaire de leur maître, il en dissimulera la plus grande partie, percevra cependant leur impôt et le fera, lors du versement, imputer au nom des hoimmes libres de sa famille.

$\mathrm{Si}$, au contraire, on cherche à entrer en relations directes avec ces nomades, leur mobilité extrême empêche de les connaître. tous; l'autorité est illusoire contre des individus qu'on ne peut joindre. En même temps, les sentiments d'indépendance que nous ne pouvons pas ne pas inspirer à ces malheureux détruisent l'autorité du propriétaire indigène. C'est done entre deux maux qu'il faut choisir.

'A mon avis, il n'y a pas à hésiter, et malgré les difficultés de l'entreprise, il faut tout faire pour entrer en relations directes avec les Babongo. C'est une race intéressante; est-ce disposition naturelle ? - est-ce le résultat du métissage ? - Toujours est-il qu'ils sont plus intelligents, plus travailleurs que les Bayaka: tout le caoutchouc qu'on vendait autrefois était de leur fabrication; ce sont eux qui fournissent le gibier, les plantes officinales.

Le Babongo a l'esprit ouvert, il apprend facilement un métier et il a des dispositions naturelles pour la poésie. J'en ai observé un à son insu; envoyé pour couper des arbres dans la forêt, il ne se séparait pas d'une de ces harpes ou guitares primitives à cinq cordes et ne se mettait pas au travail avant d'avoir chanté pour l'arbre qu'il allait sacrifier.

Leurs mœurs enfin sont plus pures, ils n'ont en général qu'une femme et sont plus honnêtes sensiblement que les individus des autres races.

A l'heure actuelle, se manifeste chez-eux une tendance à secouer le joug de leurs maîtres. Il faut la favoriser; les perceptions d'impôt en pâtiront d'abord, mais ce sera transitoire, et ce doit être secondaire. L'impôt ne doit pas être un but, c'est un moyen de civilisation. Tâchons donc de vaincre la méfiance des 
Babongo; ne leur demandons pas dabord de renoncer à leur vie nomade. Cherchons à connaître personnellement le Chef; lorsqu'il sera persuadé de nos bonnes intentions, il ne sera pas extrèmement difficile de lui faire comprendre que si la coutume les a constitués esclaves de telle ou telle tribu, en revanche les maîtres se sont mis par leur paresse, dans la dépendance économique de leurs Babongo; et si les Babongo ne veulent pas d'emblée secouer le joug traditionnel, au moins peuvent-ils, avec leurs maîtres, traiter d'égal à égal.

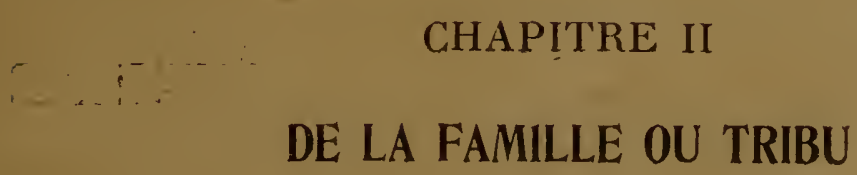

\section{Tribus libres. - Tribus serves.}

Outre la division en races qui n'est pas toujours des plus nettes par suite des mariages mixtes, les populations de la Circonscription de la Nyanga se répartissent entre un nombre assez restreint de familles ou tribus.

Chacune d'elles a son nom et habite un territoire déterminé, ou du moins, un territoire étant donné, il n'est occupé que par une seule famille et par ceux qui, pour une raison ou pour une autre, par le sang ou par le commerce, lui sont alliés.

La tribu est à la base de toute la société indigène; elle y joue le rôle attribué chez nous à la famille, à ce point que j'hésite encore sur le sens à donner au mot fiote, " tchifoumba " en vili, "ibandou " en yaka, qui désigne la chose: tribu ou famille. Le mot tribu impliquerait une cohésion d'ordre plus général, elle supposerait chez les membres qui la constituent le sentiment d'un intérêt supérieur à l'intérêt individuel, une espèce d'intérêt public, notion tout à fait étrangère à nos indigènes.

L'intérêt de la famille, encore que collectif, est ce- 
pendant déjà très particulier, et il touche chacun des membres de heaucoup plus près. Il est par conséquent beaucoup mieux compris des indigènes, individualistes forcenés, dont tous les actes ont pour principe: do ut des.

Mais la compréhension de ce groupement est tellement vaste quant aux personnes et quant aux territoires occupés, que le mot " tribu ". doit être préféré; il élait cependant nécessaire d'en préciser le sens.

Ces tribus ont dans chaque dialecte des noms particuliers, noms pluriels appartenant ou bien à la première classe des substantifs des langues bantou : substantifs personnels: préfixe " mou " au singulier, "ba " au pluriel. On dit, par exemple, Badoumbi, Bacambo, Bavèla, etc. ou bien aux autres catégories : Liaba, Mouloulou, Minzoumba. Chacun pourra faire, dans sa subdivision, un répertoire de ces noms de famille; les noms bavili, en particulier, ont une allure très difféiente. Ceux que je cite sont du dialecte yaka.

Les esclaves (femmes) peuvent également avec leur descendance arriver à constituer une tribu, nous allons le voir tout à l'heure; cette tribu est subordonnée à celle à laquelle appartenait le père, auteur de la descendance selon le sang et êlle porte un nom, où l'on veut quelquefois retrouver soit les sentiments de celui à qui appartenait l'esclave, soit encore la cause de la mise en servitude, s'il s'agit d'un esclavage d'origine juldiciaire.

Ces noms commencent généralement, en bayaka au moins, par le mot "Dibourou ", où nous retrouvons le radical " boura ", enfanter (bouta en vili). Ainsi: Dibouroupakho (Liaba), Dibouroumiviévié (Minzoumba), Dibouroubindigha (Dibamba), etc., etc., la liste en serait aussi longue sinon plus longue que celle des familles d'origine libre.

Il y a cependant des noms de tribus serves qui ne comportent pas de préliminaire; ainsi: les Bondé, les Irendé (Boumouellé). Rien n'indique alors le statut personnel de ces tribus. Il faut les connaître.

Enfin, il y a quelques tribus qui, bien que certaine- 
ment distinctes, portent le mème nom: il y a plusieurs tribus Bayengé, plusieurs Bacambo, plusieurs Badoumbi. Il faut egalement les connaitre; on les distingue les unes des autres souvent par un nom de lieu; en tous cas, elles se différencient par leur fétiche.

Chaque tribu, en effet, a un fétiche, un totem; cette coutume se manifeste dans les explications des indigènes, de la manière suivante assez inaltendue. Offrez, par exemple, à un homme de la tribu Coucongo (Minzoumba) de manger de la perdrix, il ne manquera pá de refuser en ciisanl: " la perdrix, c'est ma grand'mère! " et, quelques explications que rous lui donniez ou que rous lui demandiez, il ne démordra pas de cette parenté extraordinaire.

Je ne m'étendrai pas sur cette question des fétiches familiaux; les spécialistes, Reinach, Réville, etc., etc., en ont discuté l'origine. Je me borne à en signaler l'existence chez les races de nos régions. Je ne ferai qu'unc exception en faveur dè la tribu Bayengé. Son fétiche familial, son totem, est le perroquet gris à queue rouge, si commun chez nous; c'est de lui que les Bayengé tirent leur nom; on les appelle Bayengé Bakoussou pour les clistinguer des Bayengé Bacombo. Les uns ne mangent pas de perroquet, les autres pas de mouton et voici la légende de l'alliance des premiers avec ce singulier protecteur :

Un homme des Bayengé avait un ennemi mortel; il le rencontra un jour dans la forêt. Cet ennemi voulut profiter de la solitude du lieu pour satisfaire sa haine et tuer le Bayengé. Mais, prudent, il lui demanda d'abord: "Es-tu seul " ? - "Non, dit le Bayengé, il y a des gens avec moi "- "Appelle-les donc !"

Le Bayengé était seul, mais, payant d'audace, il appela ses soi-disant compagnons. Ce furent les perroquets qui répondirent et lui sauvèrent la vie, car celui qui voulait le tuer eut peur de n'ètre pas le plus fort et s'enfuit. Les Bayengé prirent alors le perroquet, "koussou i, comme protecteur et depuis ce jour, ils s'abstiennent d'en manger. 
Premier résultat de cette notion de tribu: nous pouvons en déduire une conclusion intẻressant l'ethnographie de notre région.

Ces noms de tribu, disais-je plus haut, varient avec les dialectes et c'est assez naturel, mais chose curieuse, il existe, généralement connues de tous, des équivalences d'un dialecte à l'autre. J'en ai rencontré entre les noms de famille Mitsogho, Banzabi, Bavili et les Bayaka. Les Echira et les Varama nous fourniraient vraisemblablement d'autres exemples.

Ne faut-il pas voir là une preuve de la commune origine de toutes ces races fiotes ainsi qu'on les appelle ? Le mot mériterait d'ailleurs de faire fortune et serait employé provisoirement à désigner les races du Gabon qui n'appartiennent pas au groupe pahouin ou au groupe Mpongwé (Mpongwé, Galloa, Nkomi, etc.)

A cette notion très répandue de l'équivalence des familles, se joint souvent chez les indigènes la connaissance de leur origine topographique et je ne saurais trop engager mes confrères à noter tous les renseignements qu'ils pourraient recueillir à cet égard. Les traditions sont nulles ou à peu près chez nos populations; chacun au-delà de deux ou trois générations ignore sa généalogie. Nous ne pourrons nous faire une idée des origines des races de la Nyanga que par la connaissance du point de dispersion des tribus. Encore faut-il se hâter de les recueillir; les mélanges de races se font rapidement; quelques lustres de civilisation suffisent pour faire oublier ces notions id'une grande importance historique.

Le rôle social de la tribu est très grand, disais-je; nous la verrons en effet intervenir dans tous les actes de la vie indigène: mariage, successions, relations de commerce, possessions territoriales, transmission de l'autorité. Aucune de ces questions dans lesquelles nous avons quotidiennement à intervenir comme juges ou arbitres ne nous apparaîtra sous son vrai jour si nous faisons abstraction de la notion de tribu et il est indispensable de l'étudier avec soin. La tribù à laquelle 
appartient chaque individu devra ètre notée au recensement à la suite de son nom.

On aura quelquefois à trancher des questions difficiles sur la possession tribale. Des femmes mises en esclavage, il y a plusieurs générations, ont souvent transmis avec soin à leurs descendants le secret de leur origine. Il est d'intérêt général de restituer à ces descendants la possession d'état qui leur revient. La question est délicate, mais une enquête discrète, habile, soigneusement menée, conduit généralement à une solution certaine et nous devons prendre très au sérieux ces revendications et les favoriser. Ces tentatives de libération collective portent plus de fruits que les libérations individuelles. Elles sont une indication que l'indigène, en tant que groupe, commence à prendre conscience de la dignité humaine, et il faut être persuadé que l'on n'obtiendra longtemps de progrès social chez l'indigène que collectivement, j'entends de progrès assuré, acquis, durable. Le progrès individuel excite la jalousie et il est à la merci de l'influence de la masse toujour's prépondérante. Le progrès collectif passe inaperçu, c’ẹt pourquoi il dure.

\section{CHAPITRE III}

\section{DE LA FILIATION}

La filiation chez les indigènes est de deux sortes:

Selon la Tribu;

Selon le Sang.

La première seule compte, la seconde semble, aux. yeux des indigènes, ne jouer qu'un rôle indicatif; son importance sociale est nulle. 


\section{Filiation selon la Tribu.}

Elle s'établit exclusivement par la mère. Tous les enfants d'une femme libre, quel que soit leur père, apparticnnent à la même tribu, ainsi que tous les descendants des filles qui sont nées d'elle, de fille en fille.

Tous les enfants, quel que soit leur sexe, 'd'une femme esclave portent la macule de servitude ainsi que tous leurs descenclants par les filles. La servitude est perpétuelle et se transmet de fille en fille jusqu'à la plus lointaine génération.

Cette descendance toutefois peut constituer ellemême une sous-tribu, subordonnée à la tribu du père, mais nettement séparée d'elle et de toutes autres, ayant son nom particulier ainsi que je l'ai expliqué plus haut.

La notion de tribu est tellement nécessaire à l'indigène qu'il en arrive quelquefois à constituer des tribus avec des gens d'origine diverse, de race différente, esclaves, hommes ou femmes, achetés par le même individu.

Ces deux principes sont assez clairs pour navoir pas à être expliqués. Mais dans la pratique, ils peuvent constituer des guides insuffisants et semblent mis en défaut.

On se trouvera souvent avoir à déterminer la tribu d'un individu, par exemple, dans le cas d'appel à une succession (attribution des veuves), de transmission d'autorité.

Nous verrons plus tard que tous les mariages sont exogames, c'est-à-dire que les deux conjoints ne peuvent appartenir à la même tribu.

Or, quand on pose des questions à un indigène sur sa filiation et sur sa tribu, il arrive fréquemment qu'il cherche à nous induire en erreur. Il ne veut pas, par exemple, que nous sachions qu'il n'est pas d'origine libre, et il se dit appartenir à telle tribu. Demandezlui à quelle tribu appartiennent son père et sa mère: 
ils doivent ètre de tribu différente; soils les dit de même tribu, c'est que l'un ou l'autre, généralement la mère, est à un degré quelconque fils d'esclave et lui pareillement.

La filiation s'établissant par la transmission du nom de la tribu, fait de ee nom un signe de reconnaissance. Deux individus appartenant à la mème tribu, éviteront quelquefois de se faire du tort, trouveront dans cette communauté d'origine une raison d'entrer en relations commerciales, arriveront même à se considérer comme parents proches, à se dire frères, malgré qu'ils ne puissent indiquer aucune aieule commune si haut qu'ils remontent. J'ai vu ceci avoir de l'importance dans des questions de mariage; il faut veiller, quand il s'agit de gens entreprenants, à ce que la communauté de tribu n'amène pas à l'usurpation des droits des membres proches de la famille, des véritables parents.

\section{Filiation par le sang.}

Elle ne joue, ai-je dit, aucun ròle social; elle sert uniquement à établir le nom des individus, à les différencier les uns des autres. Tout ce que j’ai à dire sur ce sujet trouvera place dans le paragraphe suivant.

\section{CHAPITRE IV}

\section{DU NOM}

On n'attache pas assez d'importance, en général, au nom des indigènes, en vertu du principe faux, mais que j'ai trouvé assez répandu, qu'il est impossible de le connaître avec certitude.

Il est cependant élémentaire de connaitre l'identité des indigènes auxquels nous avons affaire; soit que nous les employions à notre service, soit que nous leur demandions l'impôt, nous ne pouvons nous dispenser de déterminer leur individualité et cela mérite 
bien un effort; il n'est d'ailleurs pas grand, un peu d'attention suffit.

Je noterai d'abord que le nom de la tribu n'entre pas dans la dénomination de l'individu. Pour le connaître il faut le demander. Je n'en parlerai donc plus.

Le nom des inidigènes ne comporte pas̀ de nom de famille, mais seulement des prénoms, et il est toujours établi dans la forme: un tel fils d'un tel, le mot fils étant sous-entendu.

$1^{\circ}$ - Le second mot est donc au premier comme le régime vis-à-vis du mot dont il dépend, il est au génitif. Dans les langues bantou, le régime est relié au substantif par la répétition de la préfixe de ce nom.

Exemple : soit un individu nommé Bou-soukou, fils d'un père appelé Mikala, son nom sera normalement : Bou-soukou Bou-mikala.

Les interprètes ont une fâcheuse tendance à supprimer la répétition de la préfixe et disent quelquefois Boussoukou Mikala. Cela n'a aucun sens.

Si le premier nom ne comporte pas de préfixe, on n'en répète aucunè devant le second nom. On dit : Mouloungui Ngoma, Mboumba Manfoumbi, etc.

$2^{\circ}$ - Au lieu de faire suivre le nom de l'individu du nom de son père, on y substitue quelquefois le surnom et l'on dit : Ikapi I-mouyamba, Mwanda Issagha, etc. - Mouyamba, Issagha sont des surnoms.

$3^{\circ}$ - Je dois encore citer une forme normale, c'est celle propre aux enfants de père inconnu. Elle est extrêmement rare, l'enfant portant toujours le nom de celui qui l'a engendré, fût-il le fruit d'un adultère. Dans l'intérieur, je n'ai pas rencontré ce cas, mais à la côte, où la prostitution existe, il est assez fréquent.

Le fils de père inconnu remplace le nom de son père par le mot Nzila, la route.

Exemple : Coumba Nzila, - Mabiala Ma-nzila.

Telles sont les formes normales des noms, c'est celles que nous devons exiger pour nos recensements. La première est préférable à toutes, mais la seconde est très courante également et elle a l'avantage de permettre d'éviter les synonymes. Plusieurs enfants 
-de même père peuvent en effet porter le même nom. La synonymie absolue, j'entends: même nom, même prénom du père, même nom de tribu, est si rare que, sur dix mille noms que j'ai eu l'occasion d'écrire, je n'en ai vu qu'un seul exemple.

Il existe d'autres formes onomastiques employées par les indigènes et que je conseille d'éviter :

$4^{\circ}$ - A la côte, il arrive fréquemment que l'on compose le nom à l'aide du surnom de l'individu, suivi ou plus rarement précédé de son prénom. On dit par exemple: Manyengué Pambo pour Pambo Coumba surnommé Manyengué; - Ifounga Doucondo pour Ifounga I-mabiala surnommé Doucondo.

$5^{\circ}$ - Lorsque le père d'un enfant meurt en le lais. sant très jeune, la mère passe avec ses enfants comme épouse au frère cadet ou au neveu. L'enfant peut alors prendre le nom, non pas de son père, mais du second mari de sa mère. Ce n'est pas mon père, vous dira-t-il, c'est mon petit père. Le Garde Régional Makaïa Ma-mswami se dit de cette manière fils du chef de Mouyamba, Mswami Yembi, dit Fwanga. C'est inexact. Son père était le frère de Fwanga, Ngoma Yembi, qui est mort alors que l'enfant était en bas âge.

$6^{\circ}$ - J'engage à proscrire les noms changés par suite d'initiation à un fétiche. On les connaît à la longue. C'est une complication à éviter.

$7^{\circ}$ - Aux environs des Missions, les chrétiens se contentent de joindre un prénom européen à leur prénom indigène. C'est le cas de tous nos interprètes, - écrivains et auxiliaires indigènes généralement quelconques. Je ne suis pas partisan de cette coutume qui tend à faire prendre un prénom indigène pour un nom de famille. Cela prête par trop à la confusion.

$8^{\circ}$ - Il en est de même des prénoms précédés d'un titre, sans indication du prénom du père: Mouéné Tchibinda, Monéné Tichidounga, Massafi Tchikaïa, Mangoffo Coumba, etc. Il faut les compléter.

$9^{\circ}$ - Il faut défendre les changements de nom, usités chez les gens de l'intérieur. Venus à la côte, où les indigènes plus civilisés (?) traitent les gens dẹ 
l'intérieur de " sauvages ", les Bayaka ont pris l'habitude de s'affubler de noms Bavili: Loemba, Poati, etc.; que les Bayaka gardent leurs noms; que les esclaves conservent les leurs. Il faut éviter la confusion. Le garde dont je parlais plus haut, ne s'appelle pas Makaïa nom Bavili, mais Mikala. Inscrit à la Garde sous le nom de Makaïa Mswami, il s'appelle en réalité Mikala Mingoma.

$10^{\circ}$ - Je signale enfin l'usage de certains surnoms accolés toujours à certains noms: Bayonne à Mavoungou, Ngoulou à Mbouiti, Manete à Bwanga, etc. C'est une spécialité de la Côte. Il faut faire compléter le nom ainsi formé par le nom du père.

Enfin, il ne faut jamais se contenter d'un seul prénom. Il y a des centaines de Pambo, de Mavoungou, de Mikala, de Mswami. Un seul prénom ne détermine pas un individu, il ne signifie rien; pas plus qu'un prénom, Pierre ou Paul, ne détermine un Européen.

J'attache une grande importance à la précision des noms. C'est la condition essentielle d'une bonne police. On n'hésitera donc pas à punir de peines disciplinaires les indigènes qui changent leur nom; le maximum étant réservé à ceux chez lesquels l'intention de fraude aura été établie.

Qui impose à l'enfant son nom?

Il n'y a pas de règles fixes. Dabord, les parents n'éprouvent aucune hâte à baptiser leur progéniture, si je peux m'exprimer ainsi, et bien des fois, j'ai entendu dire d'un enfant né depuis quelques jours: il n'a pas encore de nom, il est trop petit.

Fréquemment, le père donne au fils son propre nom, ou le nom de son père; de même la mère pour une fille.

D'autres fois, c'est un passant qui se trouve être le parrain; j'ai connu ainsi un Morici Ndounrbo qui devait son nom à un certain Mauricio Castelbranco, mé- 
tis portugais mort près de Tchibanga en 1912 , je crois.

Ciest par des incidents analogues sans doute, en tous cas, au contact ancien avec les Portugais, que s'explique l'emploi courant comme noms indigènes de prénoms chrétiens, chez les Baloumbo et les Bavili; on y rencontre en effet des Louisi, Manoèla, Loumingou qui furent évidemment à l'origine des Luiz, Manoel, Domingo.

En résumé, l'attribution d'un nom à l'enfant n'est régie par aucune règle fixe.

\section{CHAPITRE $V$}

\section{Des DEVOIRS RÉCIPROQUES des PARENTS et des ENFANTS, des MAITRES et des ESCLAVES.}

Les devoirs réciproques des parents et des enfants étant les mêmes que ceux des maîtres et des esclaves, je ne les séparerai pas. J'examinerai seulement à la fin du chapitre, dans quelle mesure nous devons tenir compte de la coutume quand il s'agit des esclaves.

Les parents doivent prendre soin de leurs enfants, c'est-à-dire, les nourrir, les vêtir quand ils commencent à devenir grands. Ils ne manquent d'ailleurs jamais à ce devoir, et, si l'on peut dire que les sentiments affectifs sont à peu près absents de nos indigènes, on ne peut nier que le père et la mère manifestent à l'égard des tout petits une véritable affection. J'imagine qu'on peut l'assiniler dans une certaine mesure à celle d'une bête pour ses jeunes.

En effet, elle ne durera pas longtemps; dès que l'enfant commence à comprendre, à marcher, il semble se séparer de plus en plus de ses parents, il se déxeloppe seul, et montre déjá l'individualisme qu'il exagèrera plus tard.

Il me paraît dans une certaine mesure possible 
d'expliquer ce manque de cohésion entre parents et. enfants par l'absence totale de formation morale.

Les parents n'élèvent pas leurs enfants, ils les nourrissent, j'allais dire, comm:e des animaux, mais ils ne nourrissent pas les animaux. Il ne viendra jamais à l'esprit du père ou de la mère de corriger son enfant pour un de ces actes que nous disons répréhensibles. Quelquefois ils lui parleront en élevant fortement la voix si sa présence ou ses actions les gênent; rarement la mère lui infligera une correction manuelle bien légère. Le père n’irait jamais jusque là sans risquer une discussion grave et s'il renouvelait ses corrections, il risquerait fort de voir sa femme le quitter en l'accusant de brutaliser ses enfants et tout le monde donnerait raison à la mère.

A combien plus forte raison, un étranger ne se permettra-t-il jamais pareille chose. J'ai vu en 1914 le fait suivant: un adulte insulté par un enfant, le soufflette; le père s'interpose et menace l'adulte; une rixe prend naissance qui se termina par la mort de l'un d'eux.

Le droit de correction est exercé un peu plus souvent par les frères et sœurs aînés, frères et sœurs utérins bien entendu.

D'où qu'elle vienne d'ailleurs, la punition n'est jamais acceptée. Outre les vociférations poussées par l'enfant, hors de proportion avec le châtiment qu'il a reçu, il pratique un moyen de protestation des plus simples: il s'en va. Il s'en va dans sa famille, chez les parents de sa mère, et j'ai vu des gamins de 7 à 8 ans faire pour ce motif plusieurs heures de marche seuls en pleine forêt.

Quand je dis les parents, il ne faut pas entendre seulement le père et la mère. A tous les deux, il faut ajouter leurs frères et sœurs utérins; ceux de la mère sont les seuls oncles et tantes que la coutume et la langue reconnaissent. Les frères du père sont appelés par l'enfant, pères, surtout d'ailleur's après la mort dù père naturel. Un homme a donc plusieurs pères; 
et il en peut avoir de plus jeunes que lui, ce qui nè manque pas de dérouter. Quand on presse un individu d'expliquer ce phénomène, il vous répond: " ça n'est pas mon père, c'est mon petit père ". Et les indigènes considèrent ce " petit père " comme leur propre auteur, au point d'en prendre même le nom. J'ai signalé le fait en son temps.

Les devoirs des parents envers leurs enfants ne se bornent pas là. Quand un garçon commence à être en âge, c'est le plus fréquemment le père qui lui cherche une femme, qui l'aide à en payer la dot. Il choisit toujours dans sa famille à lui, et dans ses parents proches; c'est là qu'il a chance d'avoir à faire les moindres débours; on remarquera en effet que très souvent la première femme d'un jeune homme est de la famille de son père. Si nous examinons avec soin la parenté des jeunes époux, nous trouverons sans doute qu'ils sont, à notre sens, cousins à un degré assez rapproché. Je signale ce fait à l'attention; il faut, je crois, trouver dans ces unions consanguines répétées une des raisons de la mortalité qui décime l'enfance dans notre région.

Les devoirs des parents envers leurs enfants ne cessent qu'avec la vie et aucune excuse ne peut les en dispenser: ni l'ingratitude, ni les vices, ni la mauvaise conduite ne permettent aux parents de se désintéresser de leurs enfants. Paresseux, ils devront subvenir à tous leurs besoins; coupables de crines ou de délits, ils seront tenus d'indemniser les victimes et je n'ai jamais relevé d'exception à cette coutume.

Celui qui s'y soustrairait, ne manquerait pas d'encourir les reproches de sa famille, j'allais dire le mépris public, si ces mots ne comportaient trop d'exagération.

Il y a quelque inconséquence dans de telles mours, et le manque d'éducation s'accorde mal avec la rigueur des obligations imposées aux parents. Mais les liens qui unissent les individus de la société nègre sont bien faibles, et, quand nous en rencontrons, il faut n'y toucher qu'avec prudence. 'Tout au plus de- 
vrions-nous intervenir, à condition qu'on nous en prie, si la responsabilité pécuniaire du père se trouvait engagée par la conduite de son fils au point que celui-là refusât de se conformer aux usages. Nous devrions alors faire comprendre à la partie lésée par le fils coupable l'injustice de sa réclamation et, que notre raisonnement soit ou ne soit pas compris, refuser d'obliger le père à payer la compensation exigée.

Les enfants doivent à leurs père et mère, à leurs oncles, sincn l'obéissance, du moins la déférence. Je crois qu'ils se départent rarement d'un certain sentiment de respect envers ces personnes; mais les nuances par lesquelles il se traduit nous échappent, surtout étant donné l'individualisme féroce de nos indigènes.

Les enfants doivent partager leur travail entre leur père et la famille de leur mère; salariés, ils doivent répartir de la même manière le fruit de leur travail, et, même s'ils sont adultes ou mariés, ils ne peuvent théoriquement en conserver qu'une faible part. Nous trouvons là l'explication d'une plainte souvent soumise à notre examen: mes neveux, par exemple, vienton nous dire, restent toujours chez leur père, il serait temps qu'ils vinssent chez moi. On va même quelquefois plus loin: ma socur, nous dira-t-on, a eu des enfants et leur père les traite comme s’ils étaient des esclaves.

Cela reut dire simplement: mes neveux travaillent pour leur père seul et je n'ai pas ma part; mes nièces sont en âge de se marier et leur père se dispose à les donner à un mari cui lui versera la dot à lui seul et mıi je n'aurai rien.

Il n'est pas facile d'intervenir dans ce cas. S'il s'agit denfants, il est bon de conseiller à celui dont on se plaint de se conformer à l'usage, et, pour les filles nubiles, de lui rappeler qu'il n'a pas tout seul droit à la dot.

Quand il s'agit d'adultes et surtout de garçons, il 'n'en est plus tout à fait de même. Certes, la contume 
a raison d'imposer aux fils l'obligation de contribuer au bien-être de leurs auteurs. Ceux-ci les ont entretenus jusquà l'àge d'homme. Si peu que ce soit, ce n'a pas été sans dépenses.

Mais l'indigène est dépourvu de mesure; ayant dans son enfance et dans son adolescence travaillé pour les autres, il aspire au jour où il pourra à son tour se décharger sur de plus jeunes des soucis quotidiens: préparer les plantations, trouver l'argent de limpôt. Il naura plus alors d'autres préoccupations que ses créances à recouvrer, ses palabres à régler. C'est sa retraite, à lui, et quand sa situation de famille l'a mis en position d'en jouir, il s'y cantonne énergiquement et entend ne plus rien faire. Nous voyons ainsi, par exemple, le travailleur exporté revenir avec de l'argent ou des marchandises, relicjuat de ses salaires qu'on lui a versé au départ en fin d'engagement. De ces sommes, que lui restera-t-il ? - Bien peu de chose; tout passera entre les mains du père, des oncles, des frères aînés. C'est seulement quand il aura fait deux ou trois périodes d'engagement qu'on lui laissera de quoi payer la dot de sa première femme. C'est aussi à partir de cette époque qu'il commencera à ne plus rien faire, si ce n'est travailler à l'entretien de son ménage.

Il y a lieu de réagir contre la coutume; clle est dans ce cas un des plus grands obstacles au développement de nos populations. Il faut, autant que nous le pourrons, faire comprendre à tous que charité bien ordonnée commence par soi-même; - que, s'il est louable de contribuer au bien-être de cenx qui vous ont nourri, s'il est obligatoire de pourvoir à leurs besoins quand la vieillesse ou la maladie les a rendus incapables d'y subvenir eux-mêmes, il est recommandé d'améliorer sa situation personnelle; - quenfin l'obligation du travail est pour tous les àges et dans la mesure où les forces le permettent. De tels raisonnements ne seront guère compris; il faut les exposer quand même; il peut se faire qu'il en reste dans l'esprit de l'auditeur une trace; si faible qu'elle soit, e'est autant d'acquis.

Dans la pratique, il faut dire au pèrə qui se plaint 
du manque de libéralité de son fils, que le fiìs a bien raison de garder pour lui-même le fruit de son travail, que lui, le père, n’a qu'à travailler aussi, lui en indiquer quelques moyens, et le renvoyer des fins de sa plainte.

Si la plainte est relative à la seule résidence des enfants, déjà adultes, il va sans dire que nous n'avons pas de choix à imposer. Un adulte est libre de résider où il lui plaît. Cependant il est préférable qu'il demeure au milieu des siens; c'est là qu'il rencontrera le moins de chances de palabres et la plus grande stabilité.

Les devoirs imposés aux enfants envers leurs auteurs n'ont dans la coutume aucune sanction. Un indigène n’est nullement déconsidéré pour se désintéresser de ses ascendants. On ne lui inflige pas de sanctions, la coutume n'en connaît pas; il ne risque même pas le moindre reproche et, quoiqu'il fasse, quelque coupable que puisse être sa conduite, son père sera toujours tenu de réparer ses fautes, rien ne l'en dispensera.

Je voudrais également attirer lattention sur un cas un peu particulier. Bien que nos populations soient peu civilisées, il y a parmi elles quelques individus ayant bénéficié, le plus souvent dans les Missions, d'une formation intellectuelle et morale; si peu qu'il leur en soit resté, ils sont en progrès sur leurs congénères; et surtout, leur situation sociale s'est élevée d'un degré. Au mariage dans les formes de la coutume, ils ont même ajouté quelquefois la consécration d'une de nos religions. Quel doit être le statut des enfants?

J'ai entendu des collègues fort consciencieux déclarer: mariés sous le régime de la coutume, les enfants de ces parents ne doivent avoir d'autre statut que le statut coutumier.

Cette manière de voir est trop radicale à mon avis. Et une autre question se pose. Il me parait, en effet, que si nous ne derons toucher qu'avec prudence aux 
coutumes indigènes, nous devons aroir souci de l'intérêt des enfants. Or, dans le cas qui nous occupe, s"il y a litige, c'est que la famille de la mère s'oppose à l'éducation de l'enfant. J'ai vu en effet le cas se produrie: la femme d'un interprète, assistée de sa famille, refusant de laisser mettre dans une Mission l'enfant de celui-ci. Pour moi, il n'y a pas de doute; l'intérêt de l'enfant est de recevoir une formation morale. Il faut déroger à la coutume et laisser au père, au moins sur ce chapitre, autorité exclusive sur ses enfants.

Tout ce que je viens de dire des obligations des parents et des enfants s'applique exactement aux esclaves. Ceux-ci, au moins dans I'intérieur, ne sont ni mieux ni plus mal traités que les enfants du sang; ils n'ont ni moins ni plus de liberté. Leur maître est tenu de pourvoir à tous leurs besoins, et, quand ils sont mariés, ils peuvent s'occuper exclusivement de leur ménage. Salarićs, rien dans la coutume ne peut les contraindre à disposer de leur salaire en faveur de leur maître. Rien ne peut dispenser le maître de ses obligations; rien ne peut contraindre l'esclave à remplir les siennes.

J'attire sur ce fait l'attention des Chefs des Subdivisions de la côte; j'ai idée en effet que le sort des esclares y comporte beaucoup moins de douceur.

Les mêmes palabres se présentent pour les esclaves que pour les enfants. Le maître se plaint que son esclave s'est enfui, qu'il ne travaille pas pour lui, qu'il le maltraite. Il va sans dire que nous ne devons pas obliger un esclave à la résidence; il est libre de son choix; il est libre de même de son travail, mais trop souvent il ne fait rien que du mal et mieux vaudrait encore qu'il travaillât pour son maître.

Quant aux mauvais traitements qu'il peut faire subir à celui-ci, j'ai vu le fait se produire plus d'une fois. 
Et nous royons là avec évidence combien est peu étroite la servitude chez nous. N'étaient les risques de démoralisation que jaai signalés, on pourrait trouver excessives les pénalités du décret de décembre 1905. Nous sommes loin de la "Case de l'Oncle Tom ".

Quelles que soient les réclamations formulées par le maitre contre son esclave, j’ai déjà signalé la conduite à tenir: montrer au maître qưil n’a aucun droit sur la personne de son esclave; - rappeler à ce dernier qu'il a vis-à-vis de son maitre des obligations justifiées; - pour nous, ne pas, oublier que les palabres peuvent dégénérer, qu'un esclave court des risques graves, allant jusqu'à mettre sa vie en danger et que nous sommes hors d'état de l'en protéger. Si l'esclave est empoisonné, en admettant que le coupable avoue, la condamnation ne rappellera pas la victime à la vie, et la solution qui ramène l'esclave chez son maître est souvent la préférable.

\section{CHAPITRE VI \\ DE LA TUTELLE et DE L'ADOPTION}

Quand des enfants en bas-âge deviennent orphelins, on peut se demander quel est leur sort. Chez nous, un tuteur est désigné pour prendre soin des enfants, veiller à leur entretien, à leur éducation, à leur instruction, gérer leur's biens. Remplaçant le père, il est choisi dans l'intérêt des enfants.

Les indigènes ne sauraient concevoir cette solution désintéressée; ils prennent soin de leurs enfants assurément, mais considèrent principalement en ceux-ci leur intérêt propre. Nous venons de voir que les enfants constituent pour eux une source de profits; le travail des garçons, la dot des filles ne doivent pas être négligés; rien d'étonnant à ce que la coutume adjuge ce capital à un bénéficiaire. Il n'y a donc pas de tutelle véritable, mais il y a toujours, sauf de très rares exceptions, quelqu'un désigné pour recueillir les bénéfices dont ces enfants sont la source. 
Nous arons vu que ces derniers ne sont pas seulement soumis à lat puissance paternelle; à còté du père, il y a les oncles (maternels) et la puissance arunculaire prime certainement la puissance paternelle, puisquîe l'enfant appartient à l:ı tribu de sa mère.

Nous arons vu plus hiut que la contume altribue la veuve aux frères utérins ou aux neveux de son mari défunt. Elle emmène tout naturellement ses enfants en bas-age et leur sort est ainsi assuré.

Il ny a donc pas de tutelle, il y a remplacement automatique.

Au père défunt succèdent ses lières utérins ou ses neveux; aux oncles maternels défunts, les neveux de ceux-ci. Et la substitution s'effectue aussi longtemps qu'il est nécessaire. La puissance paternelle ou avunculaire se transmet comme n’importe quel héritage.

On imagine done difficilement qu'un enfant se trouve avoir perdu tous ceux, père ou oncles ou leurs remplaçants, qui pouvaient avoir autorité sur lui. Le fait peut se produire cependant et, dans ce cas, le plus souvent, personne ne veut se charger des orphelins et on les rend comme esclaves.

La coutume en effet ne comnait pas ladoption. On ne fait partie d'une tribu que de deux manières: par le sang ou par la servitude.

Je ne connais qu'une exception, et je l'ai constatée à propos de bàtards. Dans la très grande généralité des cas, la femme sait ou croit savoir, de qui est l'enfant qu'elle a mis au monde; illégitime ou mème adultérin, c'est de ce père naturel qu'il portera le nom. Il arrive cependant que la variété de ses amours empêche la femme de connaitre le père de son enfant; cela ne comporte aucun déshonneur pour l'une ni pour l'autre.

Si l'enfant est un garçon. il importe peu qu'il ait ou n'ait pas un père connu. N'est-il pas libre, en fait, de disposer de son travail comme il lui plaît? - Mais si c'est une fille, il n'en va pas de même et la question suivante se pose: la dot d'une fille de père inconnu 
doit-elle revenir tout entière à la famille de la mère ? - Dans la réalité, nous constatons que la prostitution n'est pour les femmes de nos régions qu'une profession passagère; tôt ou tard, elles sont données en mariage. Si elles amènent au mari des enfants sans - père, celui-ci en prend soin et la coutume lui attribue sur eux la puissance paternelle avec tous les bénéfices qu'elle comporte; c'est bien le moins qu'il soit ainsi dédommagé des peines et des dépenses que l'élevage de ces enfants lui a causées. Il y a donc là une éspèce de tutelle.

\section{CHAPITRE VII}

\section{DU MARIAGE}

\section{$\S 1$}

\section{Des conditions requises pour contracter mariage}

De tous les évènements de la vie d'un indigène, le mariage est assurément celui qui est l'origine des palabres les plus nombreux, les plus compliqués; j'ajouterai que ces palabres dus aux mariages sont ceux où la diversité des opinions se manifeste avec le plus d'évidence.

C'est qu'en effet, d'une part, le mariage des indigènes nécessite pour être conclu de façon stable l'accord simultané d'un grand nombre de volontés, la satisfaction de multiples convoitises, en dehors de celles des principaux intéressés.

En outre, les mobiles qui poussent l'indigène nous sont absolument étrangers, nous échappent complètement et nous sommes hors d'état de raisonner sur la convention matrimoniale dont les conditions nous sont soumises. Bornés à l'appréciation des questions de fait, nous avons grande chance de rendre une sentence qui reste incomprise et même inẹfficace, 
Je présenterai ici une analyse aussi détaillée que possible des conventions matrimoniales, de leurs conséquences éventuelles, des solutions à mon avis préférables. Mais je dois avouer que je n'ai pas encore trouvé la clef de l'énigme que reste pour moi le mariage des indigènes.

Le mariage est pour les indigènes un contrat entièrement comparable aux autres: vente, prêt, etc., contrat par lequel un homme se procure auprès de parents déterminés le droit d'user, lato sensu, d'une femme. Cette convention, comme toutes les autres, plus peut-c̀tre que toutes les autres, est conclue sous le régime de la mauvaise foi la plus parfaite.

La preuve que le mariage est à peu près assimilatble à une vente, c'est que le consentement de la femme n'est jamais demandé et que les veuves font partie intégrante de l'héritage du mari défunt.

La convention matrimoniale engage non pas l'époux et l'épouse, mais l'époux et la famille de l'épouse.

Les conditions nécessaires pour le mariage sont les suivantes:

$-1^{\circ}$ - Les deux conjoints doivent être de tribu différente; toutes les unions sont exogames;

$2^{\circ}$ - Le consentement du père et dc l'oncle ou des oncles maternels doit être acquis; ou, à défaut de ces derniers, celui des frères utérins;

$3^{\circ}$ - La dot doit être payće ou au moins promise et le versement commencé.

Il n’y a aucune condition d'àge; point de formalités ou rites de célébration; point de marchandises obligatoires.

$1^{\prime \prime}$ - Les unions, dis-je, sont exogames. - C'est peut-être la seule véritable condition sine qua non du mariage, celle qu'on ne transgresse jamais. Au moins n'y ai-je jamais vu d'exceptions authentiques; j'ai eu l'occasion de rencontrer des ménages où le mari et la femme portaient le même nom de tribu; mais on s'empressait aussitôt de m'expliquer qu'il s'agis. 
sait de tribus dilférentes. Je soupçonne véhémentement que l'un des deux conjoints était esclave et ne voulait pas l'avouer.

Il est de morale naturelle que le père n'épouse pas sa fille, la mère son fils, le frère sa socur. Les indigènes s'y conforment et je n'ai jamais entendu citer qu'un seul cas d'inceste.

Hors ces cas, la parenté du sang nest pas un empèchement; chez les Bayaka, l'oncle épouse très légitimement la femme de son neveu, et réciproquement, l'oncle et le neveu étant l'un et l'autre vivants; de mème, bien que ce soit rare, une lemme peut épouser un fils de son mari; on ne voit pas, à la côte, à ce que je crois, d'unions de ce genre. Les mariages entre cousius germains (à notre sens) sont des plus fréquents. A notre point de vue, il y a dans ces unions proche parenté, mais cette parenté n'est pas prise en considération par les indigènes; pour eux, le principe de l'exogamie est sauf et cela suffit.

L'identité de tribu, toutefois, doit être cxaminćc, non pas en fait, mais en droit. Assurément, un indigène n'imagine pas qu'un mariage entre conjoints d'une mème tribu puisse se faire pair erreur. D'abord le mari se renseigne toujours; mais encore, et surtout, un homme ne se marie pas n'importe où; il cherche femme, en général, dans la tribu, et mème dans la famille où ses ascendants ont autrefois choisi des épouses. Il sait donc à quelles gens, à quelle tribu il a affaire.

Mais le cas est différent quand la femme qu'il demande est esclave. Alors la question de tribu n'intervient plus. J'ai exposé plus haut comment une femme libre peut devenir esclave; un homme de la même tribu qu'elle, peut épouser ses descendantes. En fait, les conjoints sont de la même tribu; en droit, les esclaves cessent d'être membres de leur tribu d'origine pour être agrégés à la tribu de celui qui les a acquis. Le mariage peut donc se conclure et il s'en conclut de tels effectivement. 
$2 "$ - La seconde condition d'un mariage est le consentement de la famille. _ Ciest la plus difficile à réaliser. En effet, la famille de la future se compose de la ligne paternelle et de la ligne maternelle. La ligne paternelle ne comprend guère de gens ayant roix au chapitre; il $\mathrm{y}$ a le père et c'est à peu près tout; si le père est mort, ses frères ou ses neveux lui sont substitués et, même de son vivant, ils reçoivent quelques menus cadeaux.

Dans la ligne maternelle, il en est autrement. Les premiers parents à se concilier sont les frères et les søurs de la mère; et ils peuvent être assez nombreux. Puis il y a la mère; enfin les frères et søurs utérins de la future épouse.

Chacun de ces parents peut avoir reçu des sollicitations de divers côtés, touché un commencement de dot. Etant donné le soin que les indigènes mettent à cacher leurs négociations, la cupidité et l'absence absolue d'honnèteté des intéressés, on imagine facilement à quels litiges embrouillés un mariage peut donner lieu.

Les affaires seraient simplifiées si la femme était consultée; jaai déjà clit qu'il n'en était point ainsi. Et bien souvent, je dois dire que les palabres occasionnés par les mariages sont insolubles.

3" - Le consentement des personnes de la famille, qualifiées pour antoriser le mariage, est obtenu par le paiement d'une dot. - Le montant de cette dot est variable, il n'est pas inférieur en général à 20 pièces, soit 100 francs; mais cette somme peut être quadruplée suivant la bonne volonté du futur, le nombre, la cupidité des parents.

Le quantum de la dot n'est jamais fixé d'avance pas plus que les objels: espèces monnayées ou marchandises de telle ou telle nature, dont elle se composera. L'échéance du paiement n'est pas prévue davantage.

Comment la dot se paie-t-elle ? - La coutume est également muette à ce sujet. Tantôt les éléments constituant la clot sont remis en totalité au père ou à l'on- 
cle qui les répartit entre les ayant-droit; tantôt les paiements sont faits peu à peu à l'un ou l'autre des intéressés et à linsu les uns des autres; tantôt enfin, la dot est remise aux intéressés rassemblés qui se la partagent sur le champ.

Quand je dis la dot, il faut entendre une partie importante de la dot; le montant n'étant pas fixé d'avance, on peut dire que le mari n'a jamais achevé de payer la dot de sa femme; les membres de la famille de celle-ci ne cesseront guère de venir mendier des subsides au mari au titre dotal et, s'il est prudent, il tàchera de satisfaire leurs désirs, autrement, il risquerait de voir sa femme le quitter.

A quelle époque le mariage se conclut-il définitivement? - On n'en sait rien. La famille de la femme tàche de tirer le plus possible de son gendre; celui-ci use de tous les moyens dilatoires pour faire les moindres débours jusqu’à ce qu'il soit nanti de son épousc. C'est une lutte au plus adroit.

Quand jaurai dit, pour terminer, que bien souvent, la femme pour laquelle une dot est payée n'est pas déterminée d'avance, j'aurai, je crois, établi qu'il n'y a rien de plus imprécis dans les conventions entre indigènes que le mariage et rien de plus compliqué que les litiges auxquels il donne lieu.

Comparées à nos coutumes matrimoniales d'Europe, telles que des siècles de christianisme les ont faites, celles de nos indigènes apparaissent effroyablement dégradées. On peut même se demander si le mariage naturel existe chez eux, et, par mariage naturel, j'entends l'union individuelle, permanente et librement consentie. Je m'en suis souvent posé la question, préoccupé surtout que j'étais du défaut de consentement explicite de la femme.

Je me suis en définitive rangé à lavis exprimé dans 
une fort intéressante étude de la matière, exposée en détail dans "Questions pratiques sur le mariage dans les Missions " du R. P. Michel, des Pères Blancs.

La pensée de l'auteur se résume à peu près en ceci, que le mariage naturel peut exister et que c'est une question d'espèce. Quant au consentement, celui de la femme qui a vécu plusieurs années avec son mari peut être considéré comme implicitement donné, si, par ailleurs, le fait par elle de refuser un homme comme époux ne lui fait courir aucun risque grave; et cela devient de plus en plus le cas dans notre région. J'aurai cependant l'occasion de dire qu'il peut être utile, le cas échéant, de provoquer son consentement explicite.

Avant de passer à l'examen des litiges soulevés par les mariages, je voudrais exposer mon opinion sur les coutumes matrimoniales elles-mêmes. Devons-nous les admettre purement et simplement et, par l'application constante que nous en ferons dans le règlement des palabres, en perpétuer la durée ? - ou, au contraire, nous faut-il travailler à leur modification?

Je ne crois pas qu'un seul instant d'hésitation soit permis. En cette matière comme en toute autre, plus même qu'en toute autre, nous avons l'obligation de faire œuvre d'éducateur, de promouvoir la réforme de mœurs avilies yar les vicissitudes millénaires des races qui ont abouti au Gabon.

$1^{\circ}$ Et d'abord, quelle conduite tenir à l'égard de la polygamie?

Elle est générale en ce sens que tout indigène peut avoir simultanément plusieurs femmes, mais il s'en faut que ce régime soit celui de la plupart des ménages; bien au contraire.

Quelle que soit sa raison d'être, et elle n'est pas unique, faut-il la favoriser ou la combattre ? Je crois qu'il faut la combattre; elle est la cause du dévergondage des jeunes gens, de l'inconduite des femmes, et elle mène les races à leur ruine par la diminution de la natalité. 
D’abord, si la polygamie est courante, elle est loin d'être indispensable à l'indigène, puisqu'elle n'est pas le régime de la plupart des ménages.

Je surprendrai sans doute beaucoup de lecteurs si je dis que la monogamie est, au contraire, le cas le plus fréquent. Je trouve, en effet, les proportions suivantes: en 1908, chez les Baloumbo de la Nyanga, 65.40\% des ménages sont à épouse unique;

en 1918, chez les Bapounou de Moabi, 58 »" \%; en 1916, chez les Bapindji de Mouila, $\quad 71,03 \%$; en 1918, chez les Pahouins du Davo, $\quad 65,62 \%$; chez les Bavili de la Ngounyé, $\quad 80,89 \%$; chez les Baviya, $\quad 71,07 \%$; chez les Bakélé, $\quad 63,42 \%$; chez les Echira, $\quad 69,61 \%$; chez les Mitsogho, $\quad 73,96 \%$.

Tous ces chiffres sont assez comparables pour exelure la présomption d'erreur sensible dans le recensement.

D'où vient donc que les ménages polygames constituent la minorité? C"est que pour avoir de nombreuses femmes, il faut être riche, et l'on n'est devenu riche que lorsqu'on est vieux. C'est alors seulement qu'on a pu accumuler des épouses, soit en en payant la dot, soit en les recueillant par héritage.

Mais la vieillesse ne va pas sans inconvénients; les épouses, mal satisfaites, cherchent des consolateurs, et l'adultère est l'origine de troubles sociaux à répercussions interminables.

Des consolateurs, ces épouses délaissées n’en chômeront pas. J'ai relevé, en 1908, 31 \% d'hommes célibataires chez les Baloumbo de la Nyanga; en 1918 , on m'en signale encore $29 \%$ chez les Bapounou de Moabi.

J'en trouve à Sindara, en 1917 , une moyenne de $33,2 \%$ dans l'ensemble des races de cette subdivision. Ce sont pour la plupart des jeunes gens, et ils ne vivent pas, cela va sans dire, dans la continence. Ne serait-ce que dans l'intérêt de la morale, il faudrait 
leur rendre possible, facile, le mariage précoce; la paix dans les familles n'en serait que mieux assurée.

A défaut de cette considération, il y a un intérêt immédiat dont la Colonie a le devoir de se soucier. La population est d'une densité bien faible au Gabon; on dit qu'elle diminue, et c'est fort probable, bien que personne ne puisse fournir de chiffres, et, de toutes les misères, celle-là est la plus grave. Or, j'ai l'impression que la natalité est assez faible, que la mortalité des enfants avant l'àge contribuable est considérable. Il est urgent d'y porter remède.

La première mesure à prendre serait de ne pas faroriser la polygamie, laccaparement des femmes par les riches qui, de toute nécessité, sont des vieillards; leurs unions sont le plus souvent stériles.

De la sorte, les jeunes gens auraient des épouses et les enfants naîtraient plus nombreux. D'autre part, le dévergondage diminuerait et avec lui l'extension des maladies vénériennes. Ce serait tout bénéfice.

2" Danś le même ordre d'idées, il y a lieu de poursuivre la réforme d'un autre usage.

On sait que les indligènes ne sont pas, dans le choix de leurs épouses, dirigés par les mêmes motifs" que nous. Le point de vue esthétique les laisse indifférents; ce qu'ils apprécient chez une femme, ce sont les qualités de bonne ménagère, les caractères de la fécondité. Or, à ces divers titres, les jeunes filles sont moins estimées que les femmes cléjà expérimentées.

Il en résulte entre les conjoints des disproportions d'àge qui sont loin de favoriser la fécondité des unions, mais qui, en revanche, peuvent conduire l'époux à rechercher d'autres épouses. Il y a là quelque chose à modifier dans l'esprit des indigènes; il faut favoriser les unions assorties.

$3^{\circ}$ Enfin, il se conclut, par contre, des mariages qu il faut non seulement ne pas favoriser, mais proscrire; je veux parler de ceux des fillettes non nubiles. Il ne faut y donner les mains qu'en dernier recours. De telles unions sont désastreuses pour l'avenir de la 
race; si elles ne sont pas stériles, leurs produits sont rarement de qualité et on a souvent trouvé là une des causes de la mortalité infantile.

En résumé, le but que nous devons nous proposer, cest d'amener les indigènes au mariage monogame d'époux assortis et également libres d'allaches antérieures. Tout ce que nous ferons dans ce sens sera infiniment utile.

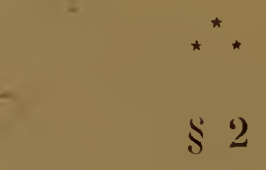

\section{Solutions proposées aux litiges occasionnés par les mariages}

La différence de tribu existe toujours entre les conjoints et je n'ai jamais vu de différend occasionné par elle; je n'y reviendrai pas.

J'ai séparé plus haut le consentement de la famille du paiement de la dot, mais seulement pour la clarté de l'exposition; en fait, la dot est augmentée ou diminuće suivant les exigences des ayant-droit; c'est la dot qui entraine le consentement, ce sont donc deux éléments inséparables.

Avant d'entrer dans les détails, je veux exposer les principes qui, à mon sens, doivent nous diriger dans le règlement des questions de mariage.

$1^{\prime \prime}$ - Le ménage, cest-à-dire, la réunion du mari et de la femme, ou des femmes, puisque la polygamic existe, le ménage, dis-je, est l'élément social auquel on aboutit en dernière analyse dans lexamen de la société indigène; supprimez le ménage, l’homme devient ragabond, il ne construit pas de case, ne fait pas de plantations, ne se fixe pas en un mot. Ciest done à la stabilité du ménage que nous devons nous efforcer d'atleindre, c'est une question d'intérèt public, c'est en mème temps une question de moralité et, à ces deux titres, nous devons sacrifier les intérêts particuliers qui s'y opposeraient. 
En conséquence de ce principe, nous devons, contrairement à la coutume, tâcher de connaître l'opinion sincère de la femme, principale intéressée. Ce n'est pas toujours facile; le plus souvent elle n'a pas de préférence et un mari en vaut pour elle un autre, ou bien elle n'agit que par caprice, car elle aime le changement et sa moralité est nulle; d'autres fois, elle parle sous le coup de menaces qu'elle craint ne pas devoir rester lettre morte. Il faut donc la mettre autant que possible en confiance, la rassurer et provoquer une déclaration sincère. De cette déclaration sincère, nous devrons tenir le plus grand compte. Il est certain que nous sommes hors d'état de maintenir existant un ménage où la femme ne veut pas du mari; - il n'est guère moins certain que rien ne pourra empêcher une femme de cohabiter avec l'homme qu'elle aura choisi; nous ne maintiendrions l'un, nous ne dissoudrions l'autre de ces ménages qu'en exerçant ou en tolérant l'exercice de la contrainte et nous ne devons pas le faire.

$J$ 'ai dit que la femme indigène est capricieuse et aime le changement; lorsque ce caractère, se manifeste, nous avons une arme excellente pour faire réfléchir la femme et plus dune fois les maris mont demandé d'en user; c'est la prison disciplinaire. Elle est efficace et l'emploi en est légitime; une femme qui quitte son mari sans motif sérieux est en état de vagabondage. (Arrêté du 13 septembre 1910, art. 9).

Nous devons donc tendre par tous les moyens, à rendre les unions solides et durables; le mari préféré par la femme est peut-être pauvre et il ne pourra pas payer une forte dot; celui qu'elle abandonne a peutêtre été très généreux et la dot qu'il a versée sera lourde à rembourser. Nous devons passer par dessus ces intérêts secondaires et si, en les sacrifiant, voire totalement, nous avons cimenté de notre autorité un mariage uni et durable, nous aurons bien travaillé.

$2^{\circ}$ - Après la stabilité du mariage, mais presque au même niveau d'importance, nous devons chercher 
à maintenir la cohésion entre eux des membres de là tribu. Nos indigènes ont une tendance exagérée à l'individualisme; quelle que soit l'origine de ce sentiment, ils sont farouchement indépendants. Un seul vestige d'autorité se rencontre, c'est celle du chef de famille, du frère aîné sur ses cadets, de l'oncle (maternel) sur ses neveux. Dans la hiérarchie des consentements exigés par un mariage, il faut donner la préférence à ceux de la ligne maternelle, l'oncle et la mère de la future (ils sont frère et sœur) seront généralement d'accord; c'est leur avis qu'il faut considérer le premier. Ciest également eux, la plupart du temps, qui sont responsables dans les séparations irrégulières de deux conjoints. Il faut de toute nécessité, à défaut de préférence marquée par la ‘femme, s'en rapporter à l'un quelconque de ses auteurs; en France, nous nous en remettrions au père; chez les indigènes, celui qui tient le rôle familial de père, qui en a l'autorité, les pouvoirs, c'est le frère de la mère, le seul qui, en fiote, porte le nom d'oncle.

Faut-il de ce fait sacrifier complètement le rôle du père ? - Non. - Il faut tàcher de lui faire donner autant que possible satisfaction; son opposition est toujours due à une question d'argent: il n'a pas assez reçu du futur, ou bien il s'est engagé ailleurs de son côté et il n’a rien, ni femme à donner, ni argent pour rembourser la dot qu'il a reçue tout seul.

En fin de compte, il faut lui faire comprendre, si on le peut, qu'en s'engageant seul, il a commis une imprudence; à son candidat, on fera des représentations analogues; à tous les deux, on fera prévoir les sanctions qu'entraînerait la rupture frauduleuse par leur fait d'une union convenable et présentant un caractère de durée.

$3^{\circ}$ - Il ne faut pas non plus oublier combien il est difficile d'amener un indigène à payer une dette; j'estime même que cela est impossible et que de ce fait la Justice Civile et Commerciale en matière indigène est illusoire. Nous devons donc, lorsque plusieurs solutions sont possibles, choisir celle qui n'implique pas 
un remboursement de dot. Il faut que nos sentences aient leur plein efiet sous peine de déconsidérer notre Justice; il est plus facile d'amener un père, un oncle, une épouse, un mari à consentir à un mariage que d'obtenir le remboursement de la dot déjà versée.

Ces trois principes nous seront d'un grand secours pour donner aux litiges soulevés à l'occasion des mariages des solutions efficaces.

Je vais à présent citer quelques espèces; tous les palabres se ramènent à trois types: une dot a été payée et la femme n'a pas été livrée; — ou, au contraire, un mariage s'est conclu et la dot n'a pas été versée; - ou enfin, la femme ne veut pas du mari proposé.

$1^{\circ}$ - La dot a été payée et la lemune n'a pas été livrée. - Il faut alors s'enquérir de la somme payce par le futur conjoint; elle doit être au moins de vingt pièces; si elle est inférieure et que la famille à qui les versements ont été faits accepte de donner une femme, il faut inviter le plaignant à compléter la dot. Le remboursement serait problématique.

J'ai payé une dot pour avoir telle femme, dit un plaignant, on l'a donnée à un autre, — ou bien elle est morte. Je veux qu'on me rembourse; je ne reux pas d'autre femme. - Le cas le plus général, en effet, est que la femme à marier n'est pas déterminée d'avance, et, si une famille a plusieurs filles disponibles, elle donne indifféremment l'une ou l'autre. Mais le candidat époux n'entend pas toujours de cette oreille, surtout lorsqu'au lieu d'une femme adulte, on lui présente une fillette de dix ans. Là encore, il faut le décider à accepter une femme, à ne pas exiger le remboursement de la dot; il est alćatoire et à tout le moins, il durera longtemps.

Un autre cas commence à se présenter fréquemment; c'est le suivant: un jeune homme, pour s'assurer la possession d'une femme, commence à en payer la dot à la famille qui accepte toujours. Puis il s'engage comme travailleur exporté et reste absent un an ou delix ans. Il revient avec des marchandises ou de l'ar- 
gent et trouve mariée la femme quil avait en quelque sorte retenue. Il vient alors se plaindre.

Je suis d'avis que la famille de la femme a eu raison; on ne peut imposer un célibat prolongé et sans terme connu à une femme indigène. Le candidat époux n'ignorait pas les risques qu'il courait et il devra ou accepter une autre femme ou attendre le remboursement de ce qu'il a versé.

L'exode des indigènes n'est pas à favoriser; cette transplantation ne leur vaut rien au point de vue moral et, s'ils veulent travailler, qu'ils travaillent chez eux; les occasions ne leur manquent pas.

Dans tous les cas de cette sorte, il faut s'enquérir d'abord si les versements ont été faits à quelqu'un de qualifié pour les recevoir et disposer de la femme, c'est-à-dire, au père ou à l'oncle,. ou à défaut de ce dernier, au frère utérin de la femme. Il ne manque pas de gens cupides qui disposeront très bien d'une femme ne leur appartenant pas, d'imbéciles pour entrer dans la combinaison et, quant à la femme, comme elle ne touche rien, cela lui est bien indifférent.

C'est bien le moins que celui dont la conduite est inconsidérée en supporte les risques; quant à celui qui est de mauvaise foi, il doit être puni. Promettre une femme qu'on n'a pas le droit de donner, e'est se faire marchand de la chose d'autrui; cette vente est nulle et peut donner lieu à des dommages-intérêts. (Civ. 1599).

Il peut se présenter d'autres cas où le dol est érident, et où la combinaison matrimoniale devient de l'escroquerie. J'en signalerai deux :

Une famille fait des propositions pour un mariage à un homme qui est son débiteur, et elle impute sur le paiement de la dette les versements effectućs à titre dotal; je ne suis pas sûr que le procédé soit bien régulier, mais il est certain, si la dette est réelle et justifiée, qu'il vaut mieux, pour la paix, reconnaître comme valables et imputer sur l'extinction de la dette les versements effectués. Se marier, surtout quand on a déjà une femme, est une dépense somptuaire; avant 
de s'offrir le superflu, il est juste de payer ses dettes.

Dans d'autres cas, l'intention de tromper est certaine et, sourent, on l'avouc. Un homme a un besoin urgent de marchandises; il promet contre versement d'une dot le mariage avec une femme. Le versenent fait, il ne livre pas la femme. Il y a là, me semble-t-il, escroquerie (Civ. 1967. - Pén. 405); l'acte doit être puni comme tel et le coupable cité devant le Tribunal indigène.

- $2^{\circ}$ - Le mariage a été conclu et la dot 'n'a pas été payée. - Le premier point à élucider est celui de la parenté du plaignant avec la femme, autrement dit, il faut qu'il établisse qu'il a des droits sur elle, qu'il est son père, ou son oncle maternel ou son frère utérin, ou le frère utérin de son père.

La légitimité de sa réclamation établie, il faut savoir du mari s'il a payé une dot et à qui il l'a payée.

Le plus souvent la dot a été payée et on vérifiera le montant des versements par témoignage. Alors ce n'est plus le mari qui est en cause, ce sont les parents de la femme; les uns ont gardé toute la dot au détriment des autres.

Ils ont agi ainsi quelquefois par fraude et il faut les obliger au partage; - quelquefois, certains parents ont profité de l'occasion pour se payer d'une dette des autres parents vis-à-vis d'eux et, si la dette est réelle, il vaut mieux souvent, pour la paix, ratifier le paiement involontaire.

D'autres fois enfin, et j'ai cité le cas dans un autre chapitre, la ligne paternelle a-gardé toute la dot parce que la fille mariée porte la macule de servitude; j'ai dit à l'endroit précité que nous ne devions point alors suivre la coutume, mais, au contraire, contraindre les parents paternels au partage.

$3^{\circ}$ - Une femme refuse le mari qu'on lui propose. - Le plus souvent son refus a pour cause une secrète préférence: la femme a un amant, si je puis m'exprimer ainsi. Le plus sage est de conseiller à la famille de satisfaire le désir de la femme; les mariages d'inclination sont plus solides que les autres. Le difficile 
est de connaitre le nom du préféré et de l'amener à payer une dot. Il n'y tient quelquefois nullement et ce n'est pas tout.

Le candidat refusé a versé lui aussi une dot; si la dot payée par l'amant compense exactement celle qu'a versée le premier et ne sert quà le rembourser, la famille de la femme dira: alors nous avons marié notre fille pour rien! L'indigène ne comprend pas que payer ses dettes c'est s'enrichir.

Il convient alors, si l'amant ne peut pas être très généreux, de faire comprendre aux parents qu'ils ne peuvent pas toucher deux dots pour la nême femme, et leur faire entrevoir des sanctions sévères au cas où le ménage serait dissous par leurs intrigues. Ces menaces seront quelquefois efficaces.

\section{$\S 3$}

\section{Des droits et des devoirs respectifs des époux}

Le mariage fait naitre entre les époux des devoirs qui n'ont qu'un lointain rapport avec les nôtres.

Le mari doit :

$1^{\circ}$ - Construire une case à sa femme. Chacune d'elles a sa case séparée chez les Bayaka, sa chambre distincte chez les races où le type de la case est différent. Autant de cases ou de portes dans un village, autant de femmes adultes. Ciest un élément précieux pour les recensements;

$2^{\circ}$ - Vêtir décemment sa femme;

$3^{\circ}$ - Lui fournir les ustensiles du ménage (marmites, nattes, tangui), et les outils de culture, au moins la machete, ailleurs hache et couteau.

4" - Débrousser et préparer le terrain que la femme complantera: la surface doit être assez grande pour suffire aux besoins de la femme et du mari.

$5^{\circ}$ - Lui réserver une part équitable dans ses faveurs et se garder de préférences trop manifestes.

La femme de son côté doit à son mari : 
1" - La fidélité. On remarquera qu'il n’en est pas question pour le mari.

2" - Elle doit lui préparer sa nourriture lorsqu'elle a son tour de cohabitation; elle le soigne quand il est malade.

$3^{\circ}$ - Elle complantera les terrains débroussés par son mari.

\section{$\S 4$}

\section{Du régime du mariage}

Les mariages sont tous conclus sous le régime de la séparation de biens.

La femme mariée garde sa personnalité à tous les points de vue; membre d'une tribu, le mariage ne l'en détache pas; ce qu'elle peut gagner lui appartient et elle est libre d'en disposer.

La case que lui a construite son mari devient sa propriété; la plantation qu'elle a complantée, mais, qu’il avait débroussée, lui appartient également, et à sa mort, case, plantation pourraient être vendues au bénéfice de la succession.

C'est done un singulier mariage que celui des indigènes; il ny a pas union, il y a à peine juxtaposition; le mari n'a sur sa femme qu'un droit d'usage, droit exclusif il est vrai, mais, étant donné que le fond sur lequel est assise cette servitude, est une personne humaine, son droit d'usage est limité par la volonté de celle-ci.

La femme, toujours membre de sa tribu d'origine, tient essentiellement à conserver des relations avec elle. De temps en temps, elle quitte le village de son mori et va passer des semaines, des mois dans sa propre famille; bien mal venu serait le mari qui s'opposerait à ces absences; on l'accuserait sur le champ de séquestrer son épouse, de la traiter comme une esclave et j’ai expliqué plus haut le sens précis de ces termes. Ce serait le divorce à bref délai. 
Pour se faire bien voir de son épouse, pour la conserver, le mari fait toutes les concessions, autorise toutes les absences, multiplie les cadeaux. At-t-il reçu une poule en gage, a-compte, ou cadeau? c'est pour sa femme. Elle n'en mange pas, il est vrai; la coutume le lui interdit, mais elle la gardera et en tirera profit le cas échéant. A-t-il reçu en salaire ou en paiement un pagne, un morceau d'étoffe ? Ce sera également pour elle, quels que soicnt dailleurs les moyens qu'elle ait elle-mème de se vètir.

Le mari qui, ayant pèché ou chassé. oublierait sa femme ou lui laisserait une part trop minime du poisson ou du gibier, risquerait de graves querelles de ménage, et voilà pourquoi il nous est si difficile d'aroir à notre solde des pêcheurs et des chasseurs.

Le ménage a-t-il des enfants? Ceux-ci suivent le sort de la mère, à la tribu de laquelle ils appartiennent exclusivement.

En somme, au milieu de ses épouses souvent nownbreuses, le mari est isolé et à la merci de la première fantaisie de ses compagnes.

Sur la foi d'observations superficielles, on va répétant les mêmes phrases sur le sort misérable de la femme indigène, astreinte aux travaux les plus pénibles, marchandise dont on dispose sans son consentement, etc... Tout le monde connait aussi bien que moi cette antienne.

Je concède que les apparences sont fàcheuses: oui, la femme est mariée sans son consentement; oui, on la rencontre pliant sous un lourd panier, rempli de bois, de bananes. Mais la réalité est bien différente.

On la marie sans son consentement, c'est vrai; mais c'est qu'à bien regarder elle n'a que faire de le donner. Ce qu'elle veut, c'est un mari qui ne soit pas un mari........ honoraire; peu lui importe quel il soit. Et d'ailleurs, si clle a une préférence, il n'y a pas de puissance légale qui soit capable de l'empêcher de rejoindre celui qu'elle a élu.

Elle porte de lourdes charges, oui: une fois par jour. Voyez-la dans son village; le matin, vers 7 ou 
8 heures, elle gagne avec ses voisines sa plantation; elle y ramassera du bois pour un jour, cueillera un ou deux régimes de bananes, quelques tarots, en un mot des vivres également pour un jour; cela ne demande pas beaucoup de temps; le reste de la journée se passera à bavarder au coin du feu avec ses compagnes ou à d'autres occupations moins avouables; la forêt est vaste et discrète. Elle rentrera à la chute du jour vers 5 heures et fera sa cuisine. Il n'y a dans ces travaux rien de bien pénible.

En réalité, la femme mariée est d'une indépendance absolue; son mari l'a payée cher, le remboursement de la dot serait au moins aléatoire; la femme sait tout cela, elle abuse de sa situation et tient la dragée haute au mari qui fait toutes les concessions.

Nayant rien à faire, la femme crée des palabres, sépare les ménages, brouille les frères; elle est à la base de tous les litiges; sa mentalité est des plus inférieures et l'on pourrait croire qu'elle éprouve la plus grande jouissance à faire le mal. Les femmes indigènes sont les êtres les moins intéressants et les moins sympathiques.

Les litiges nés du non accomplissement des devoirs des époux, des atteintes portées au régime du mariage scront examinés au paragraphe suivant.

\section{$\S 5$}

\section{De la dissolution du mariage}

Le mariage est dissous :

par la mort de l'un des eonjoints; nous en parlerons plus tard;

par la séparation des conjoints. Il n'y a pas de divorce légal; mais le mariage étant une convention comparable à toutes les autres, cette convention peut faire l'objet de modifications, subir des atteintes, soit avec le consentement, soit contre la volonté des intẹ́- 
ressés. Je rappellerai qu'on peut considérer comme intéressés dans le contrat matrimonial:

$1^{\circ}$ - Le mari ;

$2^{\prime \prime}$ - La famille de la femme;

$3^{\circ}$ - La femme elle-même.

Séparations amiables. - Je signalerai, d'abord, une coutume curieuse: la cession par le mari de sa femme à un tiers. Un acte pareil nous clioque au premier abord; les conditions où je l'ai observé le rendent acceptable. Elles sont les suivantes: un homme est àgé; le devoir conjugal lui est de jour en jour plus difficile à accomplir. Lune de ses épouses s'en plaint et semble disposée à chercher des compensations.

L'époux cède alors sa femme à son neveu, fils de sa sour, lequel s'empresse d'accepter une épouse pour laquelle il n'aura que peu de chose à débourser.

Il laut remarquer qu'il n'y a là, en somme, qu'une avance d'hoirie; nous verrons ultérieurement que les épouses du défunt passent à ses neveux ou à ses frères; la mutation, dans le cas qui nous occupe, se fait avant le décès au lieu de se produire après. Elle soulève rarement des discussions; cependant, il va sans dire que nous ne pourrions l'imposer à une feinme qui s'y refuserait; si c'est la famille de Tá femme qui s'y oppose, il me paraît que nous devous tàcher d'ol)tenir son assentiment; nous éviterons ainsi bien des palabres. Cette mutation n'est d'ailleurs pas gratuite, et il faudra toujours au nouveau mari payer au moins une demi-dot.

Hors le cas que je viens d'exposer, cas tout à fait exceptionnel, je ne crois pas qu'il y ait jamais de séparation amiable. Le mari peut se résigner à une séparation déjà consommée; cette séparation ne se produira pas de son fait.

Séparations non amiables. - Elles sont, on le sait, extrêmement fréquentes et nous devons le déplorer; l'instabilité des ménages entraîne des discussions, des litiges interminables, à répercussions multiples dans le temps et dans l'espace. Les indigènes ne reçoivent jamais aucune formation morale; dans l'impossibilité 
où nous sommes de leur faire comprendre l'immoralité, la bestialité de ces unions presque provisoires, il importe de réprimer par des sanctions sévères les séparations non justifiées ou frauduleuses.

Dans l'ordre de leur fréquence et de leur complication, ces séparations non amiables se produisent:

$1^{\circ}$ - du fait de la femme ;

$2^{\circ}$ - du fait de sa famille;

$3^{\text {n }}$ - du fait d'un tiers ;

$4^{\circ}$ - du fait du mari.

Séparation du fait de la femme. - La femme qui veut se séparer de son mari donne divers prétextes: il la traite comme esclave, il ne l'entretient pas du nécessaire, e'est un vagabond, n'ayant ni case ni plantations; il la frappe; il ne lui fait pas d'enfants ou les cufants quelle a eus de lui sont morts; il est impuissant; j’en ai mème entendu à deux reprises accuser leur mari de perversions sexuelles bien improbables chez un bayaka, si loin de la civilisation.

Lorsqu'une épouse a de tels griefs contre son mari, elle le quitte et s'en va dans sa famille, ou bien chez un mari de son choix.

Le mari abandonné entame alors des négociations pour faire revenir la femme; la famille de celle-ci s'empresse, toutes les familles ont des pourparlers matrimoniaux en train, elle s'empresse, dis-je, de donner la femme à un autre ćpoux et de toucher une dot.

Si la femme a été retrouver un amant, celui-ci se hàte de donner quelques marchandises, d'amorcer le paiement d'une dot, pour se créer des droits.

La famille de la femme reçoit donc de toutes mains, laissant à l'avenir le soin de dénouer l'imbroglio.

Toutes ces négociations ont pu durer des mois; bien souvent la femme est devenue mère des ourres du nouveau mari et c'est alors qu'en désespoir de cause, le mari abandonné par sa femme recourt à notre autorité.

Quelles solutions propose la coutume ? - En réalité, elle n'en fournit aucune obligatoire; si ie mari aban- 
donné est assez fort et assez adroit, il obtiendra satisfaction ou compensation; sinon, non. Il ne lui restera que la ressource des représailles, et il en usera, et ses héritiers en useront également. Du moins est-ce ainsi que la chose se passait autrefois.

Présentement, il y a une tendance marquée à abandonner les procédés violents; la crainte des sanctions a eu un effet salutaire.

Disons d'abord que lorsque la femme quitte réellement d'elle-même son mari, si elle ña reçu aucune suggestion, il y a peu de chance de la voir revenir. II ne restera plus que la ressource des compensations; restitution de la dot; - substitution d'une autre femme; - restitution d'une femme appartenant à la famille du plaignant.

La restitution de la dot, même proposée par la famille de la femme volage, est au moins longue, sinon improbable. Comme solution du litige, c'est un pisaller.

La meilleure solution est ćvidemment celle qui consiste à remplacer par une autre femme celle qui a fui le domicile conjugal.

Mais les noirs ont trouvé une autre solution: c'est la suivante: pour compenser la perte de dot subie par celui dont l'épouse s'est enfuic, on lui remet une femme de sa famille à lui plaignant, une femme sur laquelle il a juridiction et que par conséquent il pourra marier. La dot qu'il touchera pour elle compensera celle qu'il a perdue.

Evidemment, pour que la combinaison soit possible, il faut que la famille défenderesse ait parmi ses membres un homme marié à une femme de la famille du demandeur, mais le cas est fréquent.

Cette solution nous choque; compenser la rupture d'un mariage par la dissolution d'un autre mariage est une méthode désastreuse et immorale. Cependant si les parties l'acceptent, mieux vaut, toujours dans le même but, pour la paix, y donner notre assentiment.

TelTes sont les solutions favorables proposées par 
les indigènes. Mais il arrive que le plaignant n'arrivè pas à se faire donner satisfaction. La famille de son épouse vagabonde la lui ramène une fois, deux fois, puis elle semble se désintéresser de la chose et dit au mari: Tu as voulu prendre une femme chez nous, tu as payé la dot, nous t'avons donné une femme. Gardela, arrange-toi. En général, ces paroles sont inspirées par la plus parfaite mauvaise foi; sous le couvert de cette apparente impartialité, la famille de la fenme s'empresse d'écouter de nouvelles propositions matrimoniales, d'en provoquer au besoin, et quand, en désespoir de cause, le mari abandonné se décide à recourir à nous, son ex-fenme a trouvé un autre mari.

Comment régler un litige de ce genre ? - Déux points sont à établir avant tout: la qualité du nouveau ménage, depuis combien de temps il existe; la sincérité des griefs de la femme.

Si le nouveau ménage a déjà quelque durée, s'il semble stable, et surtout si les torts du mari sont réels, il n'y a pas à hésiter, il faut reconnaître la légitimité de cette union nouvelle et l'appuyer de notre autorité.

J'irai plus loin, et dirai que, même si les torts du mari ne sont pas prouvés, il est opportun de prononcer la dissolution du premier mariage; nous aurons quelque chance d'avoir facilité la création d'une union de quelque durée.

Il reste à régler le remboursement de la dot versée par le premier mari.

Si les griefs exposés par la femme sont reconnus exacts, le divorce doit être prononcé aux torts du mari et il perdra la dot.

Je range l'impuissance et l'infécondité parmi les torts dont le mari est responsable, si, par des unions antérieures, ces infirmités peuvent être établies.

A défaut de torts précis, le mari en a toujours un, celui de ne sêtre pas préoccupé du consentement de son épouse; et il faut le lui faire comprendre, si on le peut. .

Le remboursement de la dot s'effectuera done: par le nouveau mari, s'il n'a pas encore payé de dot; par 
la famille de la femme, si la deuxième dot a été versée. Il faut qu'elle admette qu'on ne peut toucher deux fois, sans voler, le prix d'une seule et même chose.

Evidemment le remboursement est très aléatoire, mais nous n'y pouvons rien. A défaut de remboursement, il faudra nous contenter d'une des solutions pratiquées par les indigènes et que j'ai exposées plus haut.

Séparation du fait de la famille de la femme. - La rupture du ménage du fait de la famille de la femme est aussi fréquente que celle provoquée par la femme elle-même.

J'ai exposé au début que le mariage des indigènes est une convention passée sous le régine de la mauvaise foi. Quelle meilleure opération que de tirer deux bénéfices de la même chose ? - On s'y emploie activement. On marie une femme dont on touche la dot, on la laisse quelque temps avec son mari, puis, au cours d'une des nombreuses visites que l'épouse fait à sa famille, on la marie ailleurs.

Des raisons, on en fournira beaucoup, mais en réalité, c'est toujours une question d'intérêt.

L'avis de la femme, s'il présente un caractère de sincérité, peut servir de base à notre appréciation; mais il faut examiner s'il n'est pas donné sous l'empire du caprice ou de la suggestion.

Si le nouveau mariage est déjà ancien, s'il présente des chances de durée, si surtout un enfant est né ou va naître, je crois qu'il faut donner la préférence au nouveau ménage. La dot payée par le premier mari devra lui être remboursée; on fixera un terme pour ce remboursement et on tiendra la main à ce qu'il s'effectue.

Mais nous ne devons pas nous arrêter à ce règlement du litige. Autrement, nous n'aurions aucune chance de voir finir ce chassé-croisé de maris. Prendre une femme à son mari quand le mariage a été régulier mérite une sanction et, pour qu'elle soit efficace, elle doit être sévère. Le ou les coupables doivent être traduits devant le Tribunal indigène. 
A quel titre? - Ce ne sera pas au nom de la coutúme, qui n'a jamais connu de sanctions pénales, et qui se déclare satisfaite quand la lésion est compensée par le remboursement.

L'intérêt de la tranquillité publique, de la paix entre les individus, le respect ide la morale que nous derons imposer, faute de pouvoir le faire comprendre, suffisent à mon sens pour justifier une condamnation. Si l'on tient à tout prix à la fonder en droit, nous pouvons, malgré que cette interprétation heurte violemment nos idées de civilisatión, nous pouvons considérer le mariage indigène pour ce qu'il est, une vente ou un bail à cheptel, et nous inspirer pour la répression des dispositions de l'art. 401 du code pénal sur le vol simple. Le maximum de la pénalité que j'ai toujours appliquée a été de six mois de prison et elle a été efficace.

Qui doit être traduit devant le Tribunal ? - Le ou les membres de la famille de la femme qui ont prêté la main au second mariage, l'ont négocié, et aussi le deuxième mari, s'il sarait pertinemment la femme engagée, quand il l'a demandée ou acceptée comme épouse, et cela, même dans le cas où nous jugerions convenable de laisser subsister le nouveau mariage.

Le degré de culpabilité des accusés s'établit d'après les circonstances qui ont accompagné la rupture du premier mariage. Tantôt les parents ont reçu des offres de tiers; ils ont été tentés et l'héroïsme est la moindre qualité des indigènes. Tantôt, au contraire, ils ont voulu délibérément faire une opération frauduleuse, se procurer de l'argent, se faire payer une dette arriérée. Quelles que soient les excuses, l'acte mérite une sanction sévère. A faute de pouvoir faire comprendre aux indigènes que le mariage doit être stable, nous devons leur imposer cette stabilité.

Séparation du fait d'un tiers. - Je ne parlerai pas du cas oì-l'amant de la femme lui fait quitter son mari. Je l'ai examiné plus haut.

Les faits à grouper sous cette rubrique constituent purement et simplement un enlèvement, les tiers dont 
il est question étant étrangers à la famille de la femme.

Les exemples en étaient autrefois très fréquents : enlever la femme de quelqu'un était un des plus sûrs moyens de se faire payer une dette arriérée et si, même alors, le paiement tardait, le créancier avait toujours la ressource de marier la femme ou de l'épouser lui-même ou enfin de la vendre. Mais l'usage de ces enlèvements de femme commence à se perdre.

Les coupables doivent être comme dans le cas précédent et pour la même raison déférés au Tribunal indigène. On ne peut fonder la condamnation en droit que sur les mêmes textes; ceux relatifs à l'enlèvement et à la séquestration ne sont pas applicables. La femme, en effet, étant mariée, est majeure et d'autre part elle est consentante ou au moins indifférente; ces enlèvements ne sont généralement accompagnés d'aucune espèce de violences ou sévices et peu importe à la femme quel est son mari.

Séparation du fait du mari. - J'ai exposé au début de ce chapitre que le mariage est onéreux; nous savons tous d'ailleurs combien il est difficile d'amener un indigène à se libérer d'une dette; j'estime que nous ne possédons aucun moyen légal de contraindre au paiement un débiteur qui s'y refuse.

On s'explique ainsi que la séparation d'un ménage du fait du mari est un cas exceptionnel. Il se produit cependant.

Le mari justifie quelquefois sa conduite: sa femme est vieille, ou bien dévergondée, ou bien elle est voleuse, acariâtre, lui crée des palabres, ou enfin elle est stérile.

La coutume accorde au mari la restitution de la dot qu'il a versée, sous la condition que la famille veuille bien s'y résoudre.

C'est à mon avis une solution bien sommaire et il y a lieu de distinguer les cas où la conduite du mari est justifiée de ceux où elle ne l'est pas. Evidemment nous n'imposerons pas au mari de garder une femme qu'il refuse, à tort ou à raison, de conserver comme épouse; mais suivant qu'il aura on n'aura pas contre elle de 
justes griefs, nous prononcerons le divorce aux torts de la femme ou aux torts du mari. Dans le premier cas, nous imposerons le remboursement de la dot; dans le second, nous refuserons de nous entremettre pour ce remboursement et nous dirons à la famille de la femme: tu ne dois rien. Forts de notre assentiment, il est probable que les parents de la femme ne se laisseront pas influencer ni intimider et ils profiteront au plus tôt de cette aubaine: toucher, mais légitimement, deux dots pour la même femme.

\section{Dissolution du mariage par le décès d'un conjoint}

Le mariage est dissous par le décès de l'un des conjoints; nous allons examiner les conséquences de cette dissolution.

$1^{\circ}$ - La femme est décédée. - Nous aurons sans doutè plus tard l'occasion de dire que l'indigène ne croit pas à la mort naturelle; que d'autre part la coutume, à l'inverse de ce qui se passe chez nous, veut que ce soit les malades qui se rendent chez le médecin et non point le médecin chez les malades.

Lors donc qu'une femme en puissance de mari tombe malade, son premier soin est de retourner chez ses parents; elle est étrangère dans la famille de son époux, ne l'oublions pas; elle cherche donc à échapper à des influences ennemies. Admettons que le décès suive la maladie.

La famille de la femme doit envoyer annoncer au mari la mort de son épouse et lui faire un cadeau; deux pièces. On examine alors les circonstances qui ont accompagné le décès. Si la femme n'a imputé sa mort à personne, s'il n'y a pas eu de rêve accusateur, la famille doit rembourser la dot, ou donner au veuf une autre femme pour laquelle il ne paiera que demidot, c'est-à-dire dix pièces.

Si au contraire la femme est décédée chez son mari, 
l'annonce de la nouvelle du décès, accompagnée du cadeau à la famille: trois pièces, l'examen des circonstances de la mort, tout se passe comme dans le eas précédent et si rien n'est découvert qui soit opposable au mari, on doit encore lui remplacer sa femme on lui rembourser la dot.

Mais les risques courus par le mari sont bien plus grands, et il a beaucoup plus de chances de se voir imputer la mort de sa femme, auquel cas, non seulement il n'a droit à rien, mais on lui réelame le prix du sang. Quoiqu'il en soit, le principe est qúe, après le décès de l'épouse, on doit la remplacer à son māri ou lui rendre sa dot.

Je n'ai pu jusqu'aujourd'hui m'expliquer l'origine exacte de cettè coutume. Est-elle admissible? - Il ne me paraît pas. Que si les indigènes dans un cas donné s'en accommodent, je n'y trouve pas à redire. Mais si le cas nous est soumis, je ne pense pas que nous devions intervenir, si ce n'est pour déelarer que personne n'étant responsable du décès, personne non plus n'a à dédlommager le mari.

Le veuf n'abandonnera pas volontiers ses prétentions, mais la famille de la défunte, forte de notre assentiment, se gardera bien d'y donner satisfaction. Et il y a lieu d'espérer qu’à la longue cet usage disparaîtra.

$2^{\prime \prime}$ - Le mari est décédé. - Nous devrions réserver l'examen de ce cas au chapitre de l'héritage, mais il nous parait préférable de ne point séparer tout ce qui touche au mariage.

Les épouses, en effet, font partie intégrante de l'híritage du défunt, et elles sont dévolues au même titre que les autres biens à ses héritiers, e'est-à-dire à ses neveux (fils de ses sœurs utérines) ou à ses frères utírins, à condition qu'ils soient nubiles et qu'ils les acceptent. La femme n'est pas consultée. mais, comme toujours, elle subit passivement ce changement de mari. Les veures sont d'ailleurs la partie liquide, assurée de la succession. 
De son côté, le nouveau mari paie à la famille une demi-dot, soit dix pièces.

Cette mutation donne lieu, mais en somme pas très souvent, à des litiges. Ce n'est point l'héritier qui refuse la femme, mais c'est généralement la femme qui refuse le nouveau mari; elle le trouve trop jeune, ou trop vieux, ou enfin, grief inexpiable, elle trouve que ses maris meurent trop rite ou qu'elle a perdu trop d'enfants avec eux. "Javais épousé leur oncle, ditelle, il est mort; je suis passée à son neveu, il est mort, je ne veux plus aller avec le frère de celui-là. J'aime mieux me marier ailleurs ". Avant d'examiner la solution à donner à ces litiges, voyons ce que vaut la coutume elle-même. Comment peut-elle se justifier ? -Je ny rois que deux explications, aussi peu satisfaisantes l'une que l'autre.

On peut dire: la femme qu'un homme a épousée, lui appartient; la dot est unc manière de prix d'achat. Il est juste que ce bien meuble soit dévolu et partagé comme les autres biens du défunt.

Mais contre cette explication, la coutume fournit des arguments: la femme mariée n'appartient pas à son mari; elle ne perd pas sa qualité de membre de sa tribu d'origine; - ses enfants sont à elle, non à leur père; - l'esclave achetée huit ou dix pièces est bien plus la chose de son maitre que l'épouse dont la dot a atteint 20,30, 40,60 pièces ou davantage. Le mari n'a sur son épouse que le domaine utile, il n'a pas le domaine éminent; n:ême pas; à tout bien examiner, il n'a sur sa femme que les droits du preneur dans le bail à cheptel simple.

Autre explication: la dot payée par le mari n'est pas sortie de ses seules mains; d'autres de ses parents y ont contribué ; il est juste que d'autres parents puissent aussi bénéficier de la femme, libérée de son lien matrimonial.

Mais alors, comment expliquer que les bénéficiaires soient toujours les plus jeunes; le neveu est plus jeune que son oncle, le cadet que son aîné; le neveu et le cadet étaient même, dans la plupart des cas, 
trop jeunes pour contribuer par leur travail, leurs gains, au paiement de la dot. Et même quand ils ont contribué, c'est toujours pour une petite somme. Pourquoi la femme leur est-elle attribuée, à eux spécialement plutôt qu'à tels ou tels parents qui auraient effectivement concouru au paiement de la dot?

Je laisse aux investigations de mes confrères le soin d'éclairer cette question.

Quoiqu'il en soit, les difficultés apportées à l'exécution de la coutume ne peuvent venir que de la femme qui refuse le mari imposé, ou de la famille de la femme qui aimerait mieux toucher une dot entière qu'une demi-dot.

Il est clair que nous ne pouvons pas obliger la femme à accepter un mari imposé d'office. D'autre part, nous n'avons pas trouvé de justification à la coutume. Nous savons au contraire que, si nous ne pouvons interdire la polygamie, au moins ne devons-nous pas favoriser la constitution de ménages à femmes nombreuses; on commence au Congo Belge à proscrire la transmission des femmes par héritage.

Nous n'en sommes pas là; nous ne pouvons pas défendre, mais nous pouvons ne pas consacrer de notre autorité de semblables mutations.

Il faut donc dire à celui qui réclame un pareil héritage: tu n'as droit ni à la femme, ni à la dot, parce que si ton oncle ou ton frère a payé, toi, tu n'as rien versé. Je sais que telle est votre coutume, elle est mauvaise, il faut la changer.

Aux parents de la femme, nous dirons: vous n'êtes pas tenus de marier votre fille aux parents de son mari défunt, ni à tarif réduit. Cependant, et il est prudent d'ajouter ce correctif, cependant c'est à vous de voir où est votre intérêt. De votre refus peuvent résulter des palabres graves; voyez si vous ne les éviteriez pas en donnant satisfaction aux demandes du plaignant, qui, à votre point de vue tout au moins, sont justifiées.

La plupart du temps, le conflit s'apaise par le paiement d'une dot entière; la veuve disponible au lieı 
d’ètre mariée d'office comme telle, se trouve marice comme une femme ordinaire, et le but que nous poursuivons, la destruction du mariage spécial des veuves. se trouve atteint.

\section{$\S 6$}

\section{Du mariage entre femmes}

Pour terminer l'examen de ce qui se rapporte à la convention matrimoniale, il me reste à parler d'une coutume bizarre, celle du mariage entre femmes. Il n'est pas ce que nous autres civilisés pourrions imaginer au premier abord et Lesbos n'a pas envoyé de colonies au Gabon.

Jai observé cette coutume chez les Nliomi, les Ngové, elle doit exister à Setté-Cama et peut-être à Nyanga. Je ne crois pas qu'on l'ait constatée à Mayumba et elle ne se rencontre assurément pas chez les Bayaka.

Yoici en quoi elle consiste :

Une femme, d'après cette coutume, peut payer valablement une dot pour une autre femme, à la famille de celle-ci et acquérir par là sur elle soit une puissance analogue à la puissance maritale, soit beaucoup plutôt, la puissance que détient un frère aîné, un oncle maternel, en un mot un chef de famille.

En principe, la femme qui joue le rôle de mari, agit dans l'intérêt d'un sien parent proche, généralement de son frère, qui devient alors l'époux véritable: c'est un don gracieux qu'elle lui fait. Il y a là mariage par procuration. Mais entre le mariage conclu par la femme-mari et le mariage consommé par l'époux, il peut s'écouler un laps de temps pendant lequel la femmeépouse est à la disposition de la femme-mari; celle-ci souvent la livre à la prostitution pour son compte. Je suis assez mal renseigné sur les détails et les conséquences de cette coutume et j'attire sur elle l'attention de mes confrères. 
Quoiqu'il en soit, examinons la conduite à tenir devant des cas de cette espèce.

- Si nous le pouvions, nous devrions, me semble-t-il, prohiber de telles conventions. D'abord la puissance du chef de famille ne me parait pas pouvoir être cessible contre de l'argent; elle ne peut faire l'objet d'une convention du vivant du détenteur naturel.

Le mariage des indigènes n’a que trop de tendance à se confondre avec le contrat de vente; le mariage entre femmes en est une dégradation, une aggravation. et il se rapproche encore davantage du trafic des personnes humaines.

A ce double titre, un tel usage doit être proscrit. Je ne crois pas cependant qu'il tombe sous le coup des sanctions du décret du 12 décembre 1905. La fenme mariée à une autre femme ne perd pas sa liberté et ses enfants sont libres comme elle.

Mais je crois que nous ne devons pas confirmer de notre autorité des conventions de ce genre.

Surtout nous ne devons pas, pour nous conformer à cette coutume, dissoudre une union normale contractée et consommée en violation d'un pareil usage. Tout au plus y a-t-il lieu à compensation. L'homme qui aurait pris comme épouse une ferme en puissance d'une autre femme, ne doit avoir à payer que la dot normale. S'il ne l'a pas payée, qu'il rembourse à la femmemari les débours raisonnables qu'elle a pu faire. S'il l'a payée déjà à la famille de sa femme, c'est aux membres de cette famille à dédommager, en espèces ou marchandises, la femme-mari qui a été lésée.

\section{$\S 7$}

\section{De l'Adultère}

L'adultère trouverait plutôt sa place parmi les délits punis par la coutume; mais les pénalités admises par les indigènes sont si peu nombreuses que nous n'en ferons sans doute pas l'objet d'une étude spéciale; 
noùs roulons done, à propos du mariage. épuiser tous les motifs de " palabres " et celui-là est des plus communs.

Les causes de cette fréquence de l'adultère sont multiples

La salacité des indigènes est trop connue pour que jy insiste; hommes ni femmes ne recevant de formation morale, d'éducation, aucun sentiment élevé ne vient réprimer leur propension an libertinage.

J'ai exposé ailleurs la liberté d’âllures des épouses, la ténacitéovec laquelle elles se gardent de toute suprématie du mari, le soin qu'elles mettent à entretenir, par des visites plus ou moins prolongées et fréquentes, lèurs relations avec leur propre famille. Combien doccasions ne rencontrent-elles pas de donner quelque accroc à la fidélité conjugale ?

On connaît l’inégale répartition des épouses; jai indiqué ailleurs comment elles pouvaient se trouver par l'hérédité réunies autour du même mari, le cadet recueillant les épouses de ses aînés, le neveu celles de son oncle.

Le nombre des femmes étant sensiblement égal à celui des hon:mes. il en résulte que les hommes les plus àgés ont des épouses nombreuses, dont vraisemblablement. les désirs sont mal satisfaits, et que les jeunes gens, célibataires par contrainte, ne demandent pas mieux que de consoler ces épouses délaissées.

En ouvrant au hasard nos registres de recensement, voici quelques exemples de la répartition des femmes.

Dans la forêt, chez les Bayaka :

Village Ibanga: 16 femmes, - 11 hommes dont 6 célibataires; deux ménages de 5 femmes;

- Mivengué: 16 femmes, - 16 hommes dont 10 célihataires; un ménage de 5 femmes, 1 de 4,3 de 2 el 1 monogame;

- Bilimiba: 12 femmes, - 11 hommes dont 6 célibataires; un ménage de 5 femmes, 3 de 2 et 1 monogame;

-.Moucongo-Mounéné: 12 femmes, - 13 hommes dont 6 célibataires; 
- Cambala: 16 femmes, - 13 hommes dont 6 célibataires; un ménage de 6 femmes, 1 de 4,1 de 2 et 4 monogames.

Dans les savanes de la Nyanga habitées par les Baloumbo, voici également quelques chiffres :

Village Macanda: 18 femmes, 14 hommes, dont 4 célibataires; 2 ménages de 3 l'emmes, 3 de 2 et 5 monogames;

- Sanga : 30 femmes, 31 hommes dont 10 célibataires; 1 ménage de 4 femmes, 3 de 3,2 de 2,15 monogames;

- Bwalacambo : 12 femmes, 13 hommes dont 6 célibataires; 1 ménage de 4 femmes, 1 de 3,5 monogames;

- Mouralou : 17 femmes, 21 hommes dont 10 célibataires; 1 ménage de 4 femmes, 3 de 2 et 7 monogames;

- Kouri : 34 femmes, 29 hommes dont 12 célibataires; 3 ménages de 4 femmes, 1 de 3,6 de 2 et 7 monogames.

Rien dans les noeur's ne vient contrebalancer les influences que je viens de déduire; sauf dans les endroits touchés por la civilisation, Mayumba, par exemple, la prostitution n'existe pas.

Raisons morales, état social, tout concourt à rendie l'adultère fréquent.

Il semblerait donc assez logique que les indigènes y attachassent peu dilimportance.

La faute de la femme, en effet, n'altère pas la pureté de la descendance, puisque la filiation s'établit par la mère.

Il est incontestable d'autre part qu'il n'existe aucune notion de ce que nous appelons l'honneur coniugal.

L'adultère ne cause donc au mari aucun préjudice ni moral, ni social.

J'ajouterai enflin que le soin avec leauel tout indigène, homme ou femme, cache ses allées et venues, devrait rendre le délit particulièrement difficile à étab̧lir, à consțater et, quelque soit sa fréquence, il dẹ- 
rrait ne nous ètre soumis qu'exceptionnellement. Nous savons qu'il en est tout autrement.

Quel est, en matière d'adultère, l'état de la coutume? - Le complice de la femme doit payer une indemnité presque uniformément fixée à dix pièces, tantôt au mari seul, c'est le cas dans la subdivision de Tehibanga, dans celles de Moabi et de Ndendé, tantôt par moitié au mari et à la femme comme cela se passe chez les Baséri de Nyanga.

J'attirerai l'attention sur deux points de cette coutume.

1" - La femme n'est jamais inquiétée. Non seuleninent ladultère ne la déshonore pas, mais on la tralite toujours conmme une victime. Nous autres verrions là un manque de logique, un défaut de psychologie. Il est difficile en effet d'imaginer que la femme ne soit pas au moins consentante; elle eît pu se défendre, appeler à l'aide; la vlie humaine est l'objet d'assez de respect de la part de nos indigènes; chez eux le sang est rarement versé; et, au moins depuis notre occupation, des menaces de l'homme à l'égard de la femme devraient être moins couramment prises au sérieux.

Qui peut dire, en outre, dans combien de cas la femme n'a pas été la tentatrice?

La femme n'est cependant jamalis inquiétée et roici l'explication de cette apparente générosité :

Dans un pays comme le nôtre où l'indigène cache sa vie, sisole avec soin, quels moyens y a-t-il de découvrir l'adultère? - Le flagrant délit ne pouvant être constaté que par hasard, il ne reste qu'un seul élément de preuve: l'aveu.

Peut-on espérer l'aveu de l'homme? - A priori, non; on ne recherche pas volontiers les occasions de se voir infliger des amendes.

Reste l'aveu de la femme et c'est, en effet, sur sa déclaration que toutes les procédures d'adultère sont échafaudées.

Comment les choses se passent-elles en réalité? Un incligène remarque-t-il quelque changement dans la manière de se comporter de son épouse, quelque 
froideur à son égard? - Peut-il lui-mème se reprochcr quelque négligence? - Le ménage s'est-il trouvé quelque temps séparé? - La conduite de la femme a-t-elle inspiré quelque soupçon aux parents, aux amis du mari? - Celui-ci quíi considère un manque à gagner comime aussi impossible à supporter qu'un vol, prend sa femme en particulier et lui demande si par hasard elle ne lui aurait pas fait quelque infidélité? - La femme qui n’a rien à redouter, ni déshonneur, ni amendes pour elle ou sa famille, avoue sans difficulté.

Quelquefois cependant l'aveu n'est obtenu que par des violences; si loccaslion se présentait d'en constater, il faudrait sévir contre le mari que rien n'excuse. Il nagit pas contre sa femme sous la morsure de la jalousie, mais seulemient par l'appât du gain, sentiment des moins honorables.

Voicti donc expliquée la mansuétude de la coutume vis-à-vis de la femme complice d'adultère. C'est à elle seule que peuvent être dus la découverte du délit et le bénéfice que le mari est appelé à en retirer.

$2^{\circ}$ - L’indemnité d'adultère, " boukali ", est élevée, j'entends proportionnellement. Les dots dans nos régions sont en moyenne de trente pièces. Ilindemnité d'adultère en représente donc un tiers. Si courte que soit la durée noyenne d'un ménage, j'imagine que bien des maris ont loccasion de rentrer dans leurs débours.

Pourquoi cette rigueur contre un acte irrégulier, regrettable autant qu'on le voudra, malis qui, tout compte fait, ne cause aucun préjudice à l'époux qui en est la victime?

Les indigènes ont grand peine à fournir une justification de la coutume.

" J'ai travaillé pour payer la dot, travalillé pour faire les plantations, pour fournir les vêtements; je n'admets pas qu'on se serve de ma femme ".

Mauvaise raison qui ne tient pas contre l'élévation relative des dommages-intérêts. Il est vrai que l'indigène, eût-il, à l'aide des indemnités d'adultère, recouvré le montant de la dot, ne se considérerait pas com- 
me remboursé; ce ne sont pas, en effet, les mèmes personnes qui ont touché la dot et qui payent le "boukali " et, à son idée, il ny a pas compensation.

D'autres disent: "Les femmes ne sont pas inquiétées pour fait d'adultère, nous sommes sans action sur elles; quau moins la $l_{\star}$ gueur de la punition fasse peur à leur complice ". Mauvaise raison encore; les indigènes reconnaissent sans peine que l'élévation des dommages-intérêts encourus n'a janais empêché un homme de profiter du caprice d'une femme.

En outre, cela n'explique pas pourqucli la coutume voudrait en:pêcher l'adultère, qui semble bien ne causer aucun tort ni au mari ni au ménage.

Jalousie sexuelle, dira-t-on? - Non! - Ciest un sentiment que je ne vois pas chez nos nègres. Explicable chez les animaux, sujets à des époques de rut, chez lesquels le temps des amours est linlité, l'instinct de jalousie sexuelle ne se justifie pas chez l'être humain qui fait lamour en toute saison.

Il y a à la répression rigoureuse de l'adultère par la coutume un autre motif que j'ai quelquefois aperçu. L'incligène, mais ce sentiment conmence à disparaître, l'indigène a été autrefois persuadé que la faute de la femme avait sur la personne du mari des répercussions redoutables, qu'elle pouvait entraîner des accídents graves, des maladies, la mort même. Je rappelle à cette occasion le fait, cité au chapitre de l'esclavage, l'une femme rédulite en servitude parce qu'on attribuait à un sien adultère la mort de son mari, victime d'un accident de chasse: l'éclatement de son fusil.

Chacun de nous pourrait sans doute retrouver dans ses sourenirs des allégations comparables; c'est là je crois qu'il faut chercher la viritable justiflication des rigueurs de la coutume.

$$
\text { * * }
$$

Lorsqu'une plainte en adultère nous est soumise, quelle conduite devons-nous tenir?

Et d'abord, quelles preures admettre? 
Le code pénal impose à l'adultère des preuves déterminées dont inne seule est à notre disposition: le flagrant clélit constaté. Il doit être extrêmement rare chez les indigènes, car, jamais je ne l'ai entendu invoquer; la raison en est que les complices se livrent rarement dans les villages à leurs ébats extraconjugaux; ils préfèrent l'abri discret de la campagne, l'onbre propice des bois, le plus souvent le volisinage des plantations.

Il reste donc l'aveu; mais là nous ne devrons pas nous contenter de l'areu de la femme. Celle-ci peut céder aux suggestions, aux menaces, aux violences d'un mari âpre au gain. Comme elle-même ne court le risque d'aucune pénalité, une déclaration de conplicité ne lu'i coûte guère. Il faut l'aveu des deux complices, en particulier celui de l'homme.

Etant donné les dommages-intérêts assez lourds que la coutume lui impose, cet aveu de l'homme n'est pas obtenu facilement.

Il ne saurait évidemmient être question de preuves par écrit; mais, si je cite ce mode de preuve, je prétends ne pas mériter l'accusation de naïveté. Nous trouvons dans les usages l'équivalent de ces éléments de certitude, c'est la reconnaissance de dette, ou le commencement de paiement.

Dans une affaire d'adultère, si la partie plaignante affirme et prouve que l'accusé a déjà commencé à payer l'indemnité d'usage, on peut garant'ir avec une quasi-certitude qu'il est coupable. Et cette méthode de preuve est applicable dans bien des cas de toute nature.

Si ce n'est pas l'accusé lui-même qui avait commencé à payer, mais quelqu'un de sa famille, oncle, frère aîné, la preuve ind'irecte que je propose est plus convaincante encore. Si l'on peut imaginer à la rigueur, selon moi c'est une erreur, si l'on peut imaginer à la rigueur, dis-je, qu'un accusé innocent consente à payer une indemn'ité qu'il ne doit pas, dans le seul but d'éviter de plus graves querelles, on dépasserait la limite des possibilités en faisant une hypothèse 
analogue à l'égard d'un de ses parents même proches, lequel n'est point directement mêlé au litige.

Examinons matintenant quelles solutions nous devrons donner aux plaintes en adultère.

Si nous analysons les dispositions de la coutume, nous nous rendrons compte facilement que :

$1^{\circ}$ - Elle est dépourvue d'équité, puisqu'elle suppose à priori l'innocence de la femme, alors que, la plupart du temps, on peut hardiment parier pour l'égale répart'ition de la culpabilité sur les deux complices.

$2^{\circ}$ - Elle est sans justification. Le point de vue moral est étranger aux indigènes, le dommage causé au ménage est nul; la rigueur de la répression n’a pour but que d'empêcher des actes devant occasionner un préjudice imaginaire.

$3^{\circ}$ - Enf'in, nous constatons que les pénalités sont inefficaces.

Gardons-nous cependant de négliger le règlement de ces questions; notre mentalité de civilisés à moralité diminuée nous porte à sourire des infortunes conjugales et à y attacher une min'imie importance........ quand il s'agit des autres, surtout si ces autres sont des nègres. L'adultère est immoral en soi, sa non-répression entraîne dans la société indigène des désordres à longue répercussion, et notre devoir est de le réprimer.

Il me paraît donc qu'il est 'inadmissible que le mari tire un bénéfice de l'inconduite de sa femme, et je crois que nous devons nous refuser à appliquer la coutume.

Nous avons dans notre code pénal, articles 337 et suivants, des principes de répression de l'adultère bien tombés en désuétude, il est vra'i, mais que nous pourons appliquer avec toutes les atténuations justifiées, exigées par la moralité nulle, le manque d'édu- 
cation des races primitives que nous administrons. Lappl'ication d'une peine de prison de $1,2,3$ mois donnera à réfléchir aux deux complices de l'adultère, surtout à la femme, sur la mentalité inférieure de laquelle aucun raisonnement ne peut avoir daction.

Souvent le mari sera le premier à demander cette punition pour sa femme; nous pouvons, le Code le permet, lui laisser la lattitude d'en diminuer pour elle la durée.

Il faudra en outre expliquer notre sentence; la partie de celle-ci qui punit les deux complices est-facilement comprise. Celle qui, dérogeant à la coutume, supprime pour le nègre un bénéfice, sera diff'icilement admise. C'est à notre imagination que revient le soin de trouver des arguments ingénieux susceptibles d'amener à la longue un progrès moral chez nos administrés.

Telle est la solut'ion de principe qui me parait la plus convenable. Dans beaucoup de cas, dans la plupart des cas, elle pourra être appliquée. II se peut, toutefois, qu'elle soit inopportune; c'est quand elle serait destinée à des groupemients peu pénétrés encore, éloignés des Postes; il s'en trouve de tels au sud et au sud-est de la Subdivision de Tchibanga et de Ndendé. A leur égard, cette solution logique sera'it inopérante; notre sentence ne terminerait rien et, après la sortie de prison des condamnés, le mari trompé reprendrait la poursuite per ias et nefas du paiement de l'indemnité prévue par l'usage.

A l'égard donc de ceux dont 'il est question, il nous faut faire à la coutume quelques concessions et admettre le principe de l'indemnité. Mais nous devons la rendre équitable et l'imposer par moitié à chacun des complices. Nous pouvons également y adjoindre une peine de pr'ison plus réduite, surtout dans le but d'atteindre la fen:me qui n'est pas lésée par les dommages-intérêts infligés en fayeur du mari. La femme en effet ne possède la plupart du temps rien. L'indemnité, c'est sa famille qui la paiera et nous saisirons l'occasion de faire comprendre à ses membres la res- 
ponsabilité que leur fait encourir le manque de formation morale des enfants.

Le système de répression appliqué par la coutume à l'adultère présente un danger particulier. Le mari pourrait s'apercevoir de tout le parti qu'il peut tirer de l'inconduite de sa femme, la laisser s'y livrer, l'y pousser même au besoin. Il se trouverait exercer ainsi en quelque manière le rét'ier de souteneur.

Je ne sais si beaucoup d'entre nous ont constaté cette perversion des mours, qui ne s'expliquerait que dans les parties les plus civilisées de la Circonscr'iption: Marumba et Nyanga. Je ne l'ai observée qu'une lois à Tchihanga et dans les environs du poste naturellement.

Il faut sévir énergiquement contre des cas de cette espèce. La femme est peu responsable; elle est beaucoup plus amorale cu'immorale; mais le mar'i est inexcusable. Il me paraît que le divorce doive séparer d'office un tel ménage, le mari perdant tout droit au remboursement de la dot; la femme rendue à sa famille sera mariée ailleurs et retournera sans peine aux habitudes de ses congénères. Cela sans préjudice d'une prfine de prison que le mari aura largement méritée.

J'ai achévé d'exposer, je crois, tous les détails de la coutume relatifs au Mariage; le lecteur a vu comment il se conclut et comment il se rompt, quelles obligations et quels arantages en découlent pour les intéressés; il connaît à quels litiges il donne lieu.

Je ne crois pas qu'il soit possible à un Européen de ne pas conclure: $\mathrm{Si}$ je devais payer les avantages éventuels du mariage du prix que les indigènes les paient, je ne me résoudrais au mariage, et surtout au mariage polygame. qu'arec un bien mince enthousiasme. Nous ne pourons cependant, même avec la plus grande 
bonne volonté, nous mettre à la place des intéressés et il est certain qu'à leur sens, avantages et inconvénients de la pluralité des femmes ont des coefficients différents de ceux que nous pouvons leur affecter.

Il y a toutefois quelques points de vue assez particuliers sur lesquels je voudrais attirer l'attention.

Je ne parlerai d'abord point des épouses. La femme indigène n'a que l'instinct de la maternité. Toute proche encore de la nature, elle n'est qu'une femelle; elle remplit animalement sa fonction, qui est de reproduire. Peu lui importe le mâle. Cette indifférence est assez profondément innée pour qu'elle ne la perde jamais. D'une femelle bestiale qu'elle est à l'état spontané, la civilisation et l'éducation approximatives que nous lui apportons à présent, faute de pouvoir pour l'instant davantage, font de la femme indigène une prostituée, et de ce métier elle n’éprouve aucune honte.

'Mais l'homme, quels avantages retire-t-il du mariage et de la pluralité des femmes ?

A côté de l'agrément qu'il peut trouver à voir varier l'objet de ses amours, et il est indubitable que l'indigène apprécie cette variété, il y a dans la coutume des motifs qui expliquent la polygamie. Le mari ne se rapproche pas de son épouse pendant la grossesse et pendant la lactation de l'enfant. Si l'on se rappelle que le sevrage est tardif et se pratique quelquefois à $3,4,5$ ans (j'ai vu téter des enfants ayant 20 dents!), si l'on tient compte du tempérament ardent des indigènes, on comprendra que pour éviter une aussi longue continence, ils tiennent à réunir auprès d'eux assez d'épouses pour ne point supporter de trop longs et trop fréquents jeûnes.

La coutume nous fournira encore une autre raison: comme toutes les populations primitives, les nôtres pratiquent jusqu'à un point assez élevé la spécialisation du travail. La division est dans une certaine mesure basée sur la dépense de force nécessaire, au moins sans doute à l'origine; pour le présent elle est consacrée par l'usage. Les routes des forêts, par exem- 
ple, sont débroussées par les hommes; celles des savanes le seront par les femmes. On n'aurait jamais vu autrefois dans notre région une femme servant de porteur, alors que cependant elles sont de taille à ne pas faiblir sous de lourds fardeaux. C'est pourtant commun chez les Echira, chez les Bakélé, chez les Pahouins. Je ne crois pas que les femmes se livrent davantage au commerce, au moins ne font-elles pas personnellemient les transactions, si ce n'est celles qui ont pour objet des vivres du pays; le commerce est l'apanage des hommes.

Il en est de même pour les plantations: en forêt, l'homme effectue le débroussement, coupe les arbres, brûle ce qui peut brûler, en un mot, prépare le terrain, mais c'est la femme qui plante. Dans les savanes, tout le travail. est fait par elle. Dans l'un et l'autre cas, les plantations sont sa propriété.

Il en découle directement cette conséquence que, si un homme n'a pas d'épouse, il n'a pas de plantation, - et pour une raison analogue, au moins chez les Bayaka, l'homme qui n'a pas ou n'a plus de femme, n'a pas de case. Le célibataire doit donc vivre sur le commun, et la situation n'est pas enviable.

Ȩnfin, il est une considération très importante et que je ne dois pas omettre. Elle est fort bien exposée dans l'ouvrage du Docteur Cureau oì l'on fera bien de la relire (Les Sociétés primitives de l'Afrique équatoriale, page 101). Nous pouvons la résumer ainsi : l'indigène qui ne fait point d'économies, qui est imprévoyant, non pas tant par nature que par nécessité, au moins chez nous, l'indigène connaît cependant une espèce de placement; lorsqu'il a des fonds disponibles, il se procure une fenme; l'intérêt de ce placement sera constitué par les enfants, source de profit: le travail des garcons diminuera son labeur, les dots des filles l'enrichiront, etc.

Or il arrive ceci: lorsqu'un homme a perdu sa ou ses femmes, il trouve difficilement à se remarier. Je crois que pour éviter ce célibat éventuel avec ses conséquences, l’indigène est capable de supporter beau- 
coup de sacrifices. Du moins ai-je obtenu souvent cette réponse. "Pourquoi as-tu tant de femmes, disais-je? C'est une source de difficultés; il faut faire des plantations pour chacune, construire des cases, payer leur impôt. C'est trop de travail et trop d'argent. Et je ne parle pas de la dot à payer. Et quand tu te seras donné bien du mal, un beau jour l'une ou l'autre te quittera. Ce seront des palabres sans fin où tu risques de ne pas retrouver ta dot. " - "Oui, me répondait-on, mais si je n'ai qu'une femme et qu'elle meure, je ne trouverai plus à me marier. Alors où vivrai-je? Comment vivrai-je? " - Et par là l'homme entend et la vie précaire, et les amours de hasard et remplies de risques, et le manque à gagner que lui causerait l'absence de postérité.

Voilà quelles raisons j'ai pu trouver à la polygamie des indigènes. Je ne les trouve pas suffisantes, encore qu'elles aient du poids; mais encore une fois, nous ne pourons être que de mauvais juges.

\section{CHAPITRE VIII}

\section{De la RÉPARTITION TERRITORIALE des INDIGÈNES}

Nous avons achevé d'examiner cómment les indigènes étaient groupés en tribus et comment se constituait la famille. Il nous reste à étudier comment les individus sont répartis dans les territoires que nous administrons.

La tribu, en effet, n'occupe pas tout entière un territoire continu: les groupes qu'elle englobe sont plus ou moins éloignés les uns des autres; en dehors de la filiation du sang, à la manière indigène, les alliances ont pu créer des relations assez étroites pour réunir côte à côte deux rameaux de tribus différentes. Nous en trouverons des exemples. 


\section{Du Village}

L'élément numériquement le plus faible de la répartition territoriale de la population est le village.

Ce mot "village " a besoin d'être précisé ; trois langues, au moins, en effet, sont parlées dans nos postes: la \angue indigène que nous ignorons, notre français maternel, et le français des interprètes, ces deux derniers idiômes présentant de sensibles différences, surtout quant à l'acception des vocables.

Je définirai donc le village " un groupe d'habitations contiguës »-quelque soit d'ailleurs le nombre de celles-ci.

- Quant aux individus qui le composent, le village est habité par une famille, ses alliés, leurs enfants, les enfants des soeurs des uns et des autres, leurs clients ou esclaves, et en proportion infime, des étrangers.

En ouvrant au hasard le recensement de la Subdivision de Tchibanga, j’y prends un exemple: celui l'un village composé de :

un chef et ses deux femmes,

son frère germain et sa femme,

un frère d'une femme du chef et ses deux femmes,

un fils du chef, marié,

un fils du chef, célibataire.

Total, 6 cases, 11 habitants.

Multipliez ces parentés et ces alliances, en admettant comme les indigènes la représentation illimitée des défunts; ajoutez quelques esclaves et vous aurez une idée très exacte de la manière dont se compose, en quelque sorte mécaniquement, un village de notre région.

Il est possible, cependant, que, dans les subdivisions de la côte, ce mode de groupement ait été influencé par la civilisation, quelle ait rendu plus fréquente l'accession d'individus complètement étrangers. 
Quelle est l'importance des villages? - Elle est très variable. Leur population peut se réduire à un seul ménage polygame: elle n'atteint jamais un chiffre très élevé; le maximum que jaie pu constater a été observé au village de Mibengué, dans la subdivision de Ndendé, où j'ai compté en 1914 cent cinq cases. Je n'ai jamais vu, dans aucune des autres subdivisions, de villages atteignant ce chiffre, ni même en approchant quelque peu.

Quels que soient les motifs qui ont groupé les individus constituant le village, leur réunion est essentiellement temporaire.

L'indigène vit dans un état de terreur continuelle, il craint tout de tout le monde et surtout les paroles, c'est-à-dire les sorts. Sous un prétexte qui nous paraît futile, des gens vivant ensemble aujourd'hui se sépareront demain. Mais la dispersion peut ne pas être complète. Si les causes de dissentiment sont graves, chacun des individus s'en ira planter sa case ou bien chez d'autres de ses parents, ou bien chez ceux de sa femme, et le village n'existera plus. Mais si elles sont légères, le groupement, dont nous avons vu tout à l'heure la consțitution essentiellement familiale, se fragmentera et les sous-groupes ainsi produits s'établiront dans un périmètre restreint, chacun d'eux cependant restant nettement séparé: chacun des frères, par exemple, entraînant avec soi sa clientèle, érigera un village particulier; tous ces villages continueront à porter ensemble le même nom, à reconnaitre la prééminence du même chef, et il y a dans ces coutumes un élément de confusion énervant.

Lorsque nous avons à établir l'identité d'un indi'gène, nous ins'crivons, à côté de son nom, celui de son village, et cellui de son chef. Questionné dans ce sens, l'intéressé donne le nom du groupe de villages et celui de leur chef. Si plus tard l'individu est recherché, on 'questionne le chef qui répond: "Un tel n'est pas dans mon village ». Strictement, il ne ment pas. Cela déroute et d'autant mieux que le vocabulaire géographique est très restreint, peu varié dans ses procédés, 
et surtout peu usité: un village est désigné par les indigènes, non par une appellation topographique, mais par le nom du chef. L'interprète, qui a la mème mentalité que l'indigène, n'attache pas d'importance à la précision et, quel que soit-le terme employé, il le traduit par village.

Quelques-uns de nos camarades ont désigné ces sous-groupes dispersés du même village sous le nom de " campement ". C'est une dénomination inexacte, et qui ne correspond nullement au fait, ni davantage au mot indigène. Ce démembrement d'un village est aussi définitif que le village lui-même, du moins il n'est pas plus provisoire. Aux yeux des habitants, il n'est pas provisoire du tout. Ce n'est pas un campement, c'est un " écart ". Nous devrions enseigner ce mot à nos interprètes, car il détermine exactement ce que nous roulons désigner.

Cette aggrégation et cette désaggrégation continuelles des individus sont une des difficultés les plus grandes que nous rencontrions dans notre administration des indigènes. On ne peut avoir d'action sur des gens en quelqūe sorte insaisissables. J'ai constaté des in'divildus fui restaient, avec de très bonnes raisons à leur point de vue, sans résidence certaine pendant des années. On ne pouvait que très difficilement faire payer l'impôt de ces hommes; les chefs des villages successifs occupés par eux répondaient de très bonne foi: ". Un tel n'est pas chez moi ,". Ces ragabonds sont souvent des esclaves; j'ai cependant connu un chef de terre de la subidivision de Tchibanga qui ne s'est fixé que l'année de sa mort; il avait passé la plus grande partie de sa vie en chemineau, suivi de ses deux ou trois femmes.

Quels sont les responsables dë cette mobilité, de ce quasi-nomadisme?

C'est la crainte des sorts, disais-je, qui cause la plupart du temps le démembrement et la dispersion du village; ce sont les mêmes motifs đui conduisent un individu à changer de demeure, mais la personnalité agissante, responsable, est presque toujours celle 
d'une femme. Une altercation avec une voisine, uı rêve prêtant aux commentaires ou un cauchemar trop effrayant, et voilà la femme la tête aux champs, poursuivant son mari de lamentations et finissant par lui dire: "Si nous ne quittons pas d'ici, je m'en vais... chez ma mère!"

Le mari qui voit surtout les risques courus par la dot par lui versée et qui sera difficilement remboursée, le mari, dis-je, donne satisfaction à la femme et change de résidence; il s'installera tout seul, ou bien se réunira à un groupement déjà existant où lui-même aura des relations id'alliance ou de famille.

D'autrds motifs de dispersion du village ou du départ de quelques-uns de ses habitants se rencontrent dans les évènements ordinaires de la vie humaine. La maladie, la mort du chef de fanille, de sa femme, ou de ses enfants, sont des raisons très fréquentes de désaggrégation. J'ai vu des villages qui s'étaient, pour de telles raisons, dispersés avant mêmie 'd'être entièrement terminés. Aux yeux des indigènes, la maladie, la mort sont produites par le mauvais vouloir ide certains individus et l'un des plus sûrs moyens d'y 'échapper, est de s'en aller. Notez au passage cette ldcctrine gue la nagie cōntemporaine ne renierait lpoint. Ou bien, ils renłent respensable de ces évènefments malheureux l'endroit lui-même oì est bàti le village et ils ont une expression énergique pour traduire leur pensée: "L'endroit, disent-ils, est pourri ".

Il faut remarquer que, dans leurs déplacements successifs, les villages reviennent souvent aux lieux anciennement occupés par le même groupe, où certains avantages, par exemple, l'existence de palmiers, les rattirent. On pourrait idonc penser avoir raison de leur déplorable coutume par la simple logique. J'ai souvent argumenté avec eux: "Tu as quitté tel endroit " parce que tes honmes y meurent, disais-je au chef; " Inais là où tu t'es mis, des hommes ne sont-ils pas " morts jadis, tes hommes n’y mourront-ils pas à leur "tour?-Oui ! - Alors?"

Y a-t-il , là obllitération d’une croyance ancienne, 
oubli d'une tratition jadis raisonnée? Je l'ignore. Je n’ai jamais eu de réponse précise; pour le présent, ces déplacen:ents de villages, ces départs d'habitants se font sans régularité. Ils sont soumis au simple caprice des intéressés.

Il y a cepeldant un cas oủ le déplacement du villagge est certain, sa décomposition très probable: c'est le cas où le chef disparait.

Je rlisais plus haut que le village se forme en quelque sorte mécaniquement par le fail des parentés et iles alliances. Il a une raison d'être, un lien: le chef. De même que le village s'est constitué à cause de lui, de la même manière, il se dispersera lorsque le chef aura disparu.

Ses femmes seront réparties entre ses neveux ou ses frères; elles entraincbont avec elles leurs propres parents; - ses fils iront vivre dans leur famille à eux; - ses esclaves se ont partagés conlme ses épouses.

Si le village ne disfiarait pas, il se dépllace; sa composition se mcdifie, et continuellement. Le chef necurt. son neveu viendra le remplacer et recueillera sur place sa succession. Il viendra quelquefois ${ }^{-d e}$ fort loin avec ses épouses, ses ćlients. Une femme meurt, ses frères, qui souvent l'avaient suivie, retourneront dans leur famille.

Ajoutez à cela que, à la différénce ça ce qui se passe chez nous, un homme tient étroiterrent, non pas à une mais à deux familles, lla famille maternelle, la paternelle, et que ses habitats successifs manifestent une oscillation continuelle entre ces deux attractions. II cède tantôt à l'une, tantôt à l'autre, et ne se fixe jamais pour très longtemps.

Pourons-nous quelque chose contre le quasi-nomadisme des indigènes, 'contre cette instabilité qui les rend insaisissables? Je veux flire: Arons-nous une manière de procéder, une sanction qui soient d'effet certain? Nous ne disposons, je crois, ni de l'une ni de l'autre. Comme sanction, nous navons que les peines de l'indigénat, et tout le monde est d'accord sur leur 
non-efficacité. De manière de procéder, assurément, nous n'en avons point.

Comment, en effet, s'opèrent les dispersions, les déplacements dont il s'agit?

Les indigènes, sachant très bien que nous y sommes opposés, se garderont de nous prévenir. Nous sommes passés au cours d'une tournée dans un village qui semblait installé pour durer: bonnes cases, palmiers, etc., tous les avantages appréciables par les indigènes semblaient réunis. Six mois, un an, deux ans après, suivant la grandeur tle !la bivision athministrative, nous voulons repasser au même village, il a changé d'emplacement, ou a refait une route d'accès, ou bien même le village n'existe plus du tout; en tout cas sa composition a changé, et c'est alors l'occupation énervante de toute l'année, qui consiste à biffer dans 'le recensement, ides noms ici pour les reporter là, mutations qui rendent à ipeu près illusoire le rensseignement porté sur nos rôles: noms des chefs sous il'autorité desquels l'impôt est perçu, — surtout en ce qui concerne les célibataires ou les jeunes gens.

En un mot, nous ne sommes prévenus des mutations ou des déplacements de villages que longtemps après qu'ils se sont produits. Que devons-nous faịe alors?

Punir? Qui? Pouvons-nous trouver le responsable? Un chef de village meurt: nous ne pouvons pas empêcher les veuves d'être dispersées, les frères de cellesci de les suivre, etc. Que restera-t-il du village après cela?

Nous ne pouvons nous opposer à ce qu'un neveu vienne recueillir sur place la succession de son oncle, ni à ce qu'il amène avec lui sa clientèle.

S'agit-il de mutations pour cause de !dissensions intestines? Jamais un mari n'avouera que sa femme en est l'auteur; si elle se trouvait punie, ce serait la séparation certaine. Nous avons lde granides chances de punir un innocent.

Et ce n'est pas tout. La punition serait inutile. La mutation est consommée depuis longtemps; forcer-les 
gens à revenir à l'ancien état ide choses, c'est ajouter une mutation aux autres et c'est bien inutile.

Notre rôle consiste beaucoup plutôt à prévenir qu'à punir. Prévenir la dispersion des villages heureusement situés, en obligeant les indigènes à établir des cimetières; il n'en existe pas chez les Bayaka; s'enquérir des successeurs possibles Idu vivant du chef, bien que celui-ci n'aime guère aborder ce lugubre sujet, et les investir en quelque sorte du vivant du titulaire. Tenter, en un mot, 'd'empêcher la solution de continuité à la faveur de laquelle s'opérerait la dispersion. Tel me semble pouvoir être notre rôle.

S'il s'agit, au contraire, d'un village mal établi, provoquer son déplacement peut être opportun; en tous cas, ne pas l'empêcher et veiller aux conditions de l'établissement nouveau.

Quant aux mutations individuelles, il nous est bien plus difficile d'agir. L’intérêt les indigènes est de vivre là où ils ont le moins lde risques de disputes, c'est$\dot{a}$-dire au milieu des gens de leur tribu. Mais tout est relatif, et puis la question n'est pas là: si le mari vit plus paisible dans sa tribu, la femme se jugera plus en sécurité łans la sienne, et l'accord est impossible. Quel choix leur imposer?

Il n'y a que deux solutions: ou briser le cadre de leur société, supprimier les liens traditionnels pour y substituer à la longue des relations analogues aux nôtres; - ou réformer peu à peu la mentalité, faire disparaître cette terreur superstitieuse de la mort, des maladies, des sorts et des maléfices, qui plane sur l'existence de l'indigène et explique les trois quarts de ses actes, et lui renldre possible le travail, l'effort laborieux et productif qui l'amènera au progrès.

De notre occupation actuelle au Gabon, partout où elle est ancienne: Libreville, Cap-Lopez, Fernan-Vaz, le résultat le plus clairement visible est la disparition des liens sociaux traditionnels: liens lde tribu, liens de famille même. C'est la mise à l'expérience de la première solution.

Jẹ reproche à cette méthode d'être aléatoire. En fai- 
sant disparaìtre la société indigène, nous supprimons une organisation, défectueuse, j'en conviens, mais existante. Que mettons-nous à la place? Rien. Il n'y a pas dans toute la colonie de société plus pulvérisée, plus réduite à l'élément indivilduel que celle des Nkomi et des Mpongwé. Ces indigènes comprendront-ils le groupement d'étranger's, d'indépendants, dans un but l'intérèt public, ou au moins ld'intérêt commun restreint? S'adapteront-ils à notre civilisation? Les Socićtés noires créées de toutes pièces par les vicissitudes de la politique ou l'idéologie humanitaire donnent, il faut bien l'avouer, peu d'espoir.

Je préférerais personnellement le second procédé. Réformer, améliorer la société traditionnelle des indigènes, renforcer les liens trop ténus, instituer l'autorité là où n'existe que la prééminence, enseigner l'obéissance dans un but t'intérêt commun restreint, pour en arriver plus tard à la notion d'intérêt général, en un mot, faire évoluer les indigènes, mais non leur imposer une civilisation qu'ils ne semblent pas aptes à comprendre et dont il se pourrait fort bien qu'ils vinssent à mourir.

La méthode est longue, onéreuse, mais elle laisse au hasard le minimum de place.

Je ne vois pas 'd'autre moyen de fixer les indigènes. Si on laisse le choix de la résidence à l'intérêt particulier de chacun, comme tous sont pour longtemps mauvais juges, et que d'ailleurs cet intérêt peut varier, nous n'avons pas chance de voir cesser ni même diminuer le vagabondage.

\section{Du nom des villages}

Lc vocabulaire géographique des indigènes de nos régions me paraît pauvre aussi bien quant au nombre des vocables, que quant à la manière de les former. 
Tantòt le nom du village indique un accident de terrain: Ilou Micongo, sommet de la montagne; Moucongo Mounéné, grande montagne, ou Moucongo tout court, Ia montagne; Ibanga, lieu élevé; - tantôt ces noms répètent simplement celui de la rivière voisine, et il peut se trouver ainsi plusieurs villages de mêmenom et appartenant à des groupements différents.

D'autres fois, lingéniosité des gens s'est donné carrière, mais elle a le plus souvent le caractère mélancolique:"Inéné Imognio," c'est une grande chose que la vie; - ou triste: Nzambi ghomboula, Dieu a balayé, (c'est-à-dire, les hommes du village ont disparu comme si Dieu les avait balayés); — ou seulement sérieux: Pémo Nzambi, Mblla Nzambi, le souffle de Dieu, l'appel de Dieu; ou enfin dénigrante: Rinanzala, fuyez, ici on a faim, Pénignioundou, nu comme l'enclume, Penibantou, les hommes sont nus, Nanga, vat-en. Nais dans ce cas, il semblerait que ce soit, non pas une antiphrase, ni une lamentation, mais une précaution prise pour dissuader les passants de séjourner; l'étranger est toujours l'enemi.

Lorsque le nom alu village n'a pas de sens particulier, il semblerait qu'il corresponde non pas à un nom de lieu précisément 'déterminé, mais à celui d'un territoire nettement délimité. C'est là ce qui expliquerait la coutume dont je parlais plus haut de donner le même non à plusieurs villages, écarts du même groupe. Le nom que nous attribuons à un village serait donc plus exactement un nom de région, j'allais dire un nom de commune. Pourtant on peut soutenir l'opinion contraire, et citer des villages qui, émigrant de fort loin, emportent leur nom avec eux.

Le vocabulaire géographique est aussi peu varić dans sa constitution que dans la formation de ses rocables, et les noms identiques abondent: combien de Massoté, "le campement ", et à l'opposé, combien de Moussitou, "le dernier emplacement ", et combien de Loango, Mocaba, Bouali, Mivengué, Ibanga?

Au surplus, nous différons considérablement des indigènes sur ce point: nous ne concerons pas un 
groupe d'habitations humaines sans un nom. Dans nos pays, les hommes se sont succédés aux mêmes lieux depuis des millénaires, et un village, une ville qui ne peut justifier que de 4 ou 5 siècles d'àge est une agglomération nouveau-née. Rien udétonnant à ce que ces lieux aient un nom.

Les indigènes, au contraire, sont essentiellement instables; y a-t-il quelqu'un parmi nous qui connaisse un village ayant 10 ans d'ancienneté? Peut-être les villages de passeurs de rivières: encore ne sont-ils pas tenus de rester identiquement au même endroit.

La raison d'être du groupement, ce ne sont point les avantages présentés par l'emplacement; tous se valent à peu près. C'est la parenté avec le chef.

Aussi remarquons-nous souvent quelque hésitation sur la figure 'de nos indigènes lorsqu'à la question : "D'où es-tu? " nous voulons obtenir pour réponse, un nom de lieu et un nom précis. Dans les subrdivisions moins parcourues, c'est plus 'que de l'hésitation, c'est de lignorance. On connaît le nom du chef; on ne connaît pas de nom de lieu; ill n'y en a pas. Quand on en a mis un, c'est évidemment pour nous faire plaisir. Les habitants, à la rigueur, le connaissent; les voisins, et à fortiori les étrangers, l'ignorent.

J'ajouterai, pour terminer_ces réflexions, qu'il y a des noms beaucoup plus fixes, mieux connus que ceux des lieux habités; ce sont les lieux-dits: endroits où l'on s'arrête tra'ditionnellement sur les-longs parcours, lieux remarquables par l'abondance de tel ou tel fruit où l'on vient annuellement camper pour en faire la récolte, carrefours de sentiers où se dresse un arbre géant, etc.; tous ces endroits ont leur nom, connu dans des régions très étendues. Il faut les noter soigneusement sur nos itinéraires; ce sont des points de repère, qui, vu leur fixité, sont infiniment plus intéressants que les villages eux-mêmes, 


\section{De la Terre}

Nous avons observé en vertu de quelles relations essentiellement familiales s'établissait un village. Passons de la famille à la tribu; appliquons à cette dernière le mênie procédé et nous obtiendrons la " terre ", circonscription territoriale.

La " terre " est l'ensemble 'des villages habités par des gens de même tribu, par leurs esclaves, et par leurs alliés; il s'y rencontre souvent, toutefois, des groupes absolument étrangers. La terre est en plus grand ce qu'est le village.

Il y a cependant une différence importante: le village est essentiellement temporaire, la terre est stable, ne se disperse pas et ne disparaît que par la mort de ses habitants.

Elle se compose d'un noyau de population constituant, sinon en quantité, au moins comme importance sociale, la dominante de la population; ce noyau est formé ide membres d'une même tribu. C'est à eux qu'est la " terre "; on dit: la terre des Bouyala, celle des Bayengé, etc... Les éléments de ce noyau primitif pourront changer, l'ensemble persistera.

Les alliances amènent à ce noyau des femmes de tribus différentes; les enfants qui naitront de ces unions pourront, ou bien retourner chez leurs parents, ou bien rester au pays de leur père et y créer, sur la terre de celui-ci, des groupes à part. C'est ainsi, par exemple, que dans la terre des Bouyala, on trouve nu groupe de Basoumba, un groupe de Mitchimba, un groupe de Dibamba, les uns et les autres fils de Bouyala; - la terre de Mpokou se partage entre les Boumouellé, tribu dominante, et les Baghoyo, tribu aggrégée, fille de la précédente.

Chacun de nous, dans sa subdivision, peut trouver des exemples analogues.

Un autre mode d'accession peut être constaté: l'ad- 
mission de parents éloignés, mais de la même famille, et celle d'étrangers. Une certaine terre de la Douguégni est un exemple du premier cas: autour du noyau primitif de Dicanda, sont venus s'installer d'autres Dicanda qui n'étaient parents qu'à un degré très éloigné et qui venaient d'ailleurs.

Les exemples du second cas sont plus rares, mais j'en pourrais citer deux. La terre de Massanga, où est installé le poste de Tchibanga, appartient aux $B a$ doumbi; il y a sept générations, les Liaba ont commencé à s'y installer, venant d'au moins 3 jours au S.-E. Ils s'y sont si bien multipliés qu'aujourd'hui, ils occupent cette terre à peu près seuls, et que les Badoumbi ont presque disparu.

Un peu plus au Sud, la terre de Loubinda, occupée par des Bayengé, l'une des mieux caractérisées au point de vue territorial, a cédé une partie de son territoire aux Liaba (Loango) et une autre aux Basoumba (Maralissefa).

Nous avons tout intérêt à bien connaître les groupements naturels des indigènes: il faut conserver avec soin les liens, bien rares et-quelquefois bien faibles, qui unissent les individus de populations si dépourvues de cohésion, et je conseillerai de les étudier avec soin.

L'examen que j'en ai fait dans la subdivision de Tchibanga m'a amené à- une constatation 'curieuse. Interrogez ceux qui connaissent le peu de traditions conservées, tous vous diront:" "Notre tribu vient de tel endroit ". Nous arriverons à ce résultat que le point 'de dispersion des différents groupes est ailleurs que dans leur habitat actuel.

Et nous ne pouvons pas ne pas poser aux indigènes cette question que j'ai posée souvent: "Puisque vous venez d'ailleurs, avez-vous donc trouvé, en arrivant, le pays vide? Ou sinon, quels habitants s'y rencontraient? - Ma question est toujours restée sans réponse et le problème sans solution.

J'ai pu cependant, au cours de mes fréquentes tournées dlans le Mayombe des Bayaka, faire une observa- 
tion intéressante. Les végétaux qui accompagnent l'homme, qui perpétuent la trace de son passage, n'y sont point, dans l'espace, universellement répandus: l'arbre à safou (I), par exemple, ne se rencontre pas dans 'des conditions telles qu'on puisse le croire spontané, le colatier de même; et le plus facile à reconnầtre, le palmier à huile, n'y forme que de petits groupes attestant l'existence d'un ancien village; la plupart du temps, on pourra se faire dire le nom de l'occupant qui les a plantés.

De ces observations, je conserve l'impression que notre région n'est pas occupée depuis de très longs siècles; les populations qui l'habitent n'y ont essaimé que peu à peu et par petits groupes: Bavili du Sud, par la côte; Baloumbo du Nord, par la côte encore et par la vallée de la Nyanga; Bapounou de l'Est et du Sud-Est, par les savanes de la vallée de la Ngounyé et à travers le Mayombe.

Je signalerai, pour terminer, que certaines exceptions peuvent être constatées à ce que je viens d'exposer relativement à la terre. On peut trouver juxtaposés des villages de tribus différentes, sans découvrir de lien entre eux. Peut-être nous est-il caché; peutêtre n'y en a-t-il pas; peut-être enfin la connaissance du lien originel s'est-elle perdue.

Il peut même se rencontrer des villages contigus et de même tribu ne reconnaissant pas la prééminence d'un 'le leurs habitants. On pourrait croire que dans ce cas, il n'y a pas de "terre ". Il en serait ainsi dans la subdivision de Ndendé. J'incline cependant à croire que ces villages sont réunis entre eux par quelque lien, mais que le chef ne veut pas être reconnu par nous comme tel; la position de chef de terre présente peu d'avantages et de multiples inconvénients, et celui qui est investi de cette fonction n'a pas toujours à se louer des relations qu'elle lui impose avec le représentant de l'autorité et, par contre-coup, avec ses administrés.

(I) Pachylobus edulis G. Don. 


\section{$=96-$ \\ CHAPITRE IX \\ DE L'AUTORITÉ INDIGĖNE

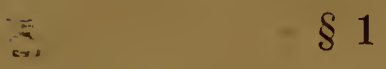

\section{Existence de l'autorité}

Ceci nous amène naturellement à examiner, à discuter l'existence de l'autorité indigène, les conditions où elle s'exerce et se transmet.

Existe-t-il des chefs indigènes, je veux dire, des individus qui, du fait de leur situation de famille, ou par le libre choix de leurs congénères, exercent une fonction leur donnant le droit de commander, leur assurant l'obéissance?

Consultons la langue indigène: nous y trouvons deux mots employés pour traduire le mot chef. C'est d'abord notre mot lui-même, " chef ", estropié et orné d'une voyelle finale pour les nécessités de la prononciation.

Il y a en outre le mot "foumou "; mais plus la population à laquelle on $s^{2}$ adresse est habituée à nous, apprivoisée, plus fréquent devientl l'usage du mot français "chef ".

Le mot "foumou ", que je viens de citer, est un des mots fondamentaux de la langue; je l'ai rencontré identique en Zambézie, et pour la forme et pour le sens. Il signifie exactement: homme libre, par opposition à homme portant à un degré quelconque la macule de servitude. Ce mot ne signifie point originairement chef (à notre sens). Mais nous le lui avons donné pour plusieurs raisons.

D'abord, nous ne concevons point d'état social, d'agglomération humaine, sans individu qui commande, qui ait l'autorité nécessaire pour faire respecter l'intérêt commun.

D'autre part, totalement étrangers à ces pays nouveaux, commerçants et missionnaires pour s'installer, fonctionnaires pour administrer, se trouvaient dans 
l'impossibilité de s'adresser individuellement à chacun de ceux dont ils avaient besoin. Certains indigènes prenaient la parole, parce que plus éloquents ou moins craintifs. Les vues exposées par eux ont été adoptées par leurs congénères; nous avons tout naturellement attribué à ces individus l'autorité: avonsnous eu raison?

D'où viendrait cette autorité? Il n'y a pas de chefs élus, l'autorité ne peut donc venir que des relations familiales. Au cours des pages qui précèdent, nous avons vu comment se constituait la famille, quelles étaient les relations quotidiennes de l'individu avec ses épouses, ses esclaves, ses enfants. Nous savons que rien ne peut dispenser l'homme de ses obligations envers ses inférieurs, qu'aucune sanction, au contraire, ne vient contraindre ceux-ci à s'acquitter de leurs devoirs envers lui. Ses épouses le quittent autant dire sans motif, ses enfants ne lui appartiennent pas, ses esclaves sont d'une indépendance regrettable. A quelque degré d'agglomération que nous nous placions, lautorité peut-elle sortir de ces relations familiales? Non, à coup sùr. Aussi n'y a-t-il pas en réalité de chef, au sens que nous attribuons à ce mot.

Il n'y a pas d'autorité constituée. La société indigène de nos régions est une collection de familles élémentaires qui ne sont soumises à aucune obligation sociale du fait de leur parenté ou de leurs alliances, et sont libres de s’ággréger à tel ou tel groupe, pour un temps plus ou moins long.

En fait, les craintes superstitieuses, qui assiègent les individus, limitent leurs choix. Mais ils sont tellement libres que, dans l'accession de tel individu à un village, ce n'est pas le chef qui autorise, c'est au contraire lui qui se considère comme l'obligé et qui, soutvent, fait un cadeau au nouveau venu. Quelle juridiction pourrait-il avoir sur lui?

Je viens d'écrire le mot: chef de village. Qu'est-ce donc? C'est littéralement l'homme libre du village, celui à cause de qui le groupe existe, celui qui par ses bons procédés, l'aménité de ses relations, la généro- 
sité de son caractère, a su grouper autour de lui des hommes qui lui sont unis par des liens de parenté ou d'alliance.

Si du village nous passons à la terre, nous trouvons également un chef, " un ancien " serait plus exact. C'est celui qui, de par la filiation, est la tête de la famille dominante de la terre, et nous verrons plus loin comment la transmission s'effectue. Les habitants de la terre sont à quelque degré ses frères, ses enfants, ses neveux, et l'on sait quel sens extensif ont ces mots chez les indigènes. Aîné de tous, il n'a sur chacun d'eux pas plus d'autorité qu'un père sur ses enfants, un oncle sur ses neveux, un ainé sur ses cadets. Il n'a d'ordres à donner à personne; s'il s'avise de commander, l'abandon le menace à brève échéance; - si quelqu'un de ses hommes est puni par nous sur sa dénonciation, il risque ou croit risquer la mort. En un mot, celui que nous appelons chef de terre ou de village, n'a que la prééminence, il n'a pas l'autorité. La fonction de chef n'existe pas chez nos indigènes; elle n'a, je crois bien, jamais existé.

Est-ce à dire qu'il ne se soit jamais rencontré chez eux de chef de famille jouissant de prestige, susceptible de commander aux autres, et de s'en faire obéir? - Il s'est rencontré et il se peut rencontrer encore de tels hommes. Kassa Maviri, le chef de Boukoulou, déporté à Bangui en 1906, - Mavouroulou, le dernier chef de la révolte de Mocabe, mort en 1913. - Mwéné Mikindou, chef Baloumbo de la subdivision de Mayumba, mort en 1906, - Binga Bantou, le chef de BandaPointe, mort en 1910, - Nwéné Tchidounga, le chef aveugle de Bilanga, -- Makâka Milongo, le chef actuel de la terre de Moucoungou, ont eu et ont de l'autorité.

D'où la tiennent-ils? Pas nécessairement de leur situation; on a dit que Mavouroulou n'était point de souche libre; et Makâka Milongo est assurément un étranger dans la terre qu'il commande.

Le prestige dont jouissent ces chefs, l'autorité dont ils disposent, sont, avant tout, essentiellement per- 
sonnels. Autrefois, ils les appuyaient d'actes de violence, d'exactions, etc., commis à l'aide de gens à leur solde; ils vendaient, ils tuaient leurs adninistrés et se montraient des plus soucieux de faire exécuter leurs sentences par la contrainte. Il n'y a pas si longtemps que Mwéné Tchidounga et Binga Bantou n'ont plus de gardes. Ce dernier avait même obtenu l'autorisation officielle d'en entretenir ! Ces dernières années, un des individus les plus redoutés et les plus obéis chez les Bayaka, était un Soudanais, traitant ou commerçant alternetivenient, Sada-Ndiaye, nort a Dicoundou en 1902: Sada-Ndiaye enlevait les femmes ou se les faisait remettre, vendait les enfants, s'instituait l'héritier de ses amis, et allait au besoin tirer des coups de fusil jusqu'aux bords de la Ngounyé, à Dilolo. Il avait des " soldats " et savait s'en servir. C'était un étranger. Les chefs d'autrefois n'ont pas assis leur autorité, quand ils en eurent, par d'autres procédés que Sada-Ndiaye.

Et à présent qu'il est fort diflicile aux chefs de se livrer sur leurs administrés aux actes de violence que j'ai dits, à présent qu'ils en sont réduits au seul prestige personnel, leur autorité n'existe plus, sauf exceptions très rares. Et il ne faut point s'en étonner.

Cette'inexistence de l'autorité chez nos populations est, avec l'état désagrégé et instable de leur société, le plus grand obstacle à leur amélioration, à leur progrès. Nous nous trouvons en présence de l'obligation suivante: Etant donné un ordre à exécuter, faire obéir des centaines ou des milliers d'individus, alors qu'entre eux et nous, il n'existe pas d'intermédiaire. C'est un problème insoluble.

Nous avons donc été amenés par la force des choses à supposer l'existence de l'autorité indigène, et nous en avons investi tout naturellement ceux qui déjà étaient revêtus de la prééminence. Nous ne pouvions agir différemment. Tant qu'on leur a peu demandé, tant que les Européens en rapport avec eux n'ont été que des Commerçants on des Missionnaires, les choses ont bien marché. Les chefs de famille, mis en contact 
avec cette face de la civilisation, ne couraient point de risques: ils en retiraient même des profits immédiats.

Pour avoir des produits naturels, le commerçant faisait des cadeaux; c'était tout bénéfice pour le chef de village ou de terre, puisque lui ne travaillait pas; et le commerçant, de son côté, faisait entrer ces cadeaux dans le prix de la marchandise. Pour avoir des enfants à catéchiser, le missionnaire aussi faisait des cadeaux; ils étaient prérus dans les frais généraux de l'apostolat.

La face des choses a changé quand le chef s'est trouvé en rapport avec l'Administration. Celle-ci ne fait pas de cadeaux, ou si minces; il n'est pas douteux qu'au bout du compte, l'indigène ne doive tirer profit de sa présence. Mais ce profit n'est pas visible, tangible pour l'individu en particulier; bien au contraire, les relations se traduisent par des obligations qui ne rapportent aucun bénéfice immédiat à personne, et des prohibitions qui gênent considérablement tout le monde. Il s'est donc le plus souvent produit ceci, que les têtes de famille, les chefs, comme nous disons à tort, se sont très rapidement mis. d'accord avec leurs subordonnés, mais contre nous. Il se rencontre encore de ces manifestations dans certains groupements de la circonscription de la Nyanga, et dans ce cas, il n'y a qu'une politique à tenir, celle de la division. Nous devons viser à nous mettre d'accord avec les individus dans les villages, avec les villages dans la terre. Les chefs s'amenderont à la longue. C'est la mise en pratique du principe: "Divide ut imperes ".

Mais il ne faut pas s'arrêter là, et il est utile, il est indispensable, de reconstituer les groupes, d'en amener la création, là où il ne s'en rencontre pas, autrement il n'y a pas d'administration possible.

C'est là que nous commençons à rencontrer des difficultés. Le métier de chef présente plus d'inconvénients que d'avantages. Le représentant de notre autorité doit lutter contre ses subordonnés pour leur 
faire exécuter nos ordres et les subordonnés sont peu souples. Du jour où un homme est adulte ou marié, il est aussi chef que n'importe qui; il peut répondre et il répond effectivement au chef de son village: "De quel droit me commandes-tu? - Allons-nous appliquer des sanctions à ces désobéissances ? La victime ne les pardonnera point au chef qui en sera la cause. Elle quittera le village; elle peut même s'en prendre à la vie du chef, au moins celui-ci attribuera-t-il ses maladies à une malveillance de cette origine.

Et l'individu adulte, chef de famille, redoute autant la solitude et l'abandon que la mort. La solitude, c'est le travail forcé à un âge où, de par la coutume, de par les circonstances, un homme voit son travail fait par les autres. C'est la case misérable, les plantations restreintes, c'est la disette et la pauvreté, puisque les jeunes n'apporteront plus leurs salaires. C'est une véritable diminution.

Quels avantages apportons-nous au chef pour contrebalancer ces inconvénients ? - Bien maigres: une remise sur l'impôt perçu dont le taux va en diminuant, à mesure que celui de la contribution augmente. Encore cette remise est-elle guignée par tous les individus du groupe, et le chef est-il le plus sourent contraint de la répartir entre tous.

Voyons maintenant la contre-partie: le chef qui se préoccupe de ne pas trop molester ses administrés, est en paix avec eux, il est entouré de leur considération, assuré de leur aide pécuniaire, assisté de leur travail; le poste est loin, les risques à courir faibles, de temps en temps quelques jours de prison, une quinzaine au maximum. Encore peut-on s'en tirer avec de I'habileté et de la diplomatie; au moins eston sûr, en vivant en bons termes avec les gardes régionaux, de voir la peine rendue supportable. Et surtout, il est facile de s'y soustraire, à celui qui sait s'absenter au moment opportun.

Je ne crois pas me tromper en disant que la plupart de nos chefs suivent plutôt cette seconde politique que la première, et je ne puis prendre sur moi de leur 
en savoir mauvais gré. Elle est humaine, et poùr une fois, elle est logique.

Pour réussir dans nos relations avec de tels chefs, il n'est pas possible d'indiquer de recette assurément efficace; notre conduite doit être toute d'adresse, de flair, dirais-je; elle doit jouer successivement de la menace, et de la promesse, plutôt de la menace, car que promettrions-nous? La flatterie ne doit pas être oublice : l'indigène y est sensible. Il y a cependant un point sur lequel je reux attirer l'attention. Si nous menaçons, il ne faut le faire que dans la mesure où nous pouvons punir. Promettre six mois de prison quand nous ne disposons que de 15 jours serait d'un résultat déplorable. Et surtout il faut nous en remettre au temps; le progrès obtenu par la contrainte ne se maintient que par la contrainte, et nos moyens de contrainte auront plutôt des tendances à s'affaiblir qu'à s'accroître.

Le nombre des gardes régionaux, dont l'entretien est une lourde dépense, sera plutôt diminué; on apportera et on apporte déjà des restrictions à leur emploi. La limite des pénalités tendra à s'abaisser. En résumé, mieux vaut se contenter de progrès plus lents, de résultats moins brillants par comparaison avec les résultats antérieurs, mais les obtenir par le consentement tacite, si ce n'est par la bonne volonté explicite des indigènes. Réalisce de cette manière, une amélioration peut être considérée comme définitivement acquise.

Nous pouvons, disais-je plus haut, rencontrer des chefs jouissant dun prestige personnel, et disposant d'une autorité reconnue quelquefois considérable. Il arrive même qu'ils ne se refusent pas à mettre cette autorité à notre service. C'est une bonne fortune, mais il nc faut pas se reposer sur un succès de hasard et laisser au chef digne de ce nom l'entière disposition sans contrôle du gouvernement de son groupe.

L'autorité que lui reconnaissent ses subordonnés a le plus souvent, disais-je encore, son fondement dans des exactions assez graves et que nous ne sau- 
rions tolérer. Tout en lui accordant, plus quaux autres, une considération justifiée, il ne faut pas lui laisser oublier que ce n'est pas seulement sa juridiction qui agit, mais la nôtre et qu'à ce titre il est tenu à l'équité. S'il se plaint, que sa plainte soit fondée et qu'il n'obéisse pas au sentiment de la vengeance personnelle; nous ne devons pas nous prêter à des représailles. Il nous faut veiller surlout au trafic des esclaves dont les autorités indigènes sont de grands commerçants. En un mot, il faut que, tout en restant chef pour ses congénères, il se sente aussi chef par notre gràce.

Ces réflexions relatives à la conduite à tenir avec les chefs sont toute la politique indigène, e'est-à-dire une manière de diplomatie. Il n'y faut s'avancer qu'avec prudence, car nous avons affaire à des gens très retors, ayant sur nous l'avantage du mensonge. C'est un procédé qui nous est interdit. Nous devons etre habiles, mais, dans nos relations avec les indigènes, nous ne devons jamais mentir. La franchise est d'ailleurs la méthode la plus simple et elle est d'aulant plus efficace que, menteurs par nature, nos administrés doivent nous croire un peu semblables ì eux.

\section{$\S 2$}

\section{Attributions de l'autorité indigène}

Je ne parlerai pas des attributions de l'autorité indigène dans le passé, attendu que dans l'intérieur de la Circonscription, que je connais mieux que la côte, je n'ai rien recueilli même de très vague sur la question.

On peut supposer, sans crainte d'erreur, que les dépositaires de l'autorité jadis en ont usé exclusivement dans leur intérêt personnel; il n'y a pas apparence que la notion d'intérêt commun se soit jamais fait jour chez nos administrés, les ait conduits à consentir des sacrifices individuels dans l'intérêt d'un groupe déter- 
miné. Même dans les conditions de l'accord le plus général, c'est-à-dire quand cet accord est réalisé contre nous, par exemple, pendant la révolte de Mocabe, nous avons toujours trouvé, parmi les révoltés, des traîtres, pour nous renseigner, nous guider, de même qu'il s'en est rencontré chez nos partisans pour indiquer aux ennemis les occasions favorables.

Nous n'avons pas trouvé, disais-je, d'autorité constituée indigène; mais nous en avons supposé une, tellement nous en avons l'habitude, tellement nous en avons besoin. Qu'est devenue cette notion chez nos administrés? - Ils se la sont appropriée dans la mesure où elle pouvait leur être utile.

Voyant que nous ne traitions qu'avec un seul individu du groupe, le chef de terre ou de village, qu'il recevait nos ordres et qu'il était, trop souvent, à mon sens, rendu responsable de leur exécution, ils ont trouvé cette idée très pratique et le chef, celui du moins que nous reconnaissions comme tel, est devenu pour eux celui derrière lequel on se met à l'abri. Dans certains cas, on a poussé cette idée très loin et on a proposé comme chefs, pour le poste, des individus des derniers rangs de la société, des esclaves. C'est une opinion très répandue chez les commerçants que la plus grande partie des chefs que nous reconnaissons, sont des hommes de paille. Mais je ne crois pas l'accident aussi fréquent.

Si l'on n'a pas partout été jusqu'à nommer de faux chefs, au moins dans tous les cas a-t-on attribué au chef le soin exclusif des relations extérieures officielles. Lors donc que nous avons à traiter avec un village, c'est le chef seul qui nous répondra; les vivres nour les porteurs sont fournis par lui et prélevés sur les plantations de ses épouses; il serait mal venu de s'adresser ailleurs; les renseignements pour le recensement sont donnés par lui, à ses risques et périls. S'il nous trompe, nous le punissons; s'il est sincère, ses concitovens lui en font reprochè. S'agit-il d'impôt? C'est lui qui nous porte l'argent et comme ni lui ni ses administrés ne sont d'une honnêteté scrupuleuse, rien 
n'est moins certain que le montant des versements effectués entre ses mains.

Le chef est-il absent? Les difficultés commencent; nous demandons des vivres: il n'y en a pas, le chef n'est pas là; - un renseignement, on ne sait pas, le chef n'est pas là; - un guide, on n'en trouve pas, le chef n'est pas là. Et la plupart du temps, si l'Européen se présente quand le chef est absent, le village se disperse.

Il en est de même quand le chef est en prison pour longtemps; son village se démembre et disparaît fatalement. Le chef est à proprement parler et exclusivement, pour les indigènes, dans leurs relations avec nous, celui qui est désigné pour assumer toutes les responsabilités et toutes les corvées. Rien d'étonnant à ce que la fonction soit peu recherchée, et les exemples abondent dans lesquels le chef naturel a refusé l'emploi. On peut être sûr d'ailleurs qu'il n'est pas empêché, pour autant, d'user du peu de prérogatives attachées à sa situation familiale, celle, entr'autres, de rendre la justice. Mais de celle-là je parlerai dans un autre chapitre.

En . bonne logique, le chef, responsable aux yeux des indigènes devant celui qui est à la tête de la division administrative, devrait posséder une autorité. Il n'en est rien, je l'ai dit. Il n'a point d'ordres à donner; s'il en donne, on n'en tient pas compte; les moins discourtois lui répondent: "Tu dis que le commandant a ordonné de faire telle ou telle chose, mais, après tout, je n'en sais rien, je ne l'ai pas entendu ".

Il y a donc beaucoup à faire pour constituer une autorité indigène. Mais ce n'est pas du côté de l'autorité elle-même que nous trouverons de l'opposition. Nos indigènes ont un goût marqué pour exercer un commandement; celui qui commande ne travaille pas, c'est appréciable; ils sont plus capables d'aluus de pouvoir que de faiblesse.

Il faut donc d'abord faire tous nos efforts pour leur oter la crainte des risques; mais là, un médecin ferait dans nos régions, plus que tous les discours. Et 
la peur des sorts jetés par ses administrés, paralysera toujours l'action du chef. Il faut aussi apprendre au chef qu'il n'a d'autorité que dans l'intérêt public; s'il s'agit de'son intérêt personnel, sa situation sociale disparaît. Ce sera également une notion bien difficile à faire entrer dans son esprit.

Or, les administrés d'un chef font systénratiquement ou inconsciemment une confusion entre les ordres émanant du poste et relotifs à des prestations d'intérèt commun, et ceux particuliers au chef qui veut de sa fonction tirer le maximum de bénéfices. Ciest une distinction que nous devons leur apprendre.

Cependant, il ne faut pas abuser des punitions; je veux bien que l'absence du chef pendant 15 jours de détention disciplinaire n'a pas trop d'inconvénients; mais la même peine appliquée à un indigène pour désobéissance à son chef est beaucoup plus grave. D'une part, en effet, l'homme u'a pas souffert excessivement de la prison, 15 jours lui sont indifférents; d'autre part, il quitte le poste vexé de la peine légère qu'il a subie et son premier soin est de chercher querelle à son chef, souvent de lui demander une indemmité, faute du paiement de laquelle il s'en va.

Il faut laisser au temps le soin de faire entrer nos idées dans les esprits des indigènes; ceux-ci ont trop d'intérêt à n'avoir pas de chefs de leur race comme intermédiaires entre eux et nous. Le jour où il en existera, les individus n'auront plus l'excuse de l'ignorance. Je ne sais pas s'ils se rendent un compte exact de cette cause qui assure le maintien de leur indépendance: l'absence d'autorité constituée. Mais ils en ont assurément une perception obscure, car ils sauvegardent jalousement leur liberté.

A la prééminence qu'il tient de la naissance, à la gestion des relations extérieures que les indigénes lui ont conférée, nous avons ajouté l'attribution au chef du soin de l'intérêt public. A ce titre nous voulons qu'il ait l'énergie et la mesure, l'exactitude et la probité. C'est beaucoup lui demander, c'est trop en atten- 
dre pour le présent. Le but est proposé, on l'atteindra avec le temps.

L'exercice de l'autorité nécessite un apprentissage; les chefs actuels le font: il nous faut leur enseigner, en quelque sorte, à se servir d'un instrument qu'ils ne connaissent pas ou plutôt qu'ils connaissent mal. L'autorité pour eux, c'est l'abus de pouvoir. Et leurs administrés, faisant la même confusion, se défient de la première par crainte du second, instruits quils sont par une expérience séculaire. L'indulgence est due aux uns comme aux autres.

Aussi, je crois opportun, à l'heure présente, de savoir fermer les yeux sur les petits excès, tant qu'ils n'offensent pas gravement la personne. Lïndigène, qui $\mathrm{y}$ est habitué depuis toujours, en souffre peu, et il n'en déduit rien qui soit à notre désavantage. Car il ne raisonne guère et surtout il est étranger à l'idće de justice.

A y regarder de trop près, nous devrions suspendre sans hésitation tous les chefs indigènes avant la fin de la première journée de leur institution. Il faut savoir patienter et attendre.

\section{$\S 3$}

\section{Transmission de l'autorité}

L'autorité, je devrais dire la prééminence, puisquil n'est jamais question que de cela, le rôle de chef, en un mot, se transmet suivant les mèmes règles que celles appliquées à une succession quelconque. En réalité, il n'y a pas transmission, mais substitution automatique d'un titulaire au dépositaire décédé.

Une seule condition est nécessaire et suffisante. Lhérilier doit ètre capable: un faible desprit, un cnfant, un absent sont des incapables et sont immédiatement élininés. Il n'est point nécessaire pour être chef, d'ètre de souche libre, et sinon des esclaves, au moins des fils d'esclaves ont été chefs et ont succédé à des hommes libres, et inversement. 
Théoriquement, le frère cadet succède à ses ainés, le neveu à son oncle, restant bien entendu qu'il s'agit de frères utérins, et de neveux fils de la sœur. Dans la pratique, il peut y avoir lieu de choisir, par exemple, entre les frères du défunt ou ses neveux; dans ce cas, les chefs de famille désignent celui qui, à leurs yeux, remplira mieux le rôle; l'âge, la situation sociale, les relations, la maturité d'esprit sont pris en considération. Pas plus pour la question qui nous occupe que pour aucun autre point de la coutume, il n'y a de règle inflexible.

Ce choix du chef de groupe à la mort du titulaire mérite d'attirer notre attention; il reste encore beaucoup de notables indigènes ayant connu plus ou moins l'époque où, libre d'appliquer les coutumes des ancêtres, la population vivait en dehors de nos lois et règlements; ils regrettent ces temps d'indépendance; à chaque fois que l'un d'eux disparaît, c'est un peu d'opposition qui s'en va. Aussi devons-nous veiller à la qualité du successeur. Mais dans quelle mesure devons-nous intervenir? A mon avis, le moins possible, et le moins ouvertement.

Nous devons d'abord être renseignés d'avance et dès longtemps sur les noms et qualités des candidats éventuels et notre choix, à nous, doit être fait.

Les chefs âgés, d'ailleurs, et nous devons les pousser dans cette voie, ont l'habitude de se faire substituer dans la partie active de leurs fonctions, par l'héritier de, leur autorité; nous avons donc eu tout le temps nécessaire pour apprécier ses qualités professionnelles, de nême que ses futurs administrés ont pris l'habitude de lui voir interpréter les ordres de l'autorité.

Nais au jour où la mort du titulaire rend le choix nécessaire, il me paraît utile de ne pas agir trop ouvertement. Souvent on viendra nous demander conseil, et notre besogne se trouvera simplifiée. Dans la majorité des cas, les indigènes sont suffisamment prudents et ne choisissent qu'un sujet dont ils savent qu'il est auprès de l'autorité persona grata. 
Je crois que nous n'avons plus à craindre de voir désigner systématiquement des individus hostiles; si cependant le seul candidat de par la coutume était de cette nature, il serait opportun, je crois, de lui laisser quelque temps exercer ses fonctions, d'attendre qu'il se soit mis en faute, ce qui ne tarderait pas, et de demander pour lui une longue peine disciplinaire à purger dans un poste éloigné (Décret du 31 Mai 1910). Après sa destitution, qui aurait une influence exemplaire, il nous serait loisible de passer à la génération suivante où nous aurions plus de chances de trouver de meilleurs sujets.

En aucun cas, nous ne devons désigner les chefs en dehors de la famille où ils sont ordinairement choisis. Cette pratique n'est justifiable que dans des agglomérations composites, formées par des travailleurs, employés, ouvriers, etc... comme il doit, j'imagine, s'en rencontrer dans les grands centres. Les indigènes y sont étrangers au pays, étrangers les uns aux autres; ils n'ont pas de lien de famille. La situation est donc toute différente.

Ce que je dis là est pour mettre en garde contre l'intrusion de certains individus plus civilisés (?) que la moyenne de leurs congénères, anciens boys, anciens traitants, anciens employés à un titre quelconque des Européens; ils ont quitté leur maitre ou leur emploi, soit à la suite de fautes dans leur service, soit purement et simplement par paresse. Leur but n'est point de coopérer à nos travaux, mais de se créer des ressources personnelles plus abondantes; plus civilisẹ́s en effet, ils ont surtout plus de vices. Gardons-nous de ces gens-là; outre que les imposer comme chefs aux indigènes, parce que les relations sont plus faciles avec eux, c'est créer des divisions dans les groupements naturels et provoquer des dispersions, nous risquerions de voir notre autorité gravement compromise et dans les affaires les plus louches. Nos administrés ne sont pas encore assez avancés pour savoir distinguer entre des ordres d'intérêt général et ceux qui n'ont d'autre but que de satisfaire aux exigences 
d'un particulier. Nous porterions à leurs yeux la responsabilité de bien des exactions.

\section{$\S 4$}

\section{Des titres indigènes}

Je n'ajouterai plus qu'un mot, sur la question des titres indigènes. Ills tendent à n'avoir plus qu'un intérêt de curiosité: c'est un vestige des temps abolis. Il n'en existe d'ailleurs guère chez les Bayaka.

Le plus connu est celui de Mwéné. J'ignore absolument comment il était attribué jadis; il se transmet l'oncle à-neveu, mais ne correspond pas nécessairement à une autorité quelconque. Mwéné Mikindou, le grand chef baloumbo mort en 1906 , a laissé son titre de Mwéné à ses neveux: Mwéné Nzengué Mounzéo, Mwéné Mboumba, Mwéné Mșwami, et même à une de ses nièces, Mwéné Macanga.

Je n'ai connu qu'un seul Mwéné sur la rive droite de la Nyanga: Mwéné Boukinda Bouifoutsi, chef des Bayengé de Loubinda.

Un autre titre est celui de Makàka; je n'en ai connu à Tchibanga que deux titulaires: Makâka Tsango Pambo, aujourd'hui disparu: e'était un Bayaka de la famille Liaba, et Makâka Milongo Nimango, le chef de terre actuel de Moucoungou.

Ce titre est plus commun à la côte.

Autres titres encore: celui de Massafi, celui de Ouello. Rares dans l'intérieur, le premier est plus fréquent sur la côte.

Y a-t-il une hiérarchie entre ces titres? - Je n'en ai pas trouvé trace. Mais, spécialement pour le titre de Mwéné, on attribuait aux enfants des titres indiquant leurs relations familiales avec les titulaires. On disait: Mwafoumou Mounzéo Nzengué, pour: le fils de Mwéné Nzengué Mounzéo, de Kabi. Mwafoumou est l'abréviation de "Mwana foumou ", fils du chef. De même, et dans le sens le plus général, on employait 
à Loango le mot " ntekolo ", par exemple Ntekolo Maloango, fils du roi de Loango. Les batekolo (en yaka, batéoulé) sont les enfants proprement dits dans leur relation avec le père, que la mère soit ou non libre.

Jai connu en Zanibézie, des races très comparables à celles de la Nyanga et aussi peu civilisées, où la hiérarchie des titres et fonctions était bien plus complète que chez nous: à la base on trouvait le chef du village: Foumou; au-dessus, le chef de la terre: Mwéné; au-dessus, mais sans ressort territorial bien défini, un chef plus élevé nommé: Ignyacouahoua. Un indigène était spécialement chargé de connaître les limites, on l'appelait Sapanda; un autre, le Samaçôa, avait dans ses attributions les relations avec les étrangers. C'était en quelque manière le ministre des al'faires étrangères et l'introducteur des ambassadeu'rs. Il n'y a, je crois bien, jamais eu, en tout cas, il n'y a plus rien de semblable dans les populations de la Nyanga.

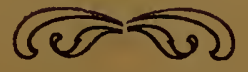





\section{DEUXIEME PARTIE}

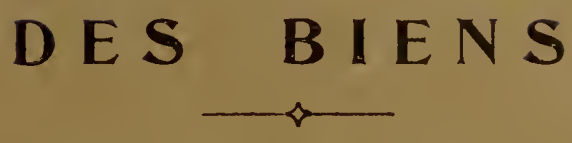

\section{CHAPITRE I}

\section{DES BIENS IMMOBILIERS et MOBILIERS}

Ayant examiné ce qui concerne les personnes, nous allons commencer l'étude de ce qui a trait aux biens des indigènes et aux conventions dont ils font l'objet.

Nous adopterons la traditionnelle division en biens immobiliers et mobiliers.

Quelqu'un s'en étonnera peut-être; dispersés en petits groupes clairsemés sur de vastes étendues, habitant des cases misérables, changeant tous les ans l'emplacement de leurs plantations, essentiellement instables et quasi nomades, les indigènes ne semblent pas organisés pour la propriété immobilière. Elle existe cependant incontestablement et je n'en voudrais pour première preuve que la reconnaissance de cette propriété par l'autorité de la Colonie.

Mais la doctrine officielle a subi des variations depuis bientôt un siècle et nous allons d'abord l'examiner sommairement: on $y$ peut distinguer trois périodes.

$1^{\circ}$ - La période diplomatique au début de notre installation dans la Colonie. Comme les autres pays, nous y avions des établissements commerciaux, il fallait nous y créer des droits de préférence. Reconnaissant officiellement les autorités indigènes et leurs droits sur la terre, le.Roi de France signa des traités avec les rois Louis, Denis, Glass, qui constituaient leurs pays en protectorat. Pour des raisons différentes, de Brazza procéda de la même manière avec le Makoko des Batéké. 
Quelles étaient l'extension territoriale des droits de ces chefs, leur nature, leur origine? On ne s'en occupa point. Nous les avons interprétés dans la suite à notre manière et dans l'intérêt de notre commerce, de notre exploitation du pays, mais nous avons reconnu leur existence.

$2^{\circ}$ - Il fallut ensuite sauvegarder cet embryon d'occupation. Les nations étrangères auraient pu, grâce à leurs établissements commerciaux, user des mêmes méthodes avec les différents chefs du pays et de fait, rien que dans la circonscription de la Nyanga, des traités de ce genre furent passés par les maisons anglaises:

avec le roi de Nyanga

avec le roi de Mamby

avec le roi de Banda-Pointe

et j'ai lieu de penser que des instruments analogues furent signés ailleurs avec d'autres chefs.

Dans les cas même où nous n'avions pas pareil envahissement à redouter, il était de simple prudence de veiller à ce que, d'une part, les emplacements favorables au commerce ne fussent pas accaparés dans les mêmes mains, que, d'autre.part, les conventions ne dissimulassent pas une intrusion violente ou un contrat de mauvaise foi, soit des deux parties, soit du chef du vendeur. Très sagement l'arrêté du 12 Juillet 1849 du Gouverneur du Sénégal et Dépendances règlementa ces conventions passées avec les indigènes et institua, pour elles, le contrôle de l'Administration locale. Celle-ci devait intervenir, c'est a noter, non pas comme partie dans la convention, mais pour en contrôler la validité, pour constater le fait que le vensleur était bien réellement propriétaire de la chose vendue.

Dès le premier texte relatif au régime foncier, l'existence de la propriété indigène a donc été reconnue formellement et officiellement, et cette reconnaissance n'a pas été abrogée.

Le déeret du 28 Mars 1899 parle des " biens appartenant aux indigènes " et stipule qu'ils seront "régis par les coutumes et usages locaux pour tout ce qui 
eoncerne leur acquisition, leur conservation, leui transmission ". Et enfin la circulaire du 10 Octobre 1902 donne des règles pour le cas où " des Européens ou assimilés se rendent acquéreurs de biens appartenant aux indigènes ".

Acheter de la terre aux indigènes est done toujours possible et c'est même le moyen le plus simple mis à la disposition de ceux qui veulent acquérir des terrains au Congo.

$3^{\prime \prime}$ - Mais, dans la pratique, le principe de la propriété indigène a subi de sérieuses atteintes et c'est la période actuelle. Dans l'intérèt public furent institués:

le Domaine Public Maritime (26 Septembre 1891)

le Domaine Public Flurial (8 Février 1899).

Enfin et surtout, le régime concessionnaire, soit qu'il s'agisse des grandes concessions: Société du HautOgooué (1893); Compagnie propriétaire du KouilouNiari (1894); soit que nous considérions seulement les concessions de 1899-1900, ou même les concessions urbaines ou rurales.

Donc, en fait, de la doctrine primitive, nous n'avons conservé que le principe.

De quel droit attribuons-nous ainsi la propriété où la jouissance de la terre?

J'ai examiné longuement cette question avec un fonctionnaire des Domaines; il a voulu appliquer à ces cas la distinction du Domaine éminenl et du Domaine utile. Je ne crois pas que cette théorie soit de circonstance ; qu'il s'agisse de l'un ou de l'aultre domaine, il a son principe dans une propriété antérieure légitime ou légitimée en fait. Si, à la rigueur. on pouvait appliquer la théorie aux terrains cédés par Denis, Louis, Glass ou Makoko, si encore on ponvait faire rentrer dans la catégorie les terrains conquis les armes à la main, les unes et les autres terres ne constitueraient pas toute la Colonie. Or les textes s'appliquent au Congo Français tout entier, à la totalité de l'Afrique Equatoriale Française.

Il est beaucoup plus simple, je crois, de s'en tenir à lexplication naturelle: les peuples les plus avancés 
colonisent les plus arriérés. Notre droit est celui du plus fort. Notre conduite s'explique ou se justifie, non pas tant par les résultats obtenus que par le but réellement poursuivi.

On me dira: Mais les concessions, quelles qu'elles soient, ou, d'une façon plus générale, l'appropriation des terrains, consentie ou déterminée par l'autorité, n'a jamais porté que sur les terres vacantes; elles seules ont été déclarées propriété de l'Etat; d'elles seules il a pris le droit de disposer. C'est seulement reculer le problème d'un degré; car on peut fort raisonnablement poser la question: Y a-t-il des terres vacantes?

L'examen du régime de la propriété chez les indigènes nous permettra de répondre à la question. Je dirai tout de suite que les terres véritablement vacantes, celles où n'existent même pas de droits d'usage, dans la circonscription de la Nyanga tout au moins, sont l'exception; je n’ai pas assez d'expérience dans l'espace pour parler de l'ensemble de la Colonie, mais je crois qu'elles y sont rares.

Je me demande d'ailleurs pourquoi on cherche à sauvegarder pour la forme, une propriété indigène de laquelle, dans la pratique, on ne tient qu'un compte infiniment restreint. Toutes les nations civilisées procèdent de la même manière avec les races faibles ou affaiblies; elles ne pourraient d'ailleurs, sans doute, procéder autrement. Est-ce un bien? - Est-ce un mal? - Cette conduite est-elle blàmable? Je crois qu'elle est indifférente. Il s'agit là d'une des faces du progrès humain. L'évolution des races est impossible à arrêter; le progrès, dont on chante les louanges, n'est ni un bien, ni un mal, pas plus que la pesanteur, la gravitation universelle, les lois physiques, chimiques, etc., etc. Nous n'en sommes pas responsables et n'avons de mérite que dans l'application.

Examinons donc la propriété foncière chez les indigènes. Elle existe, et indépendamment de l'autorité des textes; je vais le démontrer.

L'analyse des notions juridiques a décomposé les 
droits du propriétaire; elle y a déterminé des degrés dont l'ensemble constitue la propriété parfaite.

C'est d'abord le "Jus fruendi " droit de jouissance. On entend par là la perception des fruits produits par le fond. Les indigènes connaissent ce droit. On sait qu'entre leurs agglomérations existent souvent de rastes étendues désertes. S'il s'agit de savanes, on n'y peut guère récolter de fruits, mais s'il s'agit de forêts, il en va différemment. Là se recueillent les graines de Moabi (r), Moudouka (2), Mwiba (3), dont on retire des matières grasses, les fruits de Pava (4), de Poka (5), de Couba (6), de Payou, Pendo, Massikou (7), Moubili, etc., etc., dont les amandes ou la pulpe sont comestibles.

Il en est de même de certains matériaux de construction, comme les feuilles des deux ou trois espèces de Raphia qui servent à faire les " pailles " (Dirombi, Moucighi, Diboulou) ou encore celles du Raphia qui donne les fibres dont sont confectionnés les pagnes (Dignimba).

J'ai trouvé nettement établis des droits exclusifs de récolter le caoutchoue dans certaines régions.

Je ferai rentrer dans le droit de jouissance, le privilège de la chasse et de la pêche. L'un et l'autre existent incontestablement, et ils apparaissent clairement dans les cas où des limites sont discutées entre des groupes contigus. Le plus curieux que j'ai rencontré était celui du chef de Coula, petite terre de la Subdivision de Tchibanga, disparue par la mort de ses habitants dès 1906 . Le chef, il avait survécu jusqu'en 1909, avait le droit exclusif de chasser les perroquets dans la galerie forestière de la Nyanga, là où elle bordait sa terre et il percevait en nature un droit sur les chasseurs.

(1) Baillonella obovata. Pierre.

(2) Dumoria africana. A.Chev.

(3) Irvingia galonensis (Aub.Lec) Bn.

(4) Treculia Staudtii. Engl.

(כ) Panda oleosa Pierre.

(6) Poga oleosa Pierre.

(7) Pachylobus Buttneri. Engl. 
J'ai employé l'expression " droit exclusif ", et cela peut surprendre, car les palabres sont rares qui ont pour objet les droits d'usage. C'est qu'en effet si ce droit repose avec certitude sur une personne morale déterminée, nous verrons plus loin qui est propriétaire, ce propriétaire laisse jouir ses voisins sans protestation. Par générosité, bonté d'âme ou indifférence? Non point, mais bien par crainte. Il redoute la jalousie des gens moins bien partagés dont les maléfices pourraient porter atteinte à sa personne ou à ses biens. Mais encore veut-il qu'on lui fasse un mérite de sa libéralité et, si le droit s'y prête, en tirer quelques avantages. Comme j'avais demandé une fourniture de pailles aux habitants de la terre de Moulongo où les Raphia Maboulou abondent, ils prièrent leurs voisins de Loubinda de les y aider; ceux-ci refusèrent leur assistance. Les gens de Moulongo répondirent en leur interdisant de venir fabriquer sur leurs terres les pailles dont ils auraient éventuellement besoin.

En matière de droit de jouissance, la coutume peut se résumer ainsi: je veux bien que vous profitiez de mon droit, mais encore faut-il que vous reconnaissiez son existence.

Le droit de jouissance ne modifie pas la qualité du fond; au-dessus de lui se trouve un degré plus avancé d'appropriation, le ".Jus utendi " ou droit d'employer le fond, de l'affecter à quelque usage, par exemple de le cultiver, dy élever des constructions.

Je n'insisterai pas sur ce point; on sait que les habitants d'une terre sont groupés et font leurs cultures dans un périmètre déterminé; ce périmètre n'est peutêtre pas aborné, précisé, d'une façon continue au moins par des accidents naturels. Il est cependant certain qu'un chemin nouveau ne pénètre pas sur la terre, sans qu'immédiatement le point où se rencontrent les deux propriétés contiguës soit indiqué.

Toutefois les exemples sont fréquents de chevauchement de cultures d'une terre dans l'autre voisine. Ce n'est point du tout une infirmation. Il y a là une application du même principe de tolérance craintive 
que je signalais tout à l'heure à propos des droits d'usage.

On rencontre aussi quelquefois une singulière confirmation de ce droit de propriété, c'est quand il s'agit d'admettre un étranger à résider dans la terre. A premier examien, cette admission nous paraitra une faveur faite à l'étranger; pour les indigènes, c'est tout l'opposé. Dans l'admission à la résidence, dans l'aggrégation au moins corporelle, celui qui se considère comme favorisé, c'est le propriétaire de la terre, et l'étranger est plutôt sollicité; au besoin on lui fera un cadeau pour qu'il s'installe. Nous retrouvons là une manifestation du besoin qu'éprouve l'indigène de notre région de se créer, daugmenter la famille, la clientèle qui vivra autour de lui, à défaut de la famille naturelle que l'organisation sociale ne lui attache pas.

Pour inattendue que soil celte confirmation du droit de proprićté, ce n’en est pas moins une; il ešst évident que si, le propriétaire de la terre n'était pas chez lui, il ne paierait pas des gens pour y résider.

Enfin la perfection du droil du propriétaire foncier se consomme par le "Jus abutendi ", droit d'abuser, c'est-à-dire d'user du fond jusqu'à sa destruction, entendez jusquà son aliénation. Nous trouvons également chez nous ce dẹré éminent de la propriété. Des portions de "terre " ont étć vendues ou données à d'autres familles. Ainsi, dans la subdivision de Tchibanga, la terre de Loango et celle de Maralissefa sont des dépendances de la terre de Loubinda; elles ont été aliénées aux occupants actuels. Ainsi également dans la terre de Mpokou; une moitié de cette terre appartient aux Boumouellé, propriétaires originels (Mpokou Cambala), l'autre aux Baghoyo; ces derniers ny sont établis que par suite des dispositions testamentaires d'un des anciens chefs; celui-ci, laissant la terre à sa famille suivant lusage et le sens indigènes. en attribua une partie à certains de ses enfants, suivant le sang (Mpokou Dounzoumbou). On trouverait 
sans aucun doute, des exemples analogues dans d'autres subdivisions.

Ceci établi, sur qui repose la propriété immobilière, ou plutôt la propriété foncière? - Elle n'est nulle part individuelle, mais collective. Il ne viendra jamais à l'esprit de personne de dire: "Je vais chez moi ", mais conbien de fois navons-nous pas entendu dire, par exemple: "Je vais chez les Boumouellé, chez les Dibamba " ? Une grande partie de la subdivision de Ndendé porte même un nom de famille; on l'appelle "Koumou Dibamba ", la plaine des Dibamba.

La "Terre ", groupement ethnique, est établie sur un territoire qui appartient à l'ensemble de ses habitants; chacun des petits groupements qui la composent a la jouissance d'un lot plus ou moins nettement délimité, lot dans les bornes duquel la récolte des fruits naturels se pratique, les villages se déplacent, les plantations se développent, quitte, ainsi que je le disais tout à l'heure, à laisser les voisins y construire, y planter s'ils le jugent utile.

Toutefois, si les droits de jouissance et d'usage de la terre sont des droits collectifs, je pense que le privilège de l'aliénation, d'ailleurs exceptionnelle, repose sur la tête du chef de la terre, lequel sans doute ne manque pas de s'assurer le consentement des notables de son groupe. Que si on s'en étonne, je répondrai que l'aggrégation d'étranger à la terre ne rapporte guère de bénéfices et est plutôt onéreuse à celui qui l'autorise au moins au moment où la faveur est octroyée.

Toutes ces notions ne sont pas nouvelles aux fonctionnaires de l'administration régionale. Chacun d'eux a eu maintes fois loccasion de déterminer les limites territoriales d'un groupement, par exemple lorsqu'il s'agit du débroussement des sentiers; le meilleur moyen de l'assurer est de faire l'attribution de ces prestations conformément aux limites naturelles du groupement, et c'est la méthode que je conseillerai de suivre, indépendamment de toute question de longueur des sections à entretenir. 
Maintenant, existe-t-il des terres vacantes dans la circonscription de la Nyanga? Dans la subdivision de Tchibanga et dans celle de Ndendé et aussi sans doute 'dans celle de Moabi, à coup sûr, il n'en existe pas. Je ferais le pari de les parcourir dans tous les sens et de pouvoir déterminer à qui appartient la terre que je foule chaque jour. Les parties les plus désertes, par exemple, celles situées entre Moabi, le Mourindi et les Bavoungou sont parcourues par des Babongo appartenant aux Bavèla, aux Youngou, aux Bouyala; j'aimerais à savoir dans quelles conditions s'y sont installés les villages mitsogho de Sanga et Dikouka ; même observation peut se faire pour la région comprise entre Mpokou, la Douguégni moyenne, Manguélé et la terre de Nyanga.

Pour les subdivisions de Mayumba et Nyanga, l'appropriation de tout le terrain est moins évidente et moins certaine. Toutefois j'incline à croire qu'elle est réalisée. L'ancien chef de Ngolo Singandou, Iwéné Mikindou, était aussi bien chez lui à Ngolo Singandou qu'à la côte. De même l'ancien chef de Mamby pour les terres de Mamby-Lagune et Mamby-Baloumbo (terre de Bibora du rôle de Tchibanga). Il y a donc des chances pour que la forêt déserte existant entre les terres de la côte et celles de l'intérieur fût leur propriété. On pourrait peut-être en dire autant de la forêt comprise entre les terres de Mongo-Nyanga, Dikoudou et Cachimba.

En résumé je me garderai de nier qu'il existe des terres réellement vacantes; je répéterai seulement qu'elles sont rares et leur recherche, qui n'a jamais été effectuée, ne serait peut-être pas une œuvre dépourvue d'utilité.

Indépendamment de la propriété foncière, la propriété immobilière existe également.

Elle pourrait avoir pour objet les maisons d'habitation, les cases; mais celles-ci sont de valeur si in- 
fime, construites de matériaux si périssables et si faciles à se procurer, que je n'ai janıis vu d'exemple de case faisant l'objet d'une transaction. Si l'occupant s'en va, les habitants de son village se feront scrupule de toucher à sa case, la laisseront envahir par les herbes et tomber en ruines. S'il meurt, on procède de même manière en général; quelquefois cependant, l'habitation est utilisée par les célibataires du village.

Les plantations, après la mort de la femme à qui elles appartenaient, peuvent être revendiquées par sa famille; elles peuvent être également vendues, j’ai vu le cas se produire. 11 arrive cependant qu'elles restent au mari de la défunte.

Il y a d'autres biens immobiliers dont l'appropriation est plus évidente, ce sont les arbres fruitiers : orangers, citronniers, safou; plantés ou respectés dans les villages, ils survivent à la disparition de ceux-ci; mais ils ne tombent pas pour cela dans le domaine public, ils restent la propriété des descendants de ces occupants. S'ils ne constituent pas encore un bien immobilier susceptible d'être vendu, il est certain qu'on n'y peut toucher sans l'assentiment du propriétaire ou plutôt du chef de la collectivité à laquelle ils appartiennent. On ne laissera pas un européen s'installer auprès d'eux, en jouir, les abattre, sans lui réclamer une indemnité qu'il senible juste d'accorder.

Ce que je dis là est surtout manifeste pour les palmiers à huile et le régime de ces arbres est important à examiner.

On a des tendances à les considérer partout comme des végétaux croissant spontanément, en dehor's de toute intervention de l'homme et, par suite susceptibles de faire l'objet d'attribution, de concession de la part de l'autorité, sans autre considération.

A mon sens, cette opinion est en toute certitude une erreur dans la région de la Nyanga. Je n'y ai jamais vu pousser le palmier à huile en peuplement plus ou moins dense, sans qu'il reste sur la place dẹ 
signes encore visibles, des témoins de l'occupation, au moins du passage de l'homme.

Les indigènes plantent souvent des palmiers dans les villages; dans la région forestière, on les trouve sur les sommets ou la partie supérieure des pentes et alors on rencontre dans le voisinage la flore ordinaire des anciens villages: safou, citronniers, Dracœna, Ficus divers, Newbouldia lavis, papayers, etc.; ou bien, il s'agit d'anciennes plantations; les indigènes y séjournent volontiers, $y$ font leur cuisine, y ont consommé des régimes; les noyaux ont germé et se sont développés. Ils se rencontrent alors mélangés aux arbres de la forêt, lesquels portent les signes de l'ancien défrichement: frondes basses et très développées, arbres plus abondamment fourchus, dominés de très haut par certaines espèces plus dures comme le Moughoubi (Nkoubi des Vili) (I) ou utiles comme le Moabi (2), le Moudouka (3), etc., ou trop volumineux comme le Noughoma (4), le Moulenda (5), etc., et par cela même respectés. Dans les savanes, on les rencontre dans les bouquets d'arbres, vestiges d'anciens villages, ou dans les galeries forestières ou les boqueteaux ayant abrité des cultures.

A partir de ces individus, plus ou moins nombreux, la dispersion des fruits a été effectuée par les antilopes sylvestres, par les perroquets, par les petits rongeurs, etc., etc., et ainsi se sont constituées certaines palmeraies importantes comme celles de Mocabe et Moabi, celles de Bikenzi et d'Ilounga Imourombo dans la subdivision de Tchibanga; celles de la subdivision de Ndendé à Mouragni, Moughoubi, Doucanga, etc., etc. Les peuplements beaucoup moins importants de la lagune de Nayumba, de Panga, de la Nyanga ont semblable origine, mais leur extension fut arrêtée par l'existence de savanes naturelles ou secondaires dans

(1) Staudtia gabonensis Warb.

(2) Baillonella obovata. Pierre.

(3) Dumoria africana. A. Chev.

(4) Klainedoxa gabonensis, Pierre.

(5) Desbordesia insignis. Pierre. 
les deux premiers cas, formations végétales sujettes aux incendies annuels, ou par les terrains marécageux de la Basse-Nyanga dans lesquels l'Elæis se plaît peu et se développe assez mal.

J'ai eu l'occasion d'examiner de très près l'origine des palmeraies lors de l'attribution des concessions liquidant les grandes Compagnies constituées en 1899 et 1900 . A Mocabe le souvenir se conservait de Mbadinga Dissako qui avait apporté de Goungui les premiers palmiers, et à Moabi on attribuait à Mbadinga Ilama la création des palmeraies dont il avait pris les sujets à Loukandou. A Banda-Pointe, j'ai relevé l'existence d'une pénalité coutumière sanctionnant la destruction des palmiers; ce sont là des signes certains d'appropriation. Je noterai encore un fait qui se constate sans difficulté: lors de la fabrication du vin de palme, les indigènes ne s'adressent pas à n'importe quelle palmeraie; ils vont là où ils sont propriétaires, voire assez loin de chez eux, alors qu'ils peuvent trouver dans le voisinage des arbres inemployés.

D'une façon générale, on peut affirmer que tout palmier a un propriétaire, individu ou collectivité, et j'ajouterai qu'il n'est pas difficile de s'en faire indiquer le nom.

Je puis dire d'ailleurs qu'au Fernan-Vaz et à Iguéla, comme à Bongo et à Mouila, j'ai trouvé les palmiers soumis aux mêmes stipulations coutumières; et que ce régime s'explique partout par le fait que l'Elæis n'est pas spontané, qu'à l'origine on trouve l'intervention active ou passive de l'homme; celui-ci, s'il n'a pas planté l'arbre, a été la cause de sa dispersion et a respecté les germinations rencontrées.

Pour si peu d'ailleurs que l'on ait parcouru la Colonie, on a sans doute pu constater que là où l'homme n’a pas passé, l'Elæis n'existe pas.

En résumé l'existence de la propriété immobilière chez les indigènes n'est pas niable; elle est peu appa- 
rente parce que les transactions auxquelles elle donne lieu ont toujours été rares. Etant donné le peu de besoins des indigènes et la faible densité de la population, il n'en pouvait être autrement.

Quel rôle aurait à jouer éventuellement l'autorité dans des transactions ayant des fonds de terre pour objet?

Si les deux parties sont des indigènes, il est probable que nous n'aurons pas à intervenir. J'ai dit ailleurs que l'admission d'un étranger à la résidence et son aggrégation à un groupe, loin d'être onéreuse, lui valait au contraire le plus souvent un cadeau du chef de la terre.

Il n'y a pas chance, malheureusement, de voir des étrangers s'installer dans les pays constituant la région de la Nyanga; la population la quitte, bien loin d'y affluer. Si cependant le fait se présentait et donnait lieu à un- litige, il faudrait veiller à la conservation du droit des occupants et, si l'installation des nouveaux venus pouvait procurer à ces derniers quelques bénéfices, je n'y verrais que des avantages. Ce serait une occasion de les attacher à la terre.

$\mathrm{Si}$, au contraire, le cessionnaire du terrain est un Européen, il pourra être utile d'abord de rappeler à celui-ci que notre intervention au contrat est obligatoire et que l'indigène ne peut vendre que sous notre contrôle.

Notre premier soin sera d'établir quel est le propriétaire indigène et quels sont ses droits? Puis nous examinerons si le lot demandé est en rapport avec les besoins et les projets de l'acheteur éventuel. Les commerçants, exploitants ou planteurs, peuvent avoir intérêt à s'installer sur tel ou tel emplacement particulièrement bien disposé; d'autre part, l'achat de la terre aux indigènes est un procédé que son bon marché, l'absence de clauses et de charges, rendent avantageux; il faut laisser autant que possible place à la concurrence et éviter l'accaparement.

Il restera à apprécier l'équité du prix offert, et, dans cette estimation, tenir compte de deux éléments: la 
valeur infime de la terre dans notre région, d'une part, et, de l'autre, la nécessité absolue d'arriver à faire donner satisfaction au propriétaire indigène, non seulement pour le présent, mais aussi pour l'avenir. Il devra comprendre qu'une fois la terre aliénée, il n'y aura plus aucun droit d'usage, même sur les arbres à fruits, j'entends spécialement les produits du palmier à huile et surtout le vin de palme. L'existence d'arbres à fruits, tels que l'Elæis et l'arbre à safou, pourra donner lieu à une indemnité particulière. Dans l'évaluation de celle-ci on pourra se baser sur le produit annuel des arbres, mais on aura soin de le capitaliser à un taux très éleré pour ne pas aboutir à un capilal hors de proportion avec les besoins des indigènes.

Il va sans dire qu'il conviendra de tenir compte pour la délimitation, des conditions imposées par les règlements en vigueur, quant à la situation des terrains par rapport aux routes et cours d'eau.

Des transáctions du genre de celle dont nous nous occupons ne doivent pas traîner en longueur, au moins quant à la conclusion de l'accord entre l'acheteur et le vendeur.

L'existence de biens meubles n'est pas donteuse, mais ils ne sont intéressants que par les transactions auxquelles ils donnent lieu. Nous en parlerons plus loin.

\section{CHAPITRE III}

\section{DE LA PROPRIÉTÉ}

Il $\mathrm{y}$ a donc chez les indigènes des biens mobiliers et immobiliers, mais une question se pose à présent: Sur qui repose le droit de propriété?

Nous rencontrons là une question des plus obscures, des moins étudiées. Je l'ai souvent posée à des camarades; aucun n'avait d'opinion bien assise; plusieurs semblaient disposés à croire à une proprićté collec- 
tive, l'attribuaient à la famille, mais tout était très vague.

Je tàcherai d'exposer clairement mon idée personnelle, regrettant que les occasions soient si rares de la soumettre à discussion.

Je rappellerai tout d'abord combien, dans toutes ses parties, la coutume est imprécise; à peu d'exceptions près, elle ne contient ni obligation absolue, ni interdit catégorique. Au vrai, nous lui faisons bien de l'honneur en la nommant "coutume ", comme si elle était comparable aux prescriptions juridiques de notre France royale. Plus précis, nous devrions la nommer " usage ", car elle est un ensemble de stipulations auxquelles il convient de se conformer, mais auxquelles tout homme plus hardi ou plus indépendant peut se soustraire.

Nous tiendrons compte de cet élément d'appréciation et pour analyser plus facilement les caractères de la propriété chez les races de la Nyanga, nous distinguerons successivement les biens immobiliers et les biens mobiliers.

\section{$\S 1$}

\section{Propriété des biens immobiliers}

La propriété foncière est collective, sans l'ombre d'un doute et elle repose, sans discussion possible, sur l'ensemble, non pas du village, mais de la terre. Chacun des groupes constituant cette dernière division territoriale a la jouissance de la superficie nécessaire à l'établissement du village, des plantations; mais ses déplacements successifs peuvent le conduire dans un canton tout opposé.

S'il s'agit cependant d’un groupe aggrégé, son lot est nettement déterminé, ses déplacements se limitent à ce lot, mais il ny a pas cependant démembrement de la terre. Le droit du chef de ce groupe n'est pas autre que celui d'un chef de village, c'est un droit d'usufruit.

Toutefois dans les cas où une alićnation a été con- 
sentie, elle l'a toujours été par le chef de la terre. Dans les exemples que j'ai relevés, j'ai toujours constaté l'action personnelle de celui-ci; il parlait d'ailleurs à la première personne: " j'ai vendu ", "j’ai donné ". Il n'agissait cependant pas sans l'assentiment des principaux de ses parents et par suite de la collectivité.

\section{$\S 2$}

\section{Propriété des biens mobiliers}

C'est la seule intéressante, car les transactions ayant pour objet des fonds de terre sont excessivement rares.

Sur qui repose la propriété des biens meubles?

Est-elle collective et dans quelle mesure?

Est-elle individuelle?

Lorsqu'un créancier rencontre un débiteur insolvable, nous le voyons fréquemment sadresser à un parent proche de celui-ci, le rendre responsable de la dette, et il n'est pas rare de voir ce dernier acquitter les sommes dues.

Un travailleur rentre-t-il son année d'engagement terminée? La plus grande partie de son salaire n'est pas pour lui; elle passe entre les mains du frère, de l'oncle, du père.

S'agit-il de l'impôt? Il n'est pas dòuteux qu'un village étant donné, certains des habitants paient pour d'autres: les cadets pour les ainés, les adolescents pour les adultes.

Un indigène est-il chasseur ou pêcheur? Le produit de son industrie est si bien réparti et si rapidement qu'il ne lui reste pas grand chose dont il puisse disposer pour la vente.

On serait donc porté à conclure que la propriété indigène est collective et familiale. Les fonctionnaires de l'Administration régionale, nous tous, avons mis en pratique cette donnée et, dans la perception de l'impôt, par exemple, nous rendons volontiers un chef de terre ou de village responsable des contributions

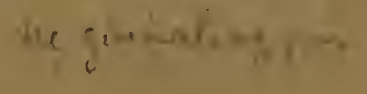


de son groupe; nous sommes tentés d'inviter un nèveu à payer pour son oncle, un carlet pour son ainé, un fils pour sa mère, ou inversement; il arrive qu'on fasse payer un homme pour un autre qui n'est que son voisin. Je crois bien que nous n'avons guère réfléchi à la qualité du procédé; nous l'employons parce qu'il est plus commode, et l'inconvénient n'est pas grave parce que c'est une manière de faire couramment pratiquée par les indigènes, conforme à l'usage si ce n'est au droit coutumier.

Est-ce légitime? Je ne le crois pas.

La propriété collective familiale supposerait un groupement constant des individus qui en bénéficient solidairement. Nous avons vu ailleurs combien les groupements sont instables, la facilité avec laquelle des parents même très proches vivent opiniàtrément séparés, l'oscillation continuelle de la résidence entre la famille paternelle et la famille maternelle, et même, pour les adultes, la famille d'alliance. Comment donc, avec une si habituelle dispersion, chacun des bénéficiaires percerrait-il sa part dans la propriété de la chose?

En outre, il devrait se rencontrer dans la langue des traces de cette collectivité, analogues à celles qui se peuvent relever dans le langage des niembres de certaines communautés religieuses austères où l'on dit: " notre lit ", " notre robe ", etc. On sait qu'il n'en est rien et combien âprement l'indigène poursuit, même contre un frère, le paiement, la restitution de ce qu'il considère comme son dû.

Les exemples que je citais plus haut sont authentiques, mais s'il est exact que des jeunes gens travail. lent pour les adultes, paient l'impôt pour eux, si le cadet est susceptible d'acquitter fréquemiment la dette de son aîné, le neveu celle de son oncle, il n'est pas moins certain que chacun peut se dispenser de pareille obligation sans encourir ni une sanction quelconque, ni le mépris public. Il n'est pas rare de voir un jeune homme travailler, par exemple, aux plantations des parents de sa femme et refuser d'aider ses 
oncles ou frères; - un travailleur reviendra de son année d'engagement les mains vides, ayant gaspillé l'intégralité de ses salaires; - quant à la capitation, j'ai plus d'une fois vu de contribuable précisant celui au compte duquel il payait un impôt, désigner quelqu'un auquel nul lien familial ne l'attachait, ce qui donnait à sa générosité le caractère d'une libéralité intentionnelle, raisonnée, motivée.

Il n'en reste pas moins que la première série de faits est beaucoup plus générale. Comment l'expliquer? Nous touchons là je crois, à un des points capitaux de la vie indigène, celui auquel une intervention de notre part aurait le maximum d'effet et produirait un essor dans l'évolution de nos races tel qu'on saurait mal l'imaginer.

Et voici comment je me figure la question :

L’indigène est dominé par la crainte perpétuelle et constante des maléfices. La maladie, la mort ne sont pas pour lui des accidents naturels; il faut qu'ils aient des auteurs. Il n'est pas de fonctionnaire qui ignore cela; il n'en est pas non plus à qui il ne soit arrivé de recevoir des plaintes d'individus se croyant en butte à la malveillance de leurs congénères. "On est jaloux de moi ", m'ont dit souvent, à tort ou à raison, des individus accusés d’actes délictueux ou criminels, pour expliquer l'accusation portée contre eux. L'explication est bien vague pour nous; elle est précise pour eux et ils ne redoutent rien tant que le reproche d' " avarice "; c'est qu'en effet, il équivaut souvent à un arrêt de mort.

L’individu qui réussit bien dans ses affaires, excite la jalousie, de même celui qui a des relations étendues, une case meilleure, des plantations plus vastes ou plus fertiles, une femme plus féconde! Rappelonsnous qu'il ne vit guère qu'au milieu de ses proches; c'est donc de ceux-là qu'il a tout à redouter, s'il sort, soit par hasard, soit grâce à son travail, de la misère commune. On dirait que la prospérité dónt il jouit est formée du malheur de ses voisins et que ces derniers ne le lui pardonnent point. Un beau jour, il tombera 
malade, mourra plus ou moins rapidement: le poison aura fait son œuvre. Si le crime même n'a pas eu lieu, la victime de la maladie, ses parents après sa mort, tous, verront, dans l'accident, la preuve de la jalousie des autres; on n'est pas malade, on ne meurt pas sans raison, à moins qu'on ne soit très vieux, et encore!

Interrogez les indigènes, leurs réponses concorderont sans exception. Les parents vivent séparés, c'est par la raison que chacun d'eux fait le possible pour jouir sans partage du peu de bien-être qu'il réussit à se procurer.

L'indigène ne travaille pas dans son pays. Pourquoi ? C'est qu'il sait ne devoir tirer aucun avantage de son effort; au fur et à mesure qu'il recueillera le fruit de son travail, il devra le partager, car il craint les maléfices que son esprit d'économie provoquerait.

Tout de même, notre contact a amené certains indigènes à souhaiter voir s'améliorer leur existence. A quoi ont-ils dî se résoudre? A l'exil. Libreville est plein de gens qui pouvant travailler, s'y résignant, veulent jouir; ils souhaitent de beaux habits, des boissons alcooliques, les femmes. Pour y parvenir, ils ont quitté leur pays et, au lieu d'être absents un an, deux ans, ils ont renoncé sans doute à le revoir. Vivant au jour le jour, travaillant au hasard, logeant chez des congénères, l'attrait des plaisir's plus ou moins malsains que la civilisation leur apporte en a fait des vagabonds. Il serait bien désirable que l'on reniédiât à cette situation.

Pourquoi rencontre-t-on sur toute la côte occidentale d'Afrique autant de Bavili? L'un d'eux, un Tchikaya, est installé à Dakar! Parce que ceux-là ont appris une profession lucrative: presque tous sont tailleurs et, s'ils ne s'enrichissent guère, ils vivent bien. Pourtant leur pays, Loango, ne profitera pas de leur progrès social; ils ny retourneront jamais, car ils auraient à choisir entre le partage de leurs biens et la mort.

En un mot, l'indigène vit sous un régime de terreur que nous n'imaginons guère et, pour qu'un esprit y 
résiste sans tomber dans la démence, il faut leur mobilité, leur inconstance de caractère.

Nous dirons donc que la propriété mobilière est certainement individuelle, mais que le régime en est modifié par un principe surajouté, celui de l'égalité dans la misère.

Avais-je tort en disant que nous touchions là au point décisif de l'évolution des races? Supprimez cette crainte de la mort, amenez l'indigène à voir que les maladies sont des accidents naturels, la mort, notre fin commune et inéluctable, et, en libérant ainsi son esprit, vous rendrez possible le déploiement des puissances de travail représentées par ce capital humain. On dit: " les populations sont paresseuses, apathiques, etc. ". Ce n'est pas vrai. Depuis combien de temps recrute-t-on chez nous, et par milliers, des travailleurs dits "Mayumba "? Travailleurs de plantations, ouvriers pour l'exploitation des bois, le roulage et le flottage des billes, partout, Baloumbo et Bayaka sont bons à toute besogne et, pour peu qu'ils soient intelligemment surveillés, on en tire encore un rendement à peu près satisfaisant. Nais leur travail est sans fruit, leur eflort est vain et la région n'en tire pas d'autre profit qu'une plus ou moins grande facilité à se libérer de l'impôt de capitation. Elle ne se développera que par le travail sur place, l'esprit d'économie: l'un et l'autre sont interdits à nos populations. Hélas! nous n'y pouvons rien. Les raisonnements seraient inutiles; il faut des preuves et, seuls, des médecins combattant leurs coutumes, soignant et guérissant leurs maladies, pourraient leur en donner. La Colonie sera-t-elle assez riche pour en installer jamais? 
$\$ 3$

\section{Des différentes manières dont on acquiert la propriété}

La propriété s'acquiert par succession et par l'effet des obligations.

On remarquera que je ne parle pas des donations. C'est qu'en effet, je suis convaincu que les indigènes ne savent pas ce que c'est que "donner " au sens propre du mot: se dépouiller irrévocablement de la chose en faveur du donataire. Le mot " donner " et les termes que cette idée suggère sont imperturbablement traduits par nos interprètes, mais les vocables indigènes qu'ils emploient ne rendent assurément pas le sens de notre mot.

L'indigène ne se défait jamais de ce qui lui appartient, sans espoir de retour; il connaît le mot " cadeau ", il l'emploie même beaucoup, mais il poursuit ce faisant un but déterminé, très bien rendu par l'expression proverbiale: "Donner un ouf pour avoir un bœuf ").

Si donc, au cours de palabres, on rencontre une donation, il faut être assuré qu'il s'agit de toute autre chose, estimer à sa valeur la chose donnée et imposer le remboursement.

Le cas se présente souvent dans les relations entre les indigènes et nos auxiliaires: interprètes, gardes, etc. On ma quelquefois soumis des réclamations qu'on peut résumer ainsi: Un Tel, disait le plaignant, m'a volé une poule. - C'est faux, répondait le garde, il me l'avait donnée.

Il y a souvent lieu, dans ce cas, de punir le garde; j'en ai connu qui savaient admirablement se faire donner. Nous ne devons pas admettre de telles habiletés.

Les seuls exemples de donations que l'on puisse à la rigueur citer, se produisent entre parents proches d'une même famille: un frère aide de ses propres res- 
sources son cadet à payer la dot de sa lemme, un oncle cède une de ses femmes à son neveu, lorsqu'il croit s'apercevoir que celle-ci chercherait ailleurs des distractions coupables, etc. Encore s'agit-il là beaucoup plus d'une avance, d'hoirie, que d'une véritable donation.

Dirai-je un mot des cadeaux traditionnels donnés par les chefs de village aux fonctionnaires de passage? Ils constituent une reconnaissance matérielle de notre autorité et sont, à mon avis, des habitudes bonnes à conserver, sauf dans les cas où, les villages se trouvant sur une route très fréquentée, ces cadeaux constitueraient pour eux une trop lourde charge.

Faut-il les exiger? Oui, spécialement de ceux dans l'abstention ou le refus desquels on verrait un manque de déférence voulu et prémédité.

Comment faut-il les payer? Car il faut, de toute nécessité les payer. Il faut les payer à leur juste valeur, et si on tient, ce qui peut quelquefois ĉtre utile, à se montrer un peu plus généreux, distinguer soigneusement le prix de la chose vendue et la libéralité gracieuse que l'on entend consentir. Le prix des choses, en effet, a tendance à monter rapidement et nous devons tout faire pour retarder cette augmentation. Les coloniaux ont la main large et ne réfléchissent guère combien il est déraisonnable de payēr un boy $30 \mathrm{fr}$. par mois, un mouton $35 \mathrm{fr}$. ou davantage, etc.; cette prodigalité met à un prix excessif l'heure de travail ou la livre de viande. Résistons autant que nous pourrons; le mouvement ascensionnel se continuera sans nous, mais au moins n'y aidons point.

\section{CHAPITRE III}

\section{DES SUCCESSIONS}

Les successions sont dévolues aux ascendants et descendants ou collatéraux du défunt dans la même famille. Il en résulte que l'ordre successoral est diffé- 
rent suivant qu'il s'agit d'un homme ou d'une femme. Mais il y a peu de chose à dire de la succession des femmes; notre région nest pas assez avancée en civilisation pour que les femmes possèdent de quoi constituer une succession. Si le cas se présente, elle est dévolue à ses enfants.

\section{$\S 1$}

\section{Des qualités requises pour succéder}

Pour succéder il faut être de la mème famille que le défunt; ce terme étant pris dans le sens le plus large: un neveu, un frère utérin sont de la même famille que l'oncle ou l'aîné; mais l'ifoula, le fils d'une femme esclave, est également de la même famille que son père. $\mathrm{Au}$ contraire, le fils de la femme libre est de la famille de sa mère et se trouve par là même exclu de la succession de son père et de tous ses parents de ce côté.

Il faut, pour recueillir un héritage, ètre en outre d'un certain âge. L'idéc de majorité et de minorité est étrangère à nos indigènes, mais ils se rendent compte qu'un enfant en bas-âge, ou même un adolescent sont des incapables.

Comme d'ailleurs ils ignorent la tutelle, les incapables par l'àge ou la démence, se trouvent purement et simplement exclus.

Chez les Bayaka, les femmes ne concourent point au partage; non pas qu'elles soient victimes d'une interdiction absolue. Je crois qu'en cherchant bien, on trouverait des cas où elles ont reçu leur part: il y a eu, et il y a sans doute encore des femmes-chefs; cependant, je ne les ai jamais vues intervenir dans les successions, si ce n'est pour sauvegarder et défendre les droits de leurs enfants. Il est possible aussi qu'à la côte, elles tiennent plus de place.

Enfin, une condition essentielle est deetre présent; chez nous, qui ne défend pas ses intérêts de sa personne risque de se voir entièrement dépouillé. 


\section{De l'ordre successoral}

Lors done qu'un décès se produit, les biens du défunt sont susceptibles d'être attribués aux parents de la même famille dans l'ordre suivant :

S'il s'agit d'un homme jeune, encore célibataire, c'est le cas, par exemple, pour les travailleurs engagés, à l'oncle ou aux oncles, frères utérins ou germains de la mère.

S'il s'agit d'un homme un peu plus âgé, ayant des frères germains ou utérins déjà mariés, établis, et, à fortiori, s'il s'agit d'un adulte ou d'un vieillard, sa succession est dévolue à ses frères germains ou utérins; si le défunt n'a pas de frère, son héritage passe $\dot{a}$ ses neveux, fils de ses sœurs.

En résumé, on peut dire que les successions se transmettent toujours dans la ligne collatérale.

J'ajouterai, pour en terminer avec les règles de principe: qu'aucun motif ne rend un individu indigne de succéder; que la renonciation n'est jamais admise. sous aucun prétexte.

\section{$\S 3$}

\section{De la prise de possession et de la répartition des héritages}

Ces principes posés, la manière de procéder des indigènes s'explique par les circonstances de leur vie et la nature des successions.

Celles-ci se composent de trois sortes de biens:

Les épouses;

Les biens liquides;

Les créances et les dettes.

De la transmission des épouses, nous ne dirons rien, ayant examiné la question au chapitre du mariage.

Les biens liquides sont toujours peu de chose dans 
les successions indigènes. D'immeubles, il n'y en a pas; ils sont propriété collective, nous l'avons vu. Ils ne font pour ainsi dire jamais lobjet dune convention; au chapitre actúel, il ne peut en être question qu'au seul point de vue de l'autorité qui les administre et les régit, et nous avons déjà exposé les règles de la transmission de l'autorité.

Quant aux biens meubles, ils se rencontrent dans la succession en quantités bien minimes. Les ustensiles de ménage sont la propriété de l'épouse, encore bien que son mari soit tenu de les lui fournir. Les produits de la culture sont aussi la propriété des femmes et pareillement ceux de l'élevage, au moins pour ce qui est des animaux de basse-cour. Ces biens spéciaux mis à part, il ne reste pas grand'chose; nos indigènes sont d'une pauvreté inexprimable. Si le travail ou le hasard leur procurent à l'occasion quelque bien, la crainte de se le voir enlever, le souci de ne pas paraître plus riche que le roisin les poussent à en faire l'objet de prêts à plus ou moins long terme, si bien que la fortune de chacun se compose on peut dire exclusivement de créances et de dettes.

Si cependant, le défunt laisse à sa mort quelques objets, on en dépose la plus grande partie à proximité de sa tombe, sur le chemin auprès duquel elle est située, après avoir pris la précaution de les rendre inutilisables afin de ne pas tenter la cupidité des passants. Ils forment là une espèce d'étalage destiné à montrer la richesse du mort; sans doute aussi, fautil voir dans cette coutume un signe des croyances, aujourd'hui plus ou moins obscurcies, de nos indigènes à une vie future.

Une mention spéciale doit être faite des esclaves. Ceux-ci sont attribués aux parents les plus proches du -défunt. Ils prennent alors comme deuxième nom, celui de leur nouveau maître.

Restent donc les créances et les dettes; par ce fait, va s'expliquer facilement le procédé de répartition des héritages. L’indigène. Bayaka, Baloumbo ou Bavili, est extrêmement seçret, comme disaient nos grands= 
pères. Il ne conte pas ses affaìres au premier venu. Il a un confident habituel qui l'accompagne dans ses voyages commerciaux, l'assiste, lui sert d'intermédiaire et de représentant. C'est toujours quelqu'un de sa famille, son frère (lato sensu), son neveu; comme l'écriture est inconnue, celui-ci est seul au courant des conventions conclues, des obligations contractées; il est héritier, du fait de sa parenté, et enfin il a vécu depuis longtemps arec celui dont la succession vient de s'ouvrir, et il est présent lors du décès.

La coutume n'imipose pas d'ordre successoral absolu ni davantage de mode de répartition.

Il se produit donc que, de par sa situation, à cause de la connaissance qu'il a des affaires du de cujus, le confident habituel dont je parlais tout à l'heure se trouve saisi de l'universalité de la succession.

Mais ce n'est pas un héritier universel, ce n'est pas davantage un simple exécuteur testamentaire. Il a des droits, car il est héritier pour partie, il a des obligations, car il n'est pas seul héritier. Quels sont ces droits, ces obligations? La coutume ne le dit pas. Il est cependant certain que,s'il gardait pour lui seul le montant des créances qu'il a recouvrées, les autres parents proches du défunt chercheraient indirectement des compensations soit à ses dépens, soit aux dépens de ses parents. Nous retrouvons, là comme partout, l'imprécision de la coutume.

Dans la pratique, l'héritier dont je viens de parler s'arrange de manière à garder pour lui la meilleure partie de l'héritage, tout en donnant aux autres satisfaction au meilleur compte. La. tâche lui est facile, puisqu'il est le seul à connaître l'état des affaires du défunt et qu'il n'est jamais procédé à rien qui ressemble à un inventaire.

Les palabres soulevés par la distribution de l'actif des successions sont donc très rares; je n'ai paŝs souvenir qu'on m'en ait jamais soumis.

La répartition du passif est beaucoup moins facile. J'ai dit que la renonciation aux successions n'était pas admise, pas plus que l'acceptation sous bénéfice d’in- 
ventaire et cela se conçoit facilement; lindigène suppose toujours qu'il pourra ne pas payer ses dettes; il ne supporte pas l'idée qu'il peut y avoir des créances irrecouvables; il ne comprend pas le manque à gagner.

L'héritier, tel que je viens d'expliquer son rôle, se trouve done, dès le décès, responsable des obligations contractées par le défunt. Il a droit de recourrer ses créances, mais il faut aussi qu'il paie ses dettes.

On peut ètre assuré qu'il y mettra toute la mauraise volonté compatible arec ses propres intérèts. II arrive done souvent ceci, qua les créanciers de la succession, désespérant de rien obtenir de l'héritier, se retournent vers les autres parents du défunt: frères puinćs de l'héritier, neveux du défunt. Ceux-ci souvent n'ont pas tiré grand bénéfice de I'hćritage, souvent ils n'ont rien reçu du lout et, pour une raison bien simple, c'est qu'ils ćtaient trop jeunes lors du partage. lis sont cependant tenus, en quelque sorte moralement, du fait de leur parenté. C'est alors quen désespoir de cause, les palabres nous sont sounis.

On nous les présente dans cette forme: un tel, dit le plaignant, me doit tant de pièces que je lui ai prêtées. Bien sourent deux circonstances attireront lattention: lélévation de la somme, au regard de l'àge du défendeur, et la disproportion d'àge entre les deux plaignants. La première précaution à prendre est de demander au plaignant: Est-ce à lui-même que tu as prèté ou à son oncle (ou à son frère aîné)? - On se rendra compte de suite de la nature de la dette; on apprendra aussi facilement du plaignant qu'il s'adresse à ce parent de son débiteur plutôt qu'à tel autre, parce qu'il lui parait plus solvable, ou qu'il a moins de cléfense, ou qu'il est moins éloigné, ou même que lui plaignant a contracté antérieurement envers ce débiteur d'élection une obligation dont il veut se décharger.

Ainsi documenté, on recherchera qui s'est saisi de l'héritage, en a disposé; on le fera appeler, l'invitera à acquitter les dettes de la succession dont il a appré- 
hendé l'actif, lui imposera un terme, des conditions de payement.

On peut encore essayer un autre procédé; rechercher avec l'héritier et le plaignant un des débiteurs de la succession et charger celui-là spécialement du remboursement, c'est-à-dire, imposer une novation par changement de débiteur, mais alors il est bon que toutes les parties soient d'accord.

En matière de succession, notre but doit être d'introduire un peu d'équité dans la coutume, car elle en est dépourvue. Si même on pouvait être certain qu'une succession ne comportât que des dettes, je ne verrais pas d'inconvénient à ce que l'héritier fût dispensé de leur paiement. Ce serait une occasion de donner aux indigènes le sentiment des risques que font courir les opérations à crédit. Cette coutume de ne jamais payer comptant est une des plus désastreuses pour nos populations, une de celles qui entravent le plus, qui rendent même quasi impossible le développement économique de notre région, et du Gabon d'ailleurs tout entier. Il est bon de lutter contre elle chaque fois que les circonstances nous le permettent.

\section{$\S 4$}

\section{Des testaments}

A bien examiner la situation de l'héritier, telle que je viens de l'exposer, on pourrait dire sans doute qu'il est, bien plus qu'un héritier, un exécuteur testamentaire et un légataire. La volonté du de cujus qui l'a de son vivant initié à ses affaires dans l'intention qu'il les prît en mains, l'a formellement désigné. Il y a eu là, en quelque sorte, testament de fait, sinon explicite.

Il y en a de plus formels; sans doute, ne s'agit-il que de dispositions manifestées oralement par un mourant ou au moins par un vieillard; elles sont d'ailleurs rares, les indigènes évitant soigneusement de penser 
à la mort et à ce qui pourra, après eux, advenir de leurs biens.

Ciest le plus souvent un chef qui entend désigner son successeur et reut au détriment de son neveu, investir son petit-neveu, ainsi qu'il s'est produit à Loussala et Boucoulou en Mourindi.

D'ailleurs, les biens meubles, esclaves compris, peuvent faire l'objet de dispositions testamentaires. Seules, les épouses ne mont jamais paru en être susceptibles, sinon exceptionnellement.

J'ai cité ailleurs le cas où un oncle cède de son vivant une de ses épouses à son neveu. C'est un avancement d'hoirie; il est extrêmement rare.

Je dois encore citer une autre exception, car elle peut se représenter. C'est la suivante: Pambo Ndoumbo, chef de la terre d'Ilala (Subdivision de Tchibanga) est mort en 1908. Avant sa mort, il interdit à ses épouses de passer par héritage à ses ayant-droit. Vous retournerez, leur dit-il, chacune dans sa famille. La raison de cette disposition était la suivante: il avait de lourdes dettes vis-à-vis des familles de ses femmes; en leur rendant la libre disposition de cellesci, il trourait un moyen de s'acquitter et d'avoir, de son vivant, sans bourse délier, la paix avec ses créanciers. Il n'est pas douteux que la famille des femmes a accepté cette combinaison avantageuse; il est beaucoup moins certain que ses héritiers s'en soient déclarés satisfaits.

Les dispositions testamentaires formelles sont toujours rares et constituent de véritables exceptions. J'en ai connu peu d'exemples. Mais il en est un que je veux mentionner: celui d'un testament écrit. Il n'avait pas été rédigé par le testateur, Mwanda Nguimbi, dit Mbami, chef de la terre de Pembé, lequel est mort fort âgé le 29 Juillet 1910 ; mais il était censé avoir été rédigé pour lui.

Par ce testament, il instituait en sa place, non pas l'un de ses neveux, arec lequel il avait d'ailleurs vécu en fort mauvais termes, mais le fils d'un de ses frères. Je dois dire que j'ai des doutes sur l'authenticité de 
ce document et jaai toujours pensé qu'il avait été écrit à l'instigation du bénéficiaire après la mort du soi-disant testateur. Il n'en est pas moins vrai que le procédé méritait d'être signalé.

Quel compte devons-nous tenir des dispositions testamentaires ? C'est selon les circonstances. Si leur authenticité est certaine et que leur exécution ne doive pas provoquer de troubles familiaux, rien n'empêche de s'y conformer. Dans le cas contraire, et si nous royons que le testateur a voulu en faire un moyen de représailles, mieux vaut les tenir pour nulles et faire appliquer la coutume.

CHAPITRE IV

\section{DES CONTRATS ET DES OBLIGATIONS}

\section{$\S 1$}

\section{Considérations générales}

Les indigènes de notre région ne connaissent qu'une sorte de contrat: le contrat bilatéral et à titre onéreux.

De toutes les conditions requises par notre code pour la validité des contrats, on peut dire qu'aucune n'est considérée comme indispensable par les indigènes; ni le consentement des parties, ni l'objet certain du contrat, ni le caractère licite de la cause. A peine subsiste comme nécessaire la capacité des contractants; un hoomme ne conclura pas une convention avec un enfant, mais j'ai connu des exemples où l'un des contractants était plus d’à moitié dément.

Du consentement. - Il n'y a point à nos yeux de contrat sans consentement. Tout autre est l'avis des indigènes, et fréquemment la convention se conclut à l'insu d'une des parties: l'emprunteur, par exemple, s'abstiendra de consulter son prêteur. Pour nous, l'acte 
ainsi commis constituerait un vol pur et simple; pour nos administrés, il y a là bel et bien contrat de prêt parfaitement valable.

A quoi tiennent cette désinvolture des uns, cette soumission des autres? A cette crainte perpétuelle des sorts qui assiège les indigènes, à leur souci de ne point s'aliéner la bienveillance d'un voisin, d'un parent, d'un ami; rebuté dans sa requête, le solliciteur pourrait prononcer des paroles, jeter un maléfice, et quels risques ne courrait-on pas! La crainte des représailles, avouée ou non, vicie donc bien souvent le consentement d'une des parties contractantes.

Il ne s'agit plus maintenant, je dois le dire, de violences ouvertes; l'usage en est abandonné. Ce que l'on craint, c'est l'empoisonnement et plus encore l'envoûtement.

S’il y a doute souvent súr la liberté du consentement donné par les parties, un point doit être mis hors de discussion: leur mauvaise foi. On peut toujours la présumer: le vendeur tardera longtemps à livrer la chose vendue; l'acheteur fera attendre le paiement. Au fond, la pensée de chacun des contractants est d'obtenir l'exécution de la promesse formulée par l'autre partie, et de s'abstenir si possible de sa propre obligation.

C'est là ce qui rend si aléatoires les affaires avec les indigènes; ils ne sont pas commerçants, mais voleurs.

De l'objet et de la matière des contrats. - Cette duplicité les amène à laisser dans l'indétermination tout ce qu'il est possible d'y dissimuler: un homme voulant se marier donnera des marchandises pour avoir une femme. Quelle femme est en cause? Quand la livrera-t-on? Quelle sera la nature, la modalité, le terme du paiement? On n'en sait. rien. - Un autre veut acheter une chose déterminée, disons, un mouton. La bête n'est pas désignće. ni davantage le prix fixé.

Ajoutons que l'indigène, très discret en ce qui concerne ses affaires, n'appelle jamais de témoins à la conclusion des conventions; tout au plus un confident 
habituel, ou quelques membres peu nombreux de sa famille proche en ont connaissance, dont le témoignage intéressé ne saurait guère être admis en cas de litige.

On voit par tout ce qui vient d'être dit sur la valeur du consentement des parties, et à propos de l'objet des contrats, combien il est difficile parfois de départager les indigènes dans leurs palabres.

Entre eux, s'ils ont chargé un chef de ce soin, ce dernier s'en tient à un moyen terme. Il ne donne pleinement tort ni raison à aucune des parties en cause. L'équité est ainsi quelquefois méconnue, mais elle l'est le moins possible; en tout cas, l'arbitre a obtenu deux résultats: il a éteint le palabre, il ne s'est aliéné aucun des plaideurs et échappe aux représailles de la partie qui aurait succombé.

De la cause. - Les obligations contractées par les indigènes peuvent avoir une cause illicite. Je ne parle pas là des causes prohibées par la loi, telle que celle qui consisterait à livrer un esclave. J'entends parler de causes contraires à la morale, à l'équité naturelles: un individu, par exemple, offrira une dot dans le but de se faire donner en mariage une femme déjà légitimement en puissance d'époux; un autre paiera quelqu'un pour commettre un empoisonnement, un meurtre, un faux témoignage. Malgré ce caractère illicite de leur cause, ces conventions ne laissent pas, pour autant, d'aroir leur plein effet.

En résumé, rien de moins précis que les conventions conclues par les indigènes; l'origine, l'existence mêne du contrat, ses clauses, son effet enfin, tout est vague, mal défini. A peine l'aveu des parties peut-il entraîner notre conviction, le défendeur parlant souvent sous le coup des menaces du demandeur.

Notre tâche sera donc de mettre dans ces conventions de la précision, dy faire intervenir la bonne foi et l'honnêteté, de poursuivre et au besoin réprimer par des sanctions appropriées celles ayant une cause illicite.

Comment procèderons-nous ? La recherche dé la 
cause nous permettra de renvoyer certains plaignants: Nous serons guidés par le montant de la somme réclamée. Celui-ci réclame dix pièces; cela ressemble beaucoup à une indemnité d'adultère (boukali); nous ne pouvons guère admettre la légitimité de telles réclamations; tout ce qu'on peut offrir au mari plaignant, c'est de mettre sa femme en prison en même temps que le complice de celle-ci; il est rare qu'il accepte.

Un autre réclame à son débiteur de six à huit pièces. Il faut lui demander s'il ne s'agit pas là d'un esclave payé d'avance (yougha); et le décret de 1905 punit comme le délit, la tentative de trafic des personnes. On tiendra toutefois compte de certaines considérations: celui qui a donné l'avance a pu être tenté, celui qui l'a reçue a pu l'être également, ou même ne l'a acceptée qu'à son corps défendant.

La mauvaise foi du plaignant paraît-elle évidente, sans cependant mériter une sanction pénale? On refusera d'intervenir et on laissera tous les risques à la charge du cemandeur; il y a bien des chances pour qu'il ne soit pas payé; la perte de l'objét de sa réclamation lui sera un châtiment équitable.

Dans les litiges concernant les conventions où la cause est licite et l'objet suffisamment déterminé, il y a encore un choix à faire et nous pourrons, je crois, refuser d'examiner les palabres trop anciens, ceux transmis par héritage et dont les témoins ont disparu. Il n'y a qu'un arbitre indigène qui puisse régler des palabres de cette sorte.

Enfin, dans les litiges que nous aurons retenus, nous devrons chercher à établir par témoignage tous les éléments de la convention. Notre religion étant éclairée, nous prononcerons la sentence. Seulement, il faut tenir compte qu'elle doit, sous peine de déconsidérer notre justice, être applicable et le plus tôt possible, immédiatement même si la nature des conventions le permet.

Il faut se rappeler que la paix est le premier besoin 
dès indigènes. Je l'ai dit et m'excuse de le répéter si souvent.

Il pourra donc être opportun de plier nos principes d'équité aux exigences de ces deux circonstances. Lorsqu'une convention nous est présentée et que la seule exécution de celle-ci est en cause, notre conduite doit être de tempérer les exigences de celui qui en est le bénéficiaire actuel.

S'agit-il d'un paiement? Les pièces ne sont pas fraîches, les fusils sont un peu vieux, toutes les marchandises constituent un bric-à-brac un peu hétéroclite. Celui qu'on paye n'est pas satisfait. Il n'a peut-être pas tort. Mais le compte y est-il? Si oni, qu'il s'en contente. Il tirera le même parti de ces marchandises que si elles étaient neuves, et surtout le palabre est éteint. Et puis, si les rôles avaient été renversés, n’aurait-il pas agi de même?

S'agit-il d'un mariage? La future est bien jeune, elle ne rendra pas de sitôt les services qu'on attend d'elle. D'accord: mais enfin ces unions sont conformes à la coutume; le remboursement de la dot est improbable. Vieux vaut conseiller la patience au créancier et l'inciter à domner son assentiment.

II ne faut pas nous montrer intransigeants.

Enfin tenons compte des ressources du plaideur qui succombe. Imaginons qu'on lui réclame très légitimement soixante pièces. Nous pouvons le condamner à les payer, mais nous pouvons être assurés que le paiement en sera impossible. Réduisons donc la somme de moitié et, si le plaignant proteste, faisons-lui comprendre qu" "un bon tiens vaut mieux que deux tu l'auras » et qu'au surplus, il est juste qu'on porte la peine de ses maladresses; car c'en est une de faire ì un indigène une avance aussi importante.

En dehors du règlement des palabres et ì l'occasion de ces règlements, nous ne devons pas manquer de poursuivre l'éducation de nos administrés sur ce point spécial.

Les conventions sont toutes passées sous le régime de la mauraise foi; nous perdrions notre temps à leur 
prècher l'honnèteté en aflaires, ils ne nous comprendraient pas; mais nous avons quelques chances de les $\mathrm{y}$ amener peu à peu et malgré eux, et c'est en leur recommandant d'abord de traiter au comptant, et non à crédit, comme ils font toujours, puis de traiter en public et derant des témoins qualifiés.

A ce point de rue, il-serait souhaitable qu'ils nous fissent intervenir dans leurs conventions, qu'ils contractassent devant nous. Mais l'institution de cette coutume, malgré des avantages incalculables, présenterait de grandes difficultés, dont la plus importante est la distance qui sépare sourent les indigènes du chef-lieu de la Subdivision.

Malgré tout, chaque fois que nous serons priés dètre témoins d'une convention quelconque: emprunt, vente, mariage, prêtons-nous-y et constatons par un écrit les clauses du contrat; nous y gagnerons deux résultats: d'abord que ce contrat aura infiniment plus de chances d'être exécuté; ensuite que la besogne sera facilitée à celui de nos successeurs auquel sera soumis le litige toujours possible entre les parties en cause.

De l'effet des obligations. - Lincertitude qui plane sur les conventions, la mauraise foi qui préside à leur conclusion, ont une répercussion profonde sur l'effet de celles-ci.

L'indigène qui s'oblige à donner a bien l'intention de s'en tirer au moindre prix, et tous les fonctionnaires des Subdivisions ont été assurément témoins des comptes extraordinaires auxquels donnent lieu les remboursements en marchandises. Avec les raleurs conventionnelles dont se servent nos administrés, on peut grouper les objets présentés en paiement de plusieurs manières et obtenir, suivant le groupement, une somme différente.

Dans le même esprit, le père ou l'oncle qui reçoivent une dot n'hésiteront pas à offrir en mariage une fille qui n'est pas, tant s'en faut. nubile, et qui ne peut être pour son mari la compagne et la ménagère à laquelle son argent lui donne droit; les parents ne verront pas 
davantage d'inconvénient à donner une femme déjá en puissance; mais le jour ou le premier mari réclamera, ils feront tout le possible pour qu'il s'adresse au second, gardant ainsi les deux dots versées pour la femme.

S'agit-il de l'obligation de faire? On peut être assurć qu'elle sera exécutée avec le minimum de soins.

D'où vient donc que les indigènes n'évitent pas, dans toute la mesure possible, de contracter des obligations? Chacun sait en effet que leur vie se passe à conclure des conventions, d'où naîtront à coup sûr des palabres, et que c'est mème à peu près la seule occupation des adultes.

Les indigènes savent parfaitement les risques qu'ils courent; ils connaissent la mauvaise foi de leurs congénères, avouent la leur avec un sourire. Mais -avec l'orgueil qui fait le fond de leur nature, chacun d'eux est persuadé, qu'il sera plus fort, plus adroit, plus rusé que son cocontractant, et que, dans le palabre, il aura raison.

En outre, la prescription n'existe pas dans leur coutume. La perte de la chose, le décès du débiteur, les années qui s'écoulent n'éteignent pas la dette. Cinquante, soixante ans après la conclusion du contrat, on voit les arrière-neveux du contractant formuler des réclamations, défendre leur bien avec autant de sérénité que si la convention était de la veille. On peut en voir, malgré la disparition de tous témoins, reconnaitre la dette, transmise d'oncle à petit-neveu, accepter de la payer et quelquefois même l'acquitter. Le créancier, d'après la coutume, a donc un recours beaucoup plus étendu que suivant nos habitudes.

Enfin, la coutume donnait au créancier une sécurité quasi absolue de remboursement en consacrant son droit de prendre des otages, dans la parenté, dans la famille, ou même dans le voisinage de son débiteur. Et, bien que des sanctions sévères aient été déjà appliquées, bien que l'on y regarde à deux fois avant de se payer sur la personne, le sentiment du risque encouru n'est pas encore entré dans l'esprit de nos 
administrés; ils n'ont pas encore compris qu'il n'y a rien d'impossible à perdre, quelque jour, ce qu'on a prêté ou vendu à crédit.

De même donc que nous devrons, à l'occasion des conventions, enseigner à nos administrés à y introduire la précision, la certitude, la clarté indispensables, de même aussi nous devrons saisir toute occasion de leur inculquer les principes élémentaires de l'équité. Ils leur font totalement défaut.

Ce disant, je vais à l'encontre d'une idée couramment reçue et exprimée, à savoir que l'indigène possède naturellement la notion de justice. Je suis persuadé qu'il n'en a aucune idée.

Les voyageurs, quelle que fût leur qualité, ont constaté que les habitants voulaient souvent les faire intervenir dans leurs palabres, les mettaient au courant de leurs litiges, sollicitaient leur avis. Ils en ont conclu à l'existence de sentiments innés d'équité naturelle. Vanité de race! Ce que le noir recherche en faisant intervenir l'Européen, c'est un appui à sa thèse; c'est un argument pour pouvoir dire à son adversaire: tu vois, le blanc dit comme moi. Combien de fois n'avons-nous pas vu les palabres portés successivement devant plusieurs chefs de poste, et n'avons-nous jamais entendu un plaignant soumettre à l'autorité une affaire où, de toute évidence, il avait tort?

Des diverses espèces d'obligations. - Je n'ai pas constaté clairement que les obligations pussent être chez les indigènes, de nature particulière. L'imprécision qui caractérise leur conclusion exclut toute possibilité de les classer.

Dans quelques cas, cependant, j’ai cru reconnaître la solidarité: solidarité entre les créanciers, solidarité entre les débiteurs.

Les auteurs d'une femme: son père, ses oncles maternels, ses frères germains ou utérins le cas échéant. semblent bien être solidairement créanciers du futur pour le montant total de la dot. Toutefois, après de plus longues réflexions, je serais porté à croire que, 
au moins dans le cas du premier mariage d'une femme, e'est le père qui est qualifié pour la recevoir, quitte à la répartir imniédiatement ou ultérieurement entre les ayant-droit.

En fait, tous les ayant-droit seraient parfaitement disposés à recevoir chacun la totalité de la dot pour peu que le futur se laissât faire. Il faut tempérer ces cupidités.

Autre exemple de solidarité: tous les héritiers possibles d'un défunt, au moins ses parents proches: neveux et frères utérins, peuvent indifféremment se voir réclamer les dettes du de cujus. Les créanciers ne se préoccupent pas s'ils ont tiré quelque bériéfice de la succession.

Là aussi il nous faut mettre un peu de justice. Je l'ai exposé plus haut.

Mais ces cas de solidarité ne sont pas explicitement prévus par la coutume, ils ne résultent que de son imprécision. En réalité, je n'y vois que des obligations simples: obligation de donner, obligation de faire.

De l'extinction ides obligations. - Notre code a prévu de nombreux modes d'extinction des obligations. Les idées de nos administrés ne sont point assez développées pour être allées si loin dans les notions juridiques.

Ils ignorent la novation. Toutefois, j'ai vu des cas où un créancier aurait très bien accepté de se faire payer par un débiteur solvable de son débiteur qui ne l'était point. Il va sans dire que ce dernier n'entendait pas de cette oreille.

La même novation par changement de débiteur était quelquefois proposée par le débiteur lui-même. Mais je dois dire que le débiteur nouveau était plus insolvable que le premier et qu'il y avait mauvaise foi de celui-ci.

Je n’ai jamais vu de substitution de créanciers : l'âpreté au gain de nos indigènes en exclut la possibilité.

Il pourrait être utile de développer ces idées embryonnaires sur la novation. Il y a là un moyen de 
diminution du nombre des litiges qui absorbent une si grande partie du temps des adultes. Imposer une novation, et la faire accepter des trois intéressés, c'est régler d'une seule fois deux palabres, et le résultat vaut deetre poursuivi; mais je ne saurais trop recommander de ne prendre cette décision, quavec l'assentiment explicite de tous, et de la constater par ćcrit.

L'indigène n'a pas l'idée qu'on puisse remettre une dette. A peine semblera-t-il l'oublier; on peut être sùr que l'oubli est temporaire et motivé. L'indigène, je l'ai dit, ne sait pas ce que c'est que donner.

Il ne connaît pas davantage la compensation, il ne la comprend miême pas et c'est grand dommage; car ce serait encore un moyen d'éteindre d'une seule décision deux ou plusieurs litiges.

Nais il faut se rappeler que dans toute convention, l'un des deux contractants est de mauvaise foi, sinon même tous les deux. Ils n'envisagent comme bénéfice de l'opération que la chance de ne pas être forcés d'exécuter ce qui leur en incombe. Si donc un indigène est en même temps débiteur et créancier d'un autre, il lui dira: paie-noi d'abord et je te paierai après, bien résolu à reporter cet " après " aussi tard que possible.

Je ne vois trace de compensation que dans certains litiges matrimoniaux compliqués où les membres de deux familles se réclament réciproquement des fenlmes et des dots.

Quelquefois, l'arbitre indigène les résout en décidant que telle dot due par une des parties compense telle femme due par l'autre. Mais la compensation n'est jamais de droit: c'est l'arbitre qui l'impose.

Pour nous, il va sans dire que nous devons, chaque fois que loccasion se présente, compenser dettes et créances. Mais ce n'est pas tout que de l'imposer, il faut le faire comprendre. Pour cela, il n'y a qu'un moyen: c'est de mettre dans les mains des parties des pièces de monnaie en quantité suffisante pour que chacune d'elles puisse payer effectivement sa dette. On fait opérer les paiements en sa présence successi-

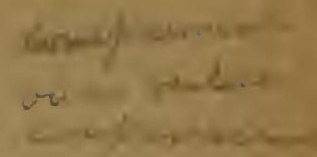


vement par les deux parties, puis on leur montre que deux opérations sont inutiles et qu'une seule, la compensation, arrive au mème résultat. Toutefois, il ne faut pas nous flatter davoir convaincu personne. Celui au bénéfice duquel la compensation s'est faite ne recherchait point ce résultat; il voulait la créance tout entière, bien décidé à ne payer. sa dette que le plus tard possible. Le but que nous devons poursuivre, ce n'est point tant de satisfaire les parties, que de leur faire comprendre le mécanisme de l'extinction de deux dettes, et d'obtenir la liquidation siniultanée de deux litiges.

Je ne conçois pas que la qualité de débiteur et de créancier puisse se réunir dans le mème indigène. Cette confusion ne pourrait se faire que par héritage. Or, d'une part, on n'hérite que de ses proches parents, et, de l'autre, on ne contracte pas d'obligation entre proches parents. - En droit, les membres d'une même famille, ne vivent pas dans la communauté, dans l'indivision des biens; la propriété est bien individuelle. En fait, l'oncle, le frère aîné disposent à peu près librement de ce qui appartient aux neve,ux, ou aux cadets, et, à leur tour, les aident asscz libéralement de_leurs ressources...Il ne peut y avoir guère entr'eux que des obligations morales.

La perte de la chose n'entraîne pas non plus l'extinction de la dette. Je n'ai en effet autant dire jamais vu un indigène acheter à un autre indigène, une chose déterminée. Il achètera des moutons, des poules, des nattes, un fusil, etc., etc.; il donnera des marchandises pour avoir une femme,-in genere.-N'importe quelle femme, quel mouton, quel fusil, peuvent convenir et satisfaire à l'obligation. Il y a mieux. Les marchandises, espèces comprises, ont des valeurs correspondantes conventionnelles, qui sans doute ont une assez lointaine origine. On peut donc payer, par exemple, un mouton avec des poules, des pièces, des fusils. On peut dans une dot remplacer ce mouton par deux pièces. Une pièce équivaut à 5 francs ou à 10 poules ou à un fusil usagé, ou à 60 boules de caoutchouc. Et, enfin, 
une fenime en raut une autre; jamais, autant dire, une dot n'est payée pour une femme déterminée. La précision en ce qui la regarde ne va pas plus loin que déterminer la famille à laquelle elle doit appartenir.

Je ne vois pas d'inconvénient à nous conformer à ces usages.

Dans un cas toutefois, celui du contrat de gardiennage de bétail, le gardien qui a reçu des moutons est tenu de restituer des moutons et, autant que possible, ceux mêmes qu'il a reçus; c'est rarement réalisé. Mais là encore la perte de la chose ne dispense pas du remboursement. Ni le cas fortuit, ni la force majeure ne sont des excuses valables pour le débiteur. Nous reviendrons là-dessus plus tard.

De la nullité et de la rescision. - Il n'y a pas d'obligations nulles pour quelque cause que ce soit; la coutume ne connait pas de causes illicites.

Elle n'imagine pas non plus qu'on puisse attaquer la validité d'une obligation pour cause de lésion. Gens simples, les indigènes trouvent que plus une affaire est avantageuse, mieux cela vaut. Tromper, voler ne constitue pas une mauvaise action; c'est de l'adresse, tant pis pour les victimes. Il n'y a pas trop à les plaindre d'ailleurs; c'est toujours plus ou moins un prêté pour un rendu.

Nous devons cependant être équitables à leur place, et, dans certains contrats de prêt, par exemple, abaisser les exigences du prêteur.

Mais ces cas sont rares; les choses ont une valeur conventionnelle entrée si profondément dans la tradition, que la tromperie n'est guère possible.

De la prescription. - La prescription est-elle admise par la coutume? Il faut distinguer.

En droit, en théorie, certainement la prescription n'existe pas. L'indigène, simpliste et àpre aux questions d'intérêt, n'imagine pas que rien, ni personne, et le temps moins que tout le reste, puisse l'empêcher de poursuivre l'obtention de tout ce qu'il considère comme son droit; aussi voit-on fréquemment soumettre à notre examen des litiges présentés par les 
petits-neveux de ceux qui les ont créés. Une, deux, trois générations se sont écoulées; les auteurs de l'obligation contestée sont morts, les témoins sont morts. Il n'importe; l'intéressé n'abandonne pas la partie.

En est-il toujours ainsi? C'est là précisément que jai des doutes. Sil s'agit d'un individu de mince importance, de quelque paurre hère, si le plaignant n'a pas su se concilier la bienveillance de l'arbitre, il y a des chances pour que ce dernier invoque l'anciennelé du différend et refuse de le trancher. Donc, en fait, quelquefois la prescription est admise, mais c'est sûrement exceptionnel et irrégulier; dans ce cas, elle n'est pas opposée par la partie adverse; elle est imposée par l'arbitre.

Pour ce qui nous regarde, si grande puisse être notre bonne volonté à régler les palabres des indigènes, en tenant compte de leurs usages, nous ne pouvons-pas ne pas admettre la prescription. Toutefois, si le demandeur s'y résigne mal, si l’intérêt lésé paraît important, si nous avons lieu de craindre des représailles du plaignant sur le défendeur, il conviēnt de renvoyer les parties devant un arbitre indigène. Celuici a chance de voir clair là où nous ne distinguerions pas la vérité et il est fort probable que la sentence sera admise. Il nous en rendra compte devant les parties et nous la confirmerons de notre autorité.

Du paiement. - En réalité, il n'existe qu'un mode d'extinction des obligations: le paiement. Nous en traiterons au paragraphe suivant.

Des différentes espèces de contrats :

\section{De la vente ou de l'échange. - Du paiement}

La vente est la plus commune des conventions conelues entre les indigènes; c'est aussi, le mariage n'en 
étant en somme qu'un cas particulier, celle qui occisiome le plus de litiges. Elle est, en effet, de toutes les conventions, celle qui est entourée de moins de certitudes.

Disons dabord qu'il ne s'agit encore que bien rarement de vente proprement dite, c'est-à-dire, de cession d'une chose contre des espèces monnayées. La monnaie a cours chez nous, on connaît dans quelques régions assez mal sa valeur, mais au moins saiton qu'elle en a; seulement dans la plus grande partie peut-être de la Circonscription, on ne l'emploie qu'à un seul usage, on ne la recherche que dans un seul but: le paiement de l'impôt. La monnaie a donc encore absolument son caractère de marchandise; aussi les indigènes ne disent pas: se procurer de l'argent, échanger un produit contre de l'argent, ils disent: " acheter de l'argent".

Dans presque toutes les conventions du genre qui nous occupe, il n'est donc question que d'échange, et la langue indigène nous l'indique encore clairement. L'échange est une convention. comment dirai-je?, symétrique; chacune des parties fait un acte identique, poursuit un but semblable: donner un objet de consommation contre remise d'un objet également de consommation. L'action étant la même, la langue le reflète avec précision: acheter et vendre se traduisent par le même vocable: Sumba. Et l'on n'a pas manqué d'être comme moi surpris d'entendre un indigène, voire un de nos gardes Soudanais, confondant les mots français, acheter et vendre, nous montrer un objet de fabrication européenne, et nous dire qu'il l'a "vendu " chez tel commerçant.

Pour ne pas être trop déroutés par les singularités que nous rencontrerons dans la vente, et encore toutes ne s'expliquent pas, il faut nous rappeler que la mauraise foi préside à toutes les conventions ; que les marchandises ont une valeur conventionnelle bien antérieure à celle qu'elles possèdent aujourd'hui, et souvent assez différente de celle-ci. la plupart du temps inférieure. Il en résulte ceci: c'est qu'un indi- 
gène qui procède à un échange, et ils ont un goût prononcé pour le trafic, se trouve dans l'impossibilité d'y trouver un bénéfice, s'il opère dans son pays, et s'il ne vole pas. Le mieux qu'il puisse lui arriver est de ne rien perdre.

Lors donc qu'un indigène veut procéder à une opération commerciale, son premier soin est de tâcher de l'entamer à crédit ou à peu près. Il veut acheter, par exemple, un mouton qui vaut deux pièces (checks de 16 yards en 12 plis); il prendra un pagne bordé, ira trouver quelqu'un qu'il sait posséder un mouton et lui fera des offres: J'ai besoin d'un mouton, tu en as un, donne-le moi; prends toujours ce pagne, je te paierai plus tard. La réponse peut être un refus; si la contre-partie accepte, elle prend le pagne et répond: Entendu, je prends le pagne; va-t-en chez toi, je te ferai porter le mouton.

On remarquera que le prix du mouton n'est pas mis en question: mâle, femelle, grand, petit, l'acheteur ne l'a pas vu, il n'importe; le prix est le même; il s'agit d'un mouton " in genere ". Cela se comprend.

Mais, ce qui se comprend mal, c'est que ni la date de livraison du reliquat, ni celle de la remise du mouton, ni la nature des marchandises, rien n'est fixé. Encore ai-je été bienveillant en supposant qu'on a versé un acompte sur le mouton. Bien souvent on n'en verse aucun.

Dès lors, l'exécution des deux parties de l'obligation traînera en longueur, l'acheteur tâchant d'obtenir le mouton contre le seul pagne bordé, le vendeur faisant le possible pour se faire donner les deux pièces sans livrer le mouton.

Pour bien voir cependant les multiples incidents provoqués par le paiement, il convient de prendre comme exemple une dette plus importante, telle que serait un remboursement de dot; estimons-le entre 20 et 30 pièces.

Le débiteur a reconnu la dette; signalons d'abord le procédé de reconnaissance, en quelque sorte, par acte authentique. Le débiteur qui s'avoue tel, remet à son 
créancier un objet de peu de valeur; un couteau, une machete, un paquet d'arachides; quelquefois il donne ce qu'on appelle Cama na Combo, littéralement (et théoriquement) : cent boules de caoutchouc et un mouton, ces marchandises pouvant être représentées par toutes autres de valeur égale.

La dette est donc reconnue, mais aucun terme n'est fixé pour le paiement: le temps passe donc, le créancier ne voit rien venir, il s'inquiète. Mais il n’ira cependant pas toujours lui-même relancer son débiteur, il y enverra quelqu'un de ses relations. Première complication. Le débiteur n'a rien, il dit à l'envoyé: Prends patience encore un peu, je porterai bientôt ce que je dois. En attendant, prends cette poule.

Pas plus que "Cama na Combo ", cette poule n'entrera en ligne de compte dans le paiement de la dette. Elle n'est qu'une confirmation de la reconnaissance.

Et les poules succèdent aux poules.

Enfin, le débiteur a réuni quelques marchandises, mais il n'ira pas les porter lui-même, il enverra quelqu'un. Deuxième complication.

Ce mandataire en effet entend bien ne pas se déplacer pour rien; on lui a donné 10 pièces à porter, il en prendra, par exemple, une. Arrivé chez le créancier, il dira: Un tel m'a chargé de te remettre ces marchandises. Au jour du règlement des comptes, le débiteur jurera qu'il a donné 10 pièces et le créancier, avec non moins de sincérité, qu'il n'en a reçu que 9 .

Mais une autre difficulté se présente quelquefois et aussi bien pour les paiements de peu d'importance, que pour ceux tels que celui qui nous sert d'exemple.

Le créancier à qui l'on veut faire un paiement, le refuse en disant: On me doit 30 pièces, je veux 30 pièces ensemble. C'est rendre le paiement impossible, car un indigène possède rarement un stock aussi important de marchandises.

Dernière difficulté enfin, le créancier refuse telles ou telles marchandises, soit à cause de leur mauvais état, soit en raison d'une préférence personnelle.

On voit combien le paiement devient entre les indi- 
gènes une chose compliquée, et cela par suite de l'imprécision voulue qui préside à la conclusion des conventions.

J'ai essayé en vain de m'expliquer la raison qui conduisait les indigènes à poursuivre les paiements et à les effectuer par mandataires. Je n'y ai jamais trouvé de justification, si ce n'est peut-être le désir de créer par là des témoins à la convention et au paiement.

Il va sans dire qu'il serait plus simple de les choisir au monent même de la convention et du paiement. Mais sans doute serait-ce trop simple pour ces mentalités primitives.

Ce que j'ai pu dire au début de ce chapitre sur notre rôle dans ce qui a trait aux obligations, s'applique particulièrement à l'échange et au paiement.

Nous devrons donc faire tous les efforts possibles pour amener les indigènes à traiter au comptant. Si l'obligation est à terme, qu'ils la formulent devant des témoins qualifiés, el autant que possible étrangers à leur famille.

Qu'ils en stipulent clairement les clauses: terme du paiement, nature des marchandises; qu'ils renoncent à l'ermploi des intermédiaires. Ceux-ci étant toujours en relations intimes avec l'une des parties, ne sauraient apporter un témoignage recevable; et, s'ils n'ont plus ce rôle de témoins, ils n'en ont aucun. Leur intervention ne sert qu'à compliquer les choses.

Prêchons l'honnêteté aux deux parties, surtout au débiteur qui doit se libérer en marchandises loyales et en bon état. Recommandons la patience au créancier, et obtenons de lui qu'il ne se montre pas trop difficile: une marchandise en vaut une autre, au moins tant qu'il n'y a pas excès de désinvolture.

Mais n'imposons notre volonté expresse qu'en dernier recours. En matière civile et commerciale, en effet, notre juridiction est absolument inefficace, illusoire; il nous est radicalement impossible de faire payer un débiteur qui s'y refuserait. Le recouvrement de l'impôt en donne des preuves quotidiennes.

Si un indigène se refuse à payer une dette et qu'on 
le laisse en liberté, il ne paie pas. Si on le met en prison, outre que son entretien est aux frais du créancier qui verra augmenter sa perte, (Décret du 14 Déc. 1910), ce débiteur, qui ne possède aucun bien liquide, réalisable, dira très judicieusement: Je suis en prison, je ne puis me procurer les moyens de payer.

Il est donc important de n'imposer à nos justiciables que des charges qu'ils puissent porter, de ne rendre en ces matières que des arrêts exécutables: l'équitable estimation des sommes dues, la division et l'échelonnement des paiements, la diminution des prétentions des créanciers nous permettront d'y parvenir. Et si ces créanciers éprouvent des pertes, il ne faut pas trop les en plaindre: elles leur enseigneront la prudence en affaires; si, par elles nous arrivions à restreindre les transactions à crédit, nous aurions obtenu un grand résultat.

Des avances. - Je voudrais dire un mot des avances consenties par le commerce européen. Elles sont assurément une des coutumes les moins recómmandables et un des obstacles les plus sensibles au développement économique. Elles sont en outre d'un usage général.

D'aucuns ont pu dire que le commerce était luimême responsable de cette institution; je n'en crois rien. Les transactions à crédit sont à peu près les seules pratiquées entre eux par les indigènes; il n'est pas douteux qu'au début de leur installation, les Européens se sont conformés à l'usage; en tous cas, les intermédiaires indigènes qu'ils employaient et emploient encore, les traitants, ne l'ont pas abandonné.

J'en signalerai, sans y insister, les inconvénients: c'est d'une part, d'élever le prix de vente des marchandises importées. Les avances augmentent les risques: il faut les compenser.

C'est, d'autre part, de diminuer la qualité des produits achetés. On est porté, pour rentrer dans les avances consenties à un débiteur très en retard, à tout accepter de ce qui vient de lui.

Quel doit être notre conduite au regard des avances? 
Je ne puis guère là-dessus donner que des conseils; les litiges soulevés par cette question sont de la compétence du tribunal européen, puisque un Européen $\mathrm{y}$ est partie. Leur solution ne nous concerne pas. Mais nous pouvons prendre des précautions.

Avances à nos auxiliaires indigènes. - Elles sont parmi les plus déraisonnables; ces indigènes ont généralement des soldes peu élevées; les gardes régionaux, le plus grand nombre, sont assez instables et peuvent être changés d'affectation même au courant du mois.

Si le poste est voisin d'établissements commerciaux, ne laissons pas ignorer à leurs tenanciers que nous sommes entièrement hostiles aux avances, - qu'elles sont consenties à l'encontre des intérêts de l'indigène et le plus souvent dans une mesure disproportionnée avec ses réssources, - que nous entendons donc ne pas intervenir entre le créancier et le débiteur, intervention qui au surplus est de la compétence du tribunal français.

Avances consenties par les traitants. - La question a deux faces, au point de vue du traitant, au point de vue des indigènes ses clients.

Le contrat qui lie un traitant à une maison de commerce, est souvent un contrat de mauvaise foi. Mauvaise foi, de la part du traitant: il ne voit, dans la situation qu'il accepte, qu'une occasion de bien vivre à peu de frais; mauvaise foi, malheureusement, trop souvent, de la part du commerçant; celui-ci se propose, en effet, d'éliminer, grâce aux clauses du contrat, tous les risques inhérents à ses opérations commerciales.

Quelles sont ces clauses? Il est stipulé généralement un salaire, une ration, des commissions. La ration, ou plutôt sa valeur représentative en espèces ou marchandises, est touchée mensuellement, ou prélevée par le traitant sur son stock ou dans sa caisse.

Le salaire est porté au compte du traitant, et il lui est loisible d'en recevoir de temps en temps, une fraction, la plus forte partie restant en compte-courant. 
Les commissions sont établies à chaque remise de produits, au moins tous les six mois à chaque inventaire, et le compte en est crédité.

Jusquici rien à dire. Nais on ajoute le plus souvent la clause suivanie: Il est interdit au traitant de faire des avances; - ou bien: les avances consenties par-le traitant, le sont à ses risques et périls.

Or; aucun commerçant n'ignore qu'il est impossible actuellement à un traitant, j'entends, un traitant de la brousse, de faire des affaires sans avances. Cet employé est donc mis dans l'alternative suivante: ou bien il ne fera pas davances, alors il ne fera pas d'affaires et sera remercié comme incapable; - ou bien il fera des avances, fera des affaires, nais comme toutes ses avances ne rentreront pas, il verra diminuer sa rétribution. C'est donc un contrat au moins léonin. Il est rare que le compte du traitant se balance sans qu'il y contribue de ses salaires ou de ses commissions.

Je sais bien que le traitant est sujet à caution; maître d'un stock de marchandises, il se laisse facilement tenter. Mais ce manque d'honorabilité n'est point nouveau, ni exceptionnel. Tout le monde est renseigné là-dessus.

Comment donc admettre qu'une maison de commerce confie une valeur importante en marchandises à un individu, suspect a priori, insolvable toujours, dont elle ignore tout: l'origine, le domicile, le passé et bien souvent le nom? - De sa part c'est une inconséquence et elle en devrait porter la peine. A un Européen se présentant dans les mêmes conditions, on ne confierait pas cinquante centimes de marchandises.

La Justice devrait se montrer clémente pour les traitants malheureux; sa bienveillance pourrait amener un excellent résultat, celui de faire renoncer au commerce sur avances.

Les chefs de Subdivision ou de Circonscription doivent-ils intervenir entre le traitant et ses débiteurs? Non.

D'abord, le traitant n'est que le repréșentant d'un 
Européen; ce dernier est le véritable créancier et la Justice de Paix est seule compétente.

Ensuite que pourrions-nous faire? On ne peut faire payer un indigène qui s'y refuse. Il resterait la ressource de la contrainte par corps. Je doute que le traitant accepte d'augmenter sa créance des frais d'entre_ tien du débiteur récalcitrant.

On a dit: Il faut punir l'indigène qui a pris des avances. Ce n'est ni juste, ni pratique.

Ce n'est pas juste, car en prenant des avances, l'indigène n'a fait que se conformer à un usage aussi vieux que sa race; et puis sait-on bien dans quelles conditions les avances ont été faites? Quelles sollicitations a subies l'indigène? De quelle contrainte souvent il est victime?

Il y a dans tous les cas des circonstances atténuantes.

Ce n'est pas pratique. Et, en effet, à rechercher tous les indigènes bénéficiaires d'avances, notre personnel ne suffirait pas. Il est beaucoup plus simple de supprimer le mal dans sa cause que dans ses effets. Qui est responsable des avances? Le commerçant ou au moins le traitant. Punissons le traitant. Aussi bien on ne peut punir celui qui reçoit des arances et absoudre celui qui les donne; l'acte de l'un est aussi répréhensible que lacte de l'autre.

Pourtant, jamais il n'a été question de punir le traitant, encore moins d'interdire au commerce un procédé d'usage ancien. Rien d'étonnant. C'est qu'en somme, pour nuisible que soit la coutume de donner des avances, de faire du commerce à crédit, elle n'a en soi rien d'illégal et il n'est pas possible de l'interdire. C'est affaire aux commerçants en général, aux traitants en particulier, d'apprécier si les risques encourus sont compensés par les bénéfices éventuels. Autrefois les risques étaient nuls et le traitant se payait sur les personnes de ses créances irrecouvrables; il emmenait comme otages on même comme esclaves des femmes, des enfants de la famille de son débiteur et l'opération n'était pas mauvaise. Chez nous, même à la côte, un esclave ne vaut pas plus de 
50 franes; dans l'Ogooué, à Libreville, il se vend trois fois plus cher.

La surveillance que nous exerçons empêche de plus en plus ces transactions inadmissibles. Sans doute, it force de voir leurs créances non recourrées, les traitants saviseront qu'il faut être plus circonspect.

Il y a une tendance très nette actuellement à réagir contre la coutume des avances. Il la faut encourager avec patience et persévérance. L'évolution sera longue pour une raison assez simple, c'est que le commerce ne fournit aux indigènes que des choses inutiles, des objets dont il n'a pas un besoin indispensable, et dont il peut très bien se passer. Toutes les dépenses qu'il effectue dans les maisons de commerce sont des dépenses somptuaires. Il est donc à souhaiter que le commerce ait la constance de supporter la période de stagnation des affaires que ne manquera pas d'amener la suppression des avances; si elle est obtenue, c'est un des plus réels progrès dont la Colonie puisse se féliciter.

\section{$\S 3$}

\section{Du contrat de louage d'ouvraxe}

Je n'ai jamais connu d'exemple d'un contrat où l'on stipulât le louage des choses, sauf un cas peut-être et peu fréquent; il s'agissait du prêt d'un fusil à titre onéreux.

Je n'y ai noté qu'un seul détail digne de remarque, à savoir la disproportion entre la valeur de la chose et le prix de location. Le bailleur avait fixé ce prix à 5 franes, ce qui était alors le tiers ou le quart de la valeur de l'arn:e. Rien d'autre d'ailleurs n'était prévu; il n'avait pas été question cle la durée de la location et la coutume ne prescrit rien quant aux conventions de ce genre:

Les contrats de louage d'ouvrage sont d'un usage plus courant; j'ai noté les suivants: contrat pour préparer une plantation, - pour chasser, - pour guérir 
un malade. Ce dernier est de tous, hélas, le plus fréquent.

La convention qui a pour objet la préparation d'une plantation est exceptionnelle. Enfant ou jeune homme, l'indigène travaille pour ses auteurs: père et mère, oncles et frères aînés, sans rémunération. L'entretien qui lui est fourni ne peut être considéré comme un salaire; il le recevrait quand même il se refuserait à rendre aucun service. Nous l'avons dit en traitant des obligations naissant du mariage.

Marié, l'homme bornera son effort aux plantations qui sont nécessaires à lui-même et à la femme qui sera longtemps son unique épouse. Agé, c'est-à-dire, chef d'une famille, ce seront les jeunes gens qui travailleront pour lui, avec les esclaves qu'il aura acquis par achat ou héritage.

On peut dire que, à aucun moment de la vie, l'indigène n'éprouve le besoin d'associer à titre onéreux quelqu un à son labeur.

Il est donc exceptionnel de voir intervenir la convention dont nous nous accupons. Je ne l'ai observée que dans un seul cas: il s'agissait d'employés d'Européens, étrangers ou non à la région, et qui, pour ne pas avoir à acheter leurs vivres, préféraient les tirer d'une plantation à eux personnelle: leur service ne leur laissant pas le temps de se livrer à ce travail, ils le faisaient exécuter par des hommes à leur solde.

Toutefois, la convention était bien dans la coutume d'après les renseignements recueillis et n'était point inconnue.

Notons que le travail est toujours dans ce cas, à forfait (le prix traditionnel est de 20 francs); ce qui fait l'objet de la convention, ce n'est point tant de journées de travail, dont le compte s'établirait à la fin de l'ouvrage, c'est une plantation. Il faut dire que la seule clause implicitement fixée est que le travail doit être achevé en temps opportun; car, hors le prix, qui est de tradition, rien n'est prévu: ni la surface de la culture, ni la manière dont elle sera complantée, ni le nombre de plants qui y seront contenus. 
Un autre cas de louage douvrage est le contrat du chasseur. Il est moins rare que le précédent, mais il est loin d'être commun.

Les chasseurs de métier, en effet, sont rares dans notre région; le fusil y est beaucoup plus une monnaie d'échange qu'une arme dont on fait usage. Ceux mêmes qui se livrent volontiers à la chasse sont très peu observateurs; ils n'ont de leurs constatations quotidiennes tiré aucune conclusion sur les mours des animaux, et, si vous les changez de localité, ils vous disent très sincèrement: Je ne peux pas chasser ici, je ne connais pas la brousse de ce pays.

En outre et surtout, la coutume apporte un obstacle considérable à ce qu'un chasseur travaille pour autrui. Les femmes n'ont le droit de manger ni poule, ni canard, ni mouton, ni cabri, encore bien que, la plupart du temps, poules et canards leur appartiennent. La chair de' ces bêtes fait pour elles l'objet d'un interdit formel et rarement transgressé. Les compagnes de nos gardes régionaux l'enfreignent quelquefois, mais s'y soumettent de nouveau dès qu'elles rentrent dans leur village.

La seule viande qui leur soit permise est celle provenant de la chasse et de la pêche. Si donc elles voient un homme de leur parenté: fils, frère, époux, chasser et ne pas leur donner de gibier parce qu'il travaille pour le compte d'autrui, ce sont des protestations sans fin, des réclamations impératives, et, de la part de l'épouse, des menaces de séparation. Le résultat le plus fréquent est que le chasseur détourne une partie de son gibier, ou qu'il refuse de continuer son service. La difficulté qu'éprouvent les Européens à se procurer des chasseurs n'a pas d'autres causes.

Dans le contrat du chasseur, comme dans celui de l'ouvrier de culture, la nourriture est implicitement stipulée. En outre, le chasseur n'est pas toujours tenu de fournir le fusil; la poudre est procurée par l'employeur. Rien d'autre n'est fixé d'avance; ni la rétribution, ni la durée du service, ni le minimum des pièces de gibier. Aussi les litiges ne sont pas rares. 
Ils soht peu faciles à apaiser, car il n'est point comnode d'établir le compte du gibier tué, moins encorc dacquérir la certitude cưil a été apporté à l'ensployeur.

Il faut noter daifleurs que ces chasseurs s'attaquent rarement aux grosses bêtes; le plús souvent ils ne présentent en compte que de petits animaux: singes, rongeurs, perdrix, antilopes de petite taille. Rares sont les spécialistes qui affrontent le bœuf et surtout l'éléphant. Encore ne le font-ils qu'après des cérémonies qui durent plusieurs jours et auxquelles leur arme ęlle-même se trouve soumise.

De tous les contrats de louage d'ourrage, le plus Iréquemment constaté est celui du Médecin.

Il existe des médecins indigènes qui exercent en dehors de toutes pratiques fétichistes, bien que, le plus souvent, formules magiques et prescriptions thérapeutiques soient appelées à concourir à la guérison.

Les conventions qui règlent l'intervention du médecin sont intéressantes et méritent quelques détails.

La classification des maladies par les indigènes es! sommaire: on a mal à la tête, à la poitrine, au ventre, on a des douleurs généralisées; puis viennent les affections à manifestations extérieures ou résultant d'accidents: enflures, ulcères, fractures, blessures, maladies vénériennes, hydrocèles.

Toutes ces affections ou lésions, mèmes celles ayant pour cause un accident, les indigènes ont des tendances à leur attribuer pour origine la malveillance. Toutefois, ils ont une idée de la contagion et répugneront à employer la case, le lit d'un malade. Par suite, d'une inconséquence très compatible avec leur versatilité d'esprit, ils n'hésiteront cependant pas à se servir de la vaisselle, de la pipe, de la femme même d'un ulcéreux quelconque, d'un vénérien confirmé.

, Les médecins eux-mêmes, qu'ils soient plus ou moins sorciers, sont spécialisés dans les diverses maladies; celui qui soigne, par exemple, la blennorrhagie ne connaît rien aux fractures et les affections de la poitrine lui sont étrangères. 
Donc, un indigène tombe malade; la famille se net cn quête du médecin spécialiste convenable el transporte son parent au village de celui-ci, call l'homme de l'art ne se déplace pas!

Rien n'est plus lamentable que ces voyages où le patient se traine sur les clienins accidentés du Nayombe, à bout de souffle, grelottant de fièrre, porté sur le dos d'un de ses proches, ou seconć dans un mauvais lipoy!

Le médecin examine le matlade el décide s`il pourra ou ne pourra pas le guérir. S’il se déclare incapable de réussir, rien n'est dù par le consultant. S'il y a, an contraire, espoir d'arrêter les progrès de la maladie, le médecin prend en pension le patient, ainsi que le parent qui l'accomipagne toujours.

Désormais, outre ses soins, il leur doit à tous les deux, le logement et la nourriture aussi longtemps que la cure ne sera pas terminée.

La coutume n'a qu'un seul tarif pour les honoraires: 50 francs ou 10 pièces, à condition que la guérison soit obtenue. Dans les affections bénignes, les plaies légères, il y a une réduction.

Si la mort survient au cours du traitement, ou si le médecin renonce à soigner le malade, rien ı̀est dû, même pour l'entretien.

La convention que nous examinons serait des plus claires et n'entrainerait aucun litige, si le médecin ne prenait soin, le plus souvent, de se faire remettre des avances, el si, de son côté, le malade une fois guéri, IIoubliait trop facilement de régler les honoraires.

Un cas plus compliqué peut se présenter: c'est quand le malade est une femme. Si l’époux est attaché à son épouse, il n'hésite pas à laire pour elle les dépenses nécessaires. Mais souvent sa palience est déjà lasséc par les indispositions fréquentes, qui ont arrêté sa femme antérieurement. Il s'en détache de plus en plus; celle-ci une fois chez le médecin, il s'en désintéresse tout à fait. Circonstance aggravante, quand la fenime est guérie, les relations devienment vite très intimes entre elle et son sauveur. Les honoraires du 
médecin se font attendre. Il va trouver le mari qui, non seulement les refuse, mais réclame l'indemnité d'adultère; il s'adresse alors à la famille de la femme. Celle-ci n'entend faire aucun sacrifice, d'autant mieux, n'est-ce pas,que la femme est guérie. Et c'est le plus souvent dans cet état que le palabre nous est soumis.

Dans les cas de l'espèce, nous appuierons nos décisions sur les réflexions suivantes:

D'une part le mari est répréhensible de se désintéresser de sa femme au point de l'abandonner dans sa maladie, et de se refuser à acquitter le prix de sa guérison. Son indifférence pourrait être rangée au nombre de ces " excès, sévices et injures graves " qui motivent dans notre loi le divorce. Mais je répugne au divorce et le réserve pour les cas d'abandon plus formels. En tous cas, l'époux a fort mauvaise grâce à se plaindré des infidélités de son épouse.

De l'autre côté, si le médecin n'est guère excusable d'avoir abusé de l'intimité où son art lui a permis d'entrer, la femme est pardonnable d'avoir cédé aux sollicitations de celui qui l'a tirée de peine.

Quant à la famille de la femme, il est certain qu'elle n'est obligée de rien payer.

Deux solutions me paraissent possibles :

$\mathrm{Si}^{-}$les deux époux acceptent de reprendre la vie commune, partager la responsabilité de l'adultère entre le mari et le médecin et réduire de moitié les honoraires de ce dernier. On me dira quainsi faisant, je reconnais la légitimité de l'indemnité d'adultère. Mais le moyen de faire autrement? Il y a intérêt à reconstituer un ménage. - Mais si le mari a abandonné nettement sa femme, prononcer le divorce à ses torts et griefs; il perdra le remboursement de la dot par lui versée, la famille de la femme paiera le médecin, dont on pourra s'il y a lieu réduire les honoraires; la femme trouvera sans doute un nouvel époux.

On peut faire pour le contrat du médecin, la même observation que pour celui de l'ouvrier de culture. Ce qui fait l'objet de la convention, e'est un acte bien 
déterminé: une guérison, peu importe le temps qu'elle exigera.

La mentalité actuelle de l'indigène est de telle forme que, s'il loue ses services, c'est toujours pour un objet précis, sa besogne est déterminée, son patron l'est également. Il ne loue pas son travail en général.

Tentez de le sortir de sa spécialité: cuisinier, boy, blanchisseur, pour en faire, couramment, par exemple, un interprète à ses moments perdus, il s'y résignera en rechignant, demandera une augmentation de salaire, souvent s'y refusera catégoriquement et cherchera un autre maître.

Il en est de même si son patron lui demande de prêter ses services à un autre Européen; c'est pour lui du travail en plus, il faut augmenter le salaire.

Le travail à ses yeux comprend une grande quantité de loisir...... le plus de loisir possible.

Nous aurons bien à faire pour changer cette tournure d'esprit.

\section{$\S 4$}

\section{Contrat de gardiennage de bétail}

Le contrat de gardiennage de bétail est un des plus singuliers que nous trouvions dans la coutume.

Par cette convention, le bailleur, mettant en garde une ou plusieurs têtes de petit bétail, ou d'animaux de basse-cour chez un preneur, ce dernier s'engage à les lui restituer sur sa demande, en même temps que toute- leur postérité, moyennant quoi le bailleur lui donnera en récompense de ses soins une ou plusieurs têtes du bétail en question, suivant l'importance du troupeau rendu.

Le preneur est responsable de toutes les circonstances qui pourraient diminuer le troupeau; ni le rapt des animaux, ni la maladie, ni le fait du prince ne peuvent l'excuser; aucun cas de force majeure n'est admis. 
'Toutefois, il peut échapper au remboursement quand les circonstances de lieu s'y prètent. Si le domicile du bailleur est proche de celui du preneur, ce dernier, en cas, par exemple, de maladie d'une des bêtes, en cas de mort par la dent des animaux, pourra, en se hatant, la lui apporter encore vivante ou fraichement morte. Sil a affaire a un individu accommodant, ce dernier se contentera peut-être du cadavre de la bête. J'ai vu, une fois, le comble de la bienveillance chez le bailleur; il avait accepté d'excusér son preneur moyennant la remise du cadare, fumé par quartiers, d'un mouton donnc en garde. Ces cas d'excuses sont assez rares, les domiciles du bailleur et du prencur étant généralement assez éloignés.

Quel but en effet poursuit le bailleur? Au premier examien, les avantages qu'il retire de la convention sautent aux yeux. En donnant son bétail en garde, il se met, par le fait même, à l'abri de tous les risques, risques qu'il ne manquerait pas de supporter s'il le conservait auprès de lui. Certes, il tire de la combinaison de sensibles avantages. Mais ce n'est point tant ceux-là qu'il recherche qu'un autre bien différent : celui de faire en sorte qu'on ignore généralement qu'il a du bétail, qu'il est " riche ". Passer pour " riche ", est particulièrement dangereux chez nos indigènes; cette réputation fait encourir de grands dangers, dont la mort est le plus commun. Quand on donne des moutons à garder, on les met donc d'habitude assez loin de chez soi; les habitants de la côte, les mettent dans les villages des savanes de la Nyanga; les Bayaka de la forêt les envoient dans la plaine de Ndendé, d'où ils gagnent fréquemment le pays des Banzabi et Bavoumbo de la rive droite de la Ngounyé.

Dans une convention à clauses aussi rigonreuses, lc preneur trouve-t-il aussi des avantages? Certainement, et le contrat dont nous noús occupons est des plus fréquemment conclus; les bailleurs n'ont point de peine à trouver des preneurs, ils sont même sollicités. Pour nous l'expliquer, il faut nous rappeler certaines notions déjà exposées antérieurement. La plus 
importante est celle-ci: que toutes les conventions se concluent sous le régime de la mauvaise foi. Celui qui accepte le bétail en garde n'a que très vaguement l'intention de le rendre. Et puis c'est toujours un contrat à long terme; on a du temps devant soi.

Celui qui est en possession est toujours favorisé, quelle que soit l'origine de cette possession. Ce mouton mis en garde peut être le point de départ d'une séric de transactions où le dépositaire espère bien trouver son avantage.

Enfin, en mettant les choses au pire, c'est-à-dire en envisageant le contrat honnêtenient exécuté, le preneur escompte qu'il évitera les risques et que, lors de la liquidation, il se trouvera propriétaire d'une ou deux têtes sans bourse délier.

Cependant, ce calcul est le plus souvent mis en défaut; les indigènes, nous l'avons vu, ignorent la compensation. Si un bailleur, lors de l'échéance d'un contrat de gardiennage de bétail, a droit à 10 têtes et qu'il juge convenable d'en donner deux en paiement, il ne dira pas à son preneur: Rends-moi huit bêtes. Il lui dira: Tu me dois 10 bêtes, donne-les moi, je te donmerai 2 bêtes plus tard. Laffaire ne se terminera pas sans palabres.

Lorsque ces litiges nous sont présentés, comment devons-nous les accueillir?

Ils nous sont soumis sous une forme généraleırent peu sincère. Un tel m'a volé 40 moutons, me dit un jour un habitant du plus misérable village! Même lorsqu'il n'est pas question d'un chiffre aussi considérable, et dès qu'on nous parle de vol de petit bétail, nous pourrons poser la question: S'agil-il de bêtes réellement volées, ou de bètes qu'on n'a pas rendues? Ce point éclairci, et_étant bien assurés qu'on nous parle de bêtes données en garde dans les conditions cidessus exposées, je crois que nous devons nous montrer résolument hostiles à la persistance de cette coutume. Disons au bailleur: Quand on a du bétail, c'est bien le moins qu'on s'en occupe soi-même, il est d'autant mieux soigné et gardé. Expliquons-lui, qu'il y a 
des risques inéluctables; nos moutons ne sont point accoutumés à vivre en troupeau, les chèvres sont des plus vagabondes: serpents, panthères, hyènes même, peuvent s'y attaque sans que le dépositaire puisse être rendu responsable. Il y a plus dangereux: c'est ce que j'appelle le fait du prince, c'est le garde régional qui, très porté sur sa bouche, est bien tenté, quand il est seul, d'améliorer son ordinaire. Heureux doit-on être quand il paie! Et, puis, il y a l'impôt! Il est bien interdit de recevoir des moutons pour l'impôt, mais c'est une prescription quasi impossible à suivre. Si nous n'avions pas les moutons de l'impôt, nous n'en aurions jamais, sinon à des prix fabuleux. Un indigène est tenté par des marchandises, il ne l'est pas par l'argent. On peut imaginer des moutons dans une factorerie, on n'en saurait voir dans un poste, obtenus par voie d'achat.

De tous ces risques de disparition, un preneur ne peut être rendu responsable, et cela d'autant moins que le bailleur n'en ignore aucun et prétend s'en défendre par la convention qu'il a conclue.

Il y a une autre considération qui doit intervenir, c'est la limite à la possibilité du paiement. Mon indigène qui, plus haut, réclamait 40 moutons, $\mathrm{y}$ avait peut-être parfaitement droit. J'avoue que je n'ai pas examiné la sincérité de la généalogie de ses brebis; je lui ai dit immédiatement qu'il n'y avait pas dans toute la Nyanga, un seul indigène capable de payer 40 moutons et j'ai d'emblée réduit ses prétentions.

En outre, il y aurait injustice à rendre un neveu responsable, dans des conditions aussi onéreuses, du manque d'honnêteté de son oncle, ou de-son grandoncle.

Nous dirons donc au défendeur qu'il rembourse quelques moutons, et qu'il n'est nullement tenu d'en rendre davantage. Sans aucun doute, il s'en tiendra au chiffre que nous aurons fixé.

En dehors de toute question de justice, nous devons, je crois, lutter de toutes nos forces contre la coutume que nous examinons ici. Outre qu'elle est l'origine de 
palabres insolubles, elle est un obstacle à la surveil. lance que nous devons établir sur le petit bétail. A Ndendé, à Moabi, à Koumouramba, l'occupation militaire a fait le vide, comme toujours; la consommation des fonctionnaires civils et de nos auxiliaires a continué son ouvre. Encore un peu de temps, et il deviendra impossible de-se procurer un mouton, à quelque prix que ce soit. A deux reprises, il y a eu un beau troupeau à Tchibanga; le premier a été dispersé à Mayumba et Nyanga. Il n'en est rien resté dans ces deux postes. C'est tout à fait regrettable. Nous devrions savoir nous priver de la mince satisfaction d'améliorer notre ordinaire, conserver les brebis et ne tuer que les mâles. L'un de nous n’a pas résisté à la tentation de vendre pour la consommation le troupeau constitué par lui dans son poste; c'est une conduite blàmable. Le troupeau d'un poste devrait passer d'un titulaire à l'autre et il n'est personne d'entre nous qui ne ferait le sacrifice de la mise de fonds nécessaire.

Chez les indigènes, nous devrions amener les propriétaires de bétail à prendre eux-mêmes soin de leurs hêtes; ils nous en déclareraient le nombre. Nous les tiendrions sous notre surveillance, contrôlerions les transactions dont elles seraient l'objet; le petit troupeau serait ainsi à l'abri d'une consommation inopportune et exagérée. Peu à peu le cheptel se reconstituerait.

Je préférerais ce moyen à celuị, qui a été préconisé, de confier, d'autorité, des animaux à des indigènes. Nous devrions, en effet, nous les procurer par voie d'achat, les payer très cher, et par conséquent les céder à l'indigène à un prix très élevé, plus élevé que celui de notre région: deux pièces. J'ai souvenir d'un bélier, acheté jadis pour l'administration, qui a été payé à Tchibanga 20 ou 25 francs et qui, vu les frais de voyage, a dû revenir à Setté-Cama, poste auquel il était destiné, à un prix invraisemblable.

Si nous ne les cédons pas à l'indigène, s'il a seulement en garde des bêtes appartenant à l'administra- 
tion, nous serons ses dupes, car il trouvera de multiples bonnes raisons pour en disposer à son bénéfice sans que nous puissions guère contrôler ses dires. Je crois que nous éviterions ce double inconvénient en procédant oomme je l'ai exposé.

\section{$\S 5$}

\section{Du prêt}

Je ne dirai rien du prêt à usage, il n'est pas pratiqué. Prêter à usage, c'est en quelque sorte donner. Liindigène ne donne pas, je l'ai dit, même l'usage occasionnel de ce qui lui appartient, d'un outil, d'un instrument de travail. Essayons de commander à quelqu'un tel travail, minime, qui s'exécute arec une machete; l'indigène nous demandera cet instrument; si nous n'en avons pas, il tàchera d'en emprunter une et n'emploiera la sienne qu'à la dernière extrémité

Et, sans chercher plus loin, ayons besoin d'un couteau, d'un couteau de poche, et demandons-en un à notre boy. Il y a cent ä parier contre un qu'il n'en a pas. Avoir un couteau de poche, c'est avoir un couteai un peu à la disposition de tout le monde. Cela n'est pas admissible.

Le seul objet que j'aie ru prêter pour un long usage, c'est un fusil; et le prêt fut toujours à titre onéreux.

Si le prêt à usage est inconnu, en revanche, le prêt de consommation est universellement et quotidiennement pratiqué, à un point même qu’il est difficile d'imaginer.

Entrons dans une case indigène, qu'y trouvons-nous comme mobilier? Si l'occupant est là ou mieux l'occupante, car en général les femmes ont seules des cases à elles, nous y verrons quelques tabourets, deux ou trois marmites, autant de calebasses, de jarres, cuillers et plats en bois," quelques paquets de graines comestibles: arachides, courges, - ou destinées à confectionner des condiments: moabi, moudonka. Dans 
la pièce destinée au sommeil, si elle est séparée, une claie en raphia (tangui), une .natte. Dispersés dans les deux pièces, de petits paciuets de substances innommables. En un mot, la case ne contient rien ayant une valeur intrinsèque, marchande, commerciale, aucun produit importé.

Sil s’agit d'un village évacué à notre approche, nous ne trouverons pas beaucoup moins d'objets mobiliers. Ce qui manque a été en partie emporté par les fuyards, en partie caché dans les bananiers et la brousse des alentours immédiats; cest là qu'on trouve toujours des tangui, des jarres, des marmites.

Pourtant les indigènes possèdent des produits importés. ils emploient couramment les étoffes, la vaisselle d'Europe, les neptunes, barres de fer, etc. Pourquoi tout cela est-il dissimulé et où le cache-t-on ?

Il $\mathrm{y}$ a deux raisons à cette dissimulation des objets qui constituent la richesse de l'indigène.

La première et la moins importante est qu'il ne saurait où les conserver. La case ne lui appartient pas; elle est la propriété de sa femme qui la lui ouvre $\grave{a}$ son tour. Et puis cette case le met tout juste à l'abri dès regards, elle ne le protège qu'à peine contre la fraîcheur des nuits et pas du tout contre les voleurs. C'est une clotture morale. Il est vrai que le vol par effraction est rare.

Si cependant l'indigène est obligé de garder avec lui des objets encombrants et de consommation quotidienne, tels que les paquets d'arachides, la provision de tabac, il les dissimulera dans la forêt ou la brousse, dans des cachettes naturelles ou préparées, connues de lui seul et accessibles à lui seul. Le sentier pour s'y rendre ne se branche sur aucun sentier; le propriétaire sait qu'à tel arbre, à telle touffe oì il a noué quelques herbes, il doit entrer sous bois, faire dans telle direction quelques pas, et là, commence la piste sommaire qui le conduira à sa réserve. Il ne faut tenter personne et, quand on a des provisions, faire en sorte de ne pas avoir à partager avec le voisin.

Et dans ce sentiment se révèle la deuxième raison 
de cette coutume qui porte les indigènes à ne rien garder par devers eux en fait de biens mobiliers.

La misère de nos populations est générale et uniforme: quiconque dans ce milieu posséderait quelque bien, se trouverait distingué des autres, et provoquerait chez ses congénères deux manifestations: des sentiments de jalousie chez les moins fortunés, si justifiée que soit leur paurreté par leur apathie, leur inconstance, ou leur maladresse, - des sollicitations de la part de ceux qui se trouveraient à un moment donné avoir besoin de ressources.

On me dira qu'il n'y a rien là de particulier à la race nègre; l'envie est de tous les pays et de tous les temps, la mendicité aussi. Je l'accorde volontiers. Mais ce qui est spécial à nos races, ce sont les conséquences qui en découlent, ou du moins que les indigènes croient devoir en découler nécessairement, ce qui, au bout du compte, est la même chose.

Celui qui a soulevé l'envie de ses congénères, celui qui a, en repoussant des sollicitations même indiscrètes, mérité le reproche d'avarice, court souvent, et croit toujours courir, risque de la vie. Qu'une maladie lui survienne, il examinera d'un regard les relations qu'il a eues, les demandes qu'il a dû rejeter, les conversations qu'il a pu surprendre, et il en déduira immédiatement que tel ou tel voisin, ou parent, est la cause de sa maladie; sa famille rendra cet homme, le cas échéant, responsable de sa mort, si l'issue est fatale.

Je l'ai déjà dit, trop souvent peut-être; le noir vit dans un état de terreur continuelle et il croit avoir tout à craindre et de tout le monde.

Superstition, dirons-nous! Mais qui n'en est pas moins profondément enracinée dans la population et de laquelle, tout en la regrettant, en la combattant, il nous est indispensable de tenir compte. Il ne nous faut d'ailleurs pas trop plaisanter sur ce chapitre les indigènes. Nous ne sommes pas exempts de reproches. Qui de nous ne pourrait citer un cas d'Européen, même très cultivé, croyant aux sorts, à Ta mauvaise 
chance, hésitant à s’asseoir treizième convive à une table amie, touchant du bois, etc., etc. Il ne faut pas trop faire grief à nos administrés de leurs faiblesses qui, elles, sont excusables, et nous devons dans bien des cas, nous pénétrer de cette idée: Tel ou tel acte de ces pauvres êtres est commandé par la peur de la mort. Quelles prescriptions, quels règlements, quelles sanctions de l'indigénat peuvent prévaloir contre une crainte de ce genre? Mettons-nous à leur place; imaginons que nous croyons qu'en faisant telle ou telle chose, nous avons la certitude de mourir; ferions-nous cette chose? Non assurément, nous ne la ferions pas, ou, pour nous y contraindre, il faudrait la perspective de risques au moins égaux et aussi certains. Nous ne trouvons pas cette force dans les règlements actuels; je crois pouvoir dire que nous ne la trouverons jamais dans aucun règlement.

Mais je m'éloigne de mon sujet, j’y reviens. Si pauvre que. soit un indigène, il y a des évènements dans sa vie qui lui apportent quelques profits. Il a des filles, des sœurs, il les a mariées et a touché la dot; il a fait un peu de caoutchouc, a trouvé une pointe d'ivoire, qu'il a vendue, - il a travaillé et le reliquat de ses salaires lui a été payé au terme de son service? Ces gains représentent une certaine somme de marchandises qu'on ne peut pas facilement dissimuler comme on ferait d'une somme d'argent. Emportera-til ce stock au village? Il s'en gardera. Son retour serait assiégé par les habitants, à peu près tous ses parents, comme nous savons; il serait assailli de demandes; il lui faudrait donner une pièce à celui-ci, un pagne à celui-là, sans compter les plus proches parents: père, oncle, frère aîné, qui, eux, ont des clroits réels et auxquels il serait malaisé de refuser.

Décidlera-t-il de ne rien donner à personne? C'est alors que se manifesteront les sentiments d'envie, que seront proférées les mauvaises paroles, que les risques commenceront.

Pour éviter tout cela, la première mesure prise par l'homme qui, à un moment donné, se trouve posséder 
quelque chose, consiste à le domner en prèt. Les em'prunteurs ne lui manqueront pas; mais, s'il ne s'en présentait point au moment opportun, le "riche " n'hésiterait pas à en rechercher, à offrir son bien occasionnel. Il trouverait toujours des amateurs. Débarrassé du souci de la fortune, il rentrera chez lui les mains à peu près vides et le cœur léger. Il n’a plus que des créances: il est à l'abri de tous les risques; à toutes les sollicitations, il pourra répondre: Je n'ai rien. Tout au plus dira-t-il: Je veux bien te donner ce que tu me demandes, mais attends qu'un tel mait payé. Autant vaudrait une fin de non-recevoir. Et voila pourquoi on ne trouve jamais rien dans une case indigène. Mais, dira-t-on, vous avez assuré ailleurs qu'il est impossible de faire payer un indigène qui s'y refuse. Comment donc le prêt est-il si souvent pratiçué?

Pour se l'expliquer, il faut se placer non au temps présent, mais dans un passé qui n'est pas encore vieux de dix ans. A cette époque, on réglail ses affaires soimême; un débiteur he payait pas? on prenait des otages, et, si le paiement tardait trop, on les rendait. Le remboursement du prêt était assuré.

Quelles sont les clauses de la convention en dehors de l'obligation de rembourser? II n'y en a pas. Aucun terme n'est préru, la dette est à tout moment exigible. Il n'est pas stipulé qu'on rendra des marchandises de même sorte'et de même qualité. On prête une valeur de, on doit rendre la même valeur.

Ce contrat est pour les objets mobiliers, ce que le contrat de gardiennage est pour le bétail, à cela près qu'il ne rapporte rien au preneur que l'arantage d'avoir à un moment donné des capitaux dont il a besoin. Mais gràce à lui, le prêteur met ses biens et sa personne à l'abri de tous les risques.

Il est bien évident que cette coutume est déplorable: qu'elle est une entrave absolue à l'amélioration matérielle du sort des indigènes, car elle rend impossible l'ẻconomie.

Plus haut, je citais le cas de ceux qui, rompant avec elle, ont voulu jouir des avantages que le travail leur 
procurait. Je veux, pour nos régions, parler des gens de la côte, spécialement des Bavili de Loango. A quoi ont-ils dî se résoudre? A émigrer sans esprit de retour.

Y a-t-il remède à la situation? Non assurément. Aucune mesure administrative ne tiendra contre la crainte de la mort. Ce qu'il faut, c'est faire comprendre aux indigènes qu'un sort ne fait pas mourir, et que l'envoûtement n'est qu'une plaisanterie. Mais ces terreurs superstitieuses, des médecins seuls, en soignant et guérissant les malades, peuvent les faire disparaître. Et ce sera long.

Une dernière observation doit être formulée en ce qui concerne le prêt. Le consentement du prêteur n'est pas nécessaire à la conclusion du contrat. Un homme pressé d'argent prendra, sans inconvénient, chez un de ses amis, des marchandises s'il s'en trouve, ou au besoin un esclave, en l'absence du propriétaire. Ce dernier sera sans donte peu satisfait, mais il y a grand'chance qu'il ne proteste pas.

Du prêt à intérêts. . Je ne ferai qu'une mention sommaire du prêt a intérèts. J'en ai vu de rares, très rares exemples. Il est peu pratiqué. Cela tient sans doute à ce cue, les opérations conmerciales des indigènes ne pouvant jamais rien leur rapporter, elles ne leur ont pas donné ce sentiment que l'argent peut, par son mourement, produire des bénéfices.

Les cas de prêts à intérêts que j'ai constatés constituaient un abus, une manière-d'usure, à cela près que l'habitude manquait. Il s'agissait de gens trouvant avantageux de profiter des besoins immédiats et pressants d'un emprunteur poursuivi par un créancier exigent, et menaçant d'une mesure de contrainte grave, de la prison au poste par exemple, dont ceux qui n'y ont jamais été ont toujours une grande frayeur. Le prêteur disait alors: Tu veux une pièce; prends; tu men rendras deux au plus tôt. Et il indiquait un terme rapproché.

Le prêt à intérêts n'est certainement pas conforme 
à la coutume, c'est un abus qu'il convient de condamner et de réprimer.

\section{Du mandat}

La méfiance, qui est au fond de toutes les âmes indigènes, interdit de se décharger sur autrui de l'administration de ses affaires. Chacun pour soi, telle est la règle générale. Un indigène ne laissera donc à personne, par exemple, le soin de vendre, d'acheter, de prêter; je n'ai jamais vu de cas où l'on ait donné mandat de conclure une convention, quelle qu'elle soit.

Toutefois, cette interdiction ne s'étend pas à l'exécution des conventions, ni davantage au règlement des litiges. Jai citć plus haut le cas du recouvrement des créances qui est poursuivi fréquemment, je crois même, le plus ordinairement, non par le créancier lui-même, mais par un intermédiaire.

Je ne vois pas de raison, disais-je alors, à cet usage si ce n'est peut-être de créer par là des témoins à une convention qui s'est formée en secret. En effet, il est possible que le débiteur ne refuse pas d'emblée de payer ce qu'il doit, qu'il n'en vienne là que par suite de son manque de ressources; on escompte sans doute qu'au début des réclamations, il se sera borné à solliciter un délai, qu'il aura donné un gage, en un mot, que, de façon plus ou moins explicite, il aura reconnu sa dette, - et l'intermédiaire pourra, devant l'arbitre, attester cette reconnaissance.

Le rôle des intermédiaires aurait alors son utilité. - Disons tout de suite que de tels témoignages ne sauraient nous satisiaire, L'intermédiaire choisi tient toujours de près à son mandant; c'est son frère, son oncle, quelquefois le chef du village, c'est presque toujours un parent, en un mot c'est quelqu'un ayant, avec le plaignant éventuel, des relations trop étroites pour que ses déclarations puissent être admises com- 
me l'expression de la vérité. Si le rôle des intermédiaires, disions-nous, n'est pas celui d'un témoin éventuel, il n'a plus de raison d'être et il faut poursuivre la disparition de eette eoutume.

A bien réfléchir, cependant, elle pourrait se justifier, au moins s'expliquer d'autre manière. Pour peu qu'un fonctionnaire ait parcouru le territoire qu“il administre, il a pu remarquer le soin que mettent les indigènes à ne s'arrèter que dans des rillages où ils ont des parents, des amis, au moins des connaissances. Chez les Bapounou, la préeaution est poussée plus loin, et on peut dire qu'à tous les villages, il existe un sentier permettant d'en éviter la traversée. Ceux qui font de longues routes, ceux qui, par exemple, ront à la côte chercher du sel, ne choisiront jamais un village pour $\mathrm{y}$ faire une eourte halte; à moins dy ètre connus, ils s'arrêteront à quelque distance auprès d'un ruisseau.

Cette conduite ne s'explique paśs seulement par le earactère absolument inhospitalier des individus, inhospitalier au point de reluser au passant mème une goutte d'eau, il faut y voir, je crois, une nouvelle manifestation de la crainte des sorts; on ne mange pas, on ne boit pas clans un endroit, auprès de gens, qu'on ne connait pas.

Si donc on a tant de méfiance des inconnus, à combien plus forte raison doit-on redouter la malveillance d'un débiteur; auprès de lui, le créancier ne saurait jamais être persona grata. Dautant, notons-le bien, que le déplacement pour aller réclamer une dette, n'est jamais de courte durée; si mal qu'il accueille son créancier, le débiteur ne peut faire autrement que de le loger et de le nourrir quelques jours. Je ne serais pas éloigné de eroire que le créancier trouve ce sćjour périlleux et qu'il préfère y envoyer quelqu'un a sa place. Le mandataire n'agissant pas pour son propre compte, ne court aueun risque de eette sorte.

Et le débiteur, me direz-vous, pourquoi ne paie-t-il pas directement? La raison est autre, et plus simple. Le dẹbiteur souhaite ne pas payer; il ne prendra donc 
jamais la peine d'aller chez son créancier; il altendra tranquillement que celui-ci vienne, ou envoie chez lui. J'ai entendu cent fois cette excuse au non paiement d'une dette, à la non-restitution d'une femme: Je ne l'ai pas payć, je ne lui ai pas rendu sa femme, parce qu'il n'est pas venu réclamer son dù.

Je donne ces hypothèses pour ce qu'elles válent, en laissant à mes confrères le soin d'en vérifier l'exactitude:

L'emploi des mandataires est également fréquent dans le règlement des litiges. Les parties plaident volontiers par procureur, mais cette coutume s'explique facilement, Le mandataire est choisi à cause de son éloquence, de son habileté; son rôle est celui de l'avocat.

Je conseillerai de ne jamais accueillir de plaintes que déposées par l'intéressé en personne, sauf excuse valable, tel que serait le cas de maladie, et de n'admettre alors comme représentanls que les tout proches parents: oncles, frères utérins. Nous avons déjà bien de la peine à savoir la vérité de la bouche des parties elles-mêmes; nous aurions moins de chances encore d'y parvenir si nous interrogions des intermédiaires, auxquels l'intéressé n'a raconté, en somme, que ce qu'il a bien voulu et c'est-à-dire ce qui est à son avantage.

Je signalerai pour terminer que, à la différence de ce qui est admis dans notre Code, le mandat nest jamais gratuit, à moins de convention contraire. L'indigène ne fait rien pour rien.

Mais suivant l'habitude générale, la rétribution du mandataire n'est pas déterminée d'avance; il se payc lui-mème sur le produit de ses démarches quand elles ont abouti. En cas d'échec, j'imagine qu'il a droit à quelque dédommagement, mais je n'en sais rien, aucun palabre de ce genre ne m'ayant été soumis. La coutume ne doit pas, je pense, s'être prononcée sur la question, car autrefois les démarches réussissaient toujours d'une manière ou d'une autre. 


\section{Du cautionnement}

On conçoit mal qu'un indigène s'offre à payer pour un autre ou seulement l'accepte. Cela se produit cependant, mais en règle générale la caution a payé les dettes d'un parent très proche: oncle pour son neveu, et réciproquement, frères entre eux. Il faut nous rappeler que ces agnats (1) vivent dans une situation de fait, voisine de l'indivision des biens.

Toutefois, j'ai vu le cas où un chef de terre a payé les dettes d'un étranger; mais il avait un but: celui de l'amener à s'installer sur sa terre. Il lui faisait ainsi le cadeau traditionnel dont j'ai parlé ailleurs.

Je n'ai pas trouvé trace d'autres conventions parmi les indigènes.

Le contrat de société est inconnu. Chacun travaille pour soi. Mais, le temps est proche où il n'en sera plus de même et j'ai entendu parler de gens de la cote ayant conclu, entre parents, il est vrai, des conventions qui rappellent l'association.

Le dépôt n'est pas plus pratiqué que la mise en gage. Ce qu'un indigène ne veut pas garder, il le prête, et s'il s'agit de bétail, il emploie la convention dont nous avons parlé. Quant au gage, il n'existe que comme moyen de procédure; j’en reparlerai ailleurs.

Si les dettes ont été quelquefois assurées par des gages, ceux-ci n'ont jamais été que des personnes, il s'agissait d'otages. Encore n'étaient-elles pas mises

(1) Sont agnats tous les individus qui. en remontant par les femmes de génération en génération. peuvent trouver une aïeule commune J'ai tracsposé à la filialion maternelle ce terme réservé à la filiation paternelle pour ne pas employer une longue périphrase. 
dans cette situation par le débiteur, mais bien saisies par le créancier. Cette coutume tend à disparaître.

Enfin, il n'y a rien à dire des transactions. De sa pleine volonté un indigène ne transige jamais. Il entendra toujours, si c'est possible, aller jusqu'au bout de son droit. Cependant, ce moyen de terminer des litiges est fréquemment imposé par l'arbitre indigène. Ce n'est pas qu'il estime avantageux d'apaiser un différend, mais il trouve ainsi le moyen de justifier son intervention et la rétribution quil a reçue, et de ne s'aliéner aucune des partiēs, puisqu'il n'a donné entièrement tort ni raison à l'une ni à l'autre.

Nous allons précisément examiner à présent ce rôle des arbitres et, d'une façon générale, comment se rend la justice chez les indigènes. 


\section{TROISIÈME PARTIE}

\section{De l'Administration de la Justice entre les indigènes}

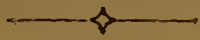

\section{CHAPITRE I}

\section{De la PROCÉDURE en MATIĖRE CIVILE. - \\ CARACTĖRE des SENTENCES.}

Les méthodes suivies pour la conclusion des conventions, telles que je les ai exposćes, laisseraient supposer au lecteur le moins prérenu que les litiges ne sont pas rares entre les indigènes. Notre expérience à tous nous enseigne que leur fréquence dépasse toutes les prévisions; on peut aller jusqu“à se demander si nos administrés ne prennent pas soin de ne contracter que dans des conditions choisies avec l'intention d'amener des litiges; et l'entretien de ces litiges, je ne dis pas la poursuite de leur solution, est l'occupation principale des indigènes ayant atteint la maturité de l'âge.

Comment ose-t-on dire que nos populations ont le sens inné de la justice puisqu'elles enfreignent ses prescriptions avec une si constante et si parfaite désinvolture?

Avec ce tempérament chicanier, et porté à méconnaitre aussi facilement les règles de l'équité la plus élémentaire, on concerrait mal que nos administrés neussent pas dans leur organisation sociale des moyens permettant d'aboutir cependant à l'exécution des conventions, à l'apaisement des différends.

Se rendre justice soi-même est un moyen radical, mais qui n'est pas à portée de la force et du carac- 
tère du premier venu. Il y faut de la décision, du courage et surtout de la vigueur; encore faut-il posséder ces dons naturellement, car l'éducation physique et morale est inexistante et l'enfant grandit avec les qualités qu'il doit à sa naissance; l'àge ne lui en fera pas acquérir.

Il devient de moins en moins commin de voir un plaideur pourvoir dé lui-même à lobtention de ce qu'il considère comme son droit; aussi bien la conduite en pareil cas était-elle simple. Au débiteur récalcitrant, au père, à l'oncle qui tardait à donner à un futur sa fille ou nièce, on prenait sa femme, son fils, sa fille, un parent, un voisin. On le gardait comme otage, et, si la convention tardait à s'exécuter, on le rendait, si c'était un homme, on la mariait pour son propre compte, si c'était une femme, ou même on l'épousait. Ces procédés radicaux ne finissaient d'ailleurs rien; si le débiteur ne réclamait pas sur le moment, il n'oubliait pas la violence subie, répondait tôt ou tard par des représailles ou en laissait le soin a ses héritiers; somme toute, au lieu d'un seul palabre à régler, il s'en trouvait plusieurs accumulés, et si bien mélangés que la patience d'un arbitre, sa sagacité auraient été mises à une rude épreuve, si jamais un bęau jour on lui eùt remis le soin d'apaiser les rancunes.

De tout temps donc, le besoin d'une organisation judiciaire s'est fait sentir; de lout temps elle a fonctionné d'une façon plus ou moins primitive, plus ou ınoins efficace, suivant le caractèré et l'autorité de ceux dont la coutume fait 'des juges.

Quels sont ces juges? Ce sont les chefs de terre, et de village; ce peuvent être également des indigènes influents bien que nayant pas de juridiction territoriale étendue. Rendre la justice est une des attributions des autorités indigènes, une de celles auxquelles ils tiennent le plus, qu'ils aiment à faire confirmer par nous, et cela pour un motif très réaliste, c'est que ce privilège est productif. On ne rend pas la justice gratis. 
Quelle est ta compétence de ces juges? Nimaginons pas que l'organisation judiciaire est calquée sur l'organisation administrative; ne supposons pas chez nos primitifs administrés des notions de la compétence ratione loci, personæ, etc. La coutume ne comporte pas de telles précisions.

En principe, un plaignant peut choisir commie arbitre qui il lui plaît. A celui qu'il désignera, il demande d'abord de lui être favorable, ensuite d'avoir assez de prestige pour que la citation envoyée par lui aboutisse, et assez dautorité pour que la sentence soit exécutée.

Il en résulte que le nombre de personnages importants entre lesquels il peut choisir, est assez limité, et qu'il désignera le plus souvent le chef de sa terre, si son adversaire réside dans la même terre que lui.

Mais si cet adversaire appartient à un autre groupe, l'affaire se complique. En général, il commencera par aller l'exposer au chef de sa terre, et celui-ci désignera quelqu'un pour l'accompagner devant l'arbitre, si l'on est obligé d'en choisir un plus éloigné et-étranger au groupe, - ou bien mêne, c'est ce chef de terre qui prendra laffaire en mains et jouera le rôle de mandataire ad litem; c'est lui qui choisira l'arbitre ou acceptera celui désigné par la partie adverse. Au besoin, il prendra part au jugement.

Notons en passant le soin pris par le plaignant de s'adresser à un juge favorable. L'impartialité est la dernière qualité qu'on exigera de lui. Ce sentiment est si intimement imprimé dans l'esprit des indigènes qu'il n'ont pas encore pu s'assimiler nos idées de compétence ratione loci. S’il y a palabre entre habilants de deux subdivisions différentes, à qui le plaigulant sadresse-t-il ? A son chef de subdivision. Celuici ne manque pas de se récuser et d'inviter le plaignant à saisir le chef de la subdivision voisine. Cette récusation n'est jamais accueillie sans mauvaise humeur; l'indigène a l'air de la considérer comme un déni de justice. Il nous prête en effet ses sentiments, croit qu'il a plus de chances d'avoir raison près de 
son "Commandant ", craint surtout d'avoir lort devant un fonctionnaire qui ne le connaît pas, ce qui est chimérique, deetre trahi par un interprète dont il n'a pas l'habitude, dont il n'a pu gagner les faveurs, ce qui l'est beaucoup moins. Bien souvent, il renonce à sa plainte et l'on remarquera la rareté relative des litiges entre indigènes de ressorts différents. Mais revenons à nos arbitres.

Le plaignant a choisi son juge, il va le trouver et lui expose son affaire.

Le premier mot de ce juge est de demander des honoraires. Le taux n'en est pas fixé, mais pour peu que l'objet soit important, ce n'est guère moins d'une pièce ou deux et le versement est préalable. Le plaignant se console sans doute en pensant que pareil versement sera demandé à son adversaire.

Je.pense, mais je n'en ai pas de preuves, que l'impartialité des juges est plus ou moins modifiée par la générosité des plaideurs. Comme tous, jai dit que la justice indigène était vénale; au fait, nous n'en savons à peu près rien. Je serais porté à croire que l'esprit dù juge est moins impressionné par les cadeaux que par les liens de famille qui le rattachent aux parties, que surtout par la crainte des maléfices de la partie qui succomberait. Toutefois, il n'y a pas de doute qu'il fait acception des personnes.

Il faut alors faire venir le défendeur ou son représentant. On peut prévoir que celui-ci y mettra la plus mauvaise volonté. La première excuse qu'il donnerait de ne pas obtempérer à la convocation, c'est celle-ci : Tu me dis, répondrait-il à l'envoyé, que tel chef m'appelle pour un palabre; mais, je ne sais pas si c'est vrai.

Nous connaissons tous cette réponse; c'est la défaite classique employée par les indigènes pour ne pas se conformer, sans toutefois dire un non catégorique, souvent dangereux, aux ordres de l'administrateur. 
Pour prévenir cette excuse, nous envoyons un garde, ou, à défaut, nous remettons une convocation écrite, authentifiée d'un sceau; l'écriture ne suffirait pas, car les " enfants de la mission " savent aussi écrire. Il faut l'ensemble: écriture et sceau.

Le juge indigène, qui ne sait pas écrire et ne possède point de sceau, munit cependant son émissaire d'un signe sensible attestant que celui-ci vient de sa part: il lui confie dans ce but son bâton, un bracelet d'ivoire ou de métal. Sur l'un ou l'autre son nom a été écrit par un Européen ou quelque indigène lettré. Les anciens chefs importants avaient reçu des commerçants, des anglais surtout, des cannes genre tambour-major, ou des bracelets massifs en métal argenté qui étaient des insignes très prisés. La canne et le bracelet du " roi " Tchidoumi, Mwéné Mikindou, dont j’ai déjà parlé, sont encore à Mayumba entre les mains de ses héritiers.

Le signe en question est remis à l'indigène cité; c'est lui qui le rapportera au chef qui le convoque.

Au jour dit, les parties se rassemblent dans le village de l'arbitre ou dans tel autre désigné. Il y a là, outre celles-ci et l'arbitre, les tenants des deux adversaires, les voisins, des indifférents, des badauds. Tout le monde est entassé dans le corps de garde ou maison commune; on fume, on bavarde à mi-voix et les parties s'expliquent elles-mêmes ou par l'organe de leur représentant; les partisans des uns et des autres donneront leur avis et joueront le rôle de l'avocat.

Le spectacle de ces réunions est souvent curieux; l'assemblée est réunie dans le corps de garde, mais les discours se prononcent au dehors; ils sont accompagnés abondamment de gestes, comportent des séries d'interrogations, d'exclamations qui doivent être de style, car l'assemblée y répond d'une seule voix; l'orateur prend souvent à partie quelqu'un dans l'auditoire; d'autres fois, car il ne reste pas en place, il esquisse un pas de danse et le morceau d'éloquence s'achève souvent dans une chorégraphie quelque peu extravagante. Ces audiences sont assez rarement ob- 
servées; comme elles absorbent une ou deux journées, on n'en décide pas la réunion aux époques où l'on attend un déplacement de l'administrateur.

Mais les arguments finissent par s'épuiser et il faut bien prendre une décision. Quelle sera-t-elle?

Jé l'ai déjà laissée entrevoir. Larbitre tiendra compte de plusieurs considérations, dont la première sera de ne pas se faire d'ennemis; il ne demandera pas mieux que de donner raison à celui qu'il sait, qu'il voit être dans son droit, meis il ne lui donnera pas complètement raison, car ce serait donner complètement tort à l'adversaire et ce dernier n'oublierait jamais cet échec humiliant. Il fera donc, comme on dit, une cote mal taillée, adjugera à l'un une partie de ce qu'il réclame, et fera comprendre à l'autre qu'il faut tout de même qu'il se décide à payer. Celui qui aura eu gain de cause ne sera pas entièrement-satisfait, mais il a la ressource de considérer comme un à-compte ce que la décision de l'arbitre lui a alloué. Plús tard, par lui-même oú par ses héritiers, l'affaire sera reprise, si l'on voit joür à la faire réussir.

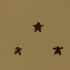

Reste à faire exécuter la sentence. Ciest la partie la plus difficile. De deux choses l'une, ou celui qui a succombé est résigné à s'y conformer, ou il ne l’est pas.

S’il est résolu à payer ce qu'on lui a imposé, il donne le plus souvent sur le champ un gage. C'est un paquet d'arachides, un couteau, une machete; c'est toujours un objet de peu de valeur, l'indigène ne possédant jamais avec lui de biens mobiliers de quelque importance. Ce gage signifie: je paierai. C'est une reconnaissance de dette en quelque sorte par acte authentique et la valeur du gage n'entre pas en compte dans le paiement.

Dès lors, le palabre est terminé; le créancier est satisfait; il n'a rien touché, mais peu lui importe, à 
moins qu'il nait un besoin immédiat de ressources; s'il touchait quelque chose ne se hâterait-il pas d'aller le prêter? Un débiteur en vaut un autre; autant vaut. mieux vaut même celui qui a reconnu sa dette devant de nombreux témoins. Aussi ne fixe-t-on point le terme du paiement, ni d'une façon générale aucune des ronditions où il devra s'effectuer: modalité, nature des marchandises, etc.; tout dépendra de la bonne volonté du débiteur, de la diligence, des besoins du créancier."

Mais si celui qui succombe ne prend point son parti de l'échec subi, s'il n'accepte pas la décision de l'arbitre et refuse de payer, la situation est insoluble.

Autrefois, le créancier ou même l'arbitre prenaient des otages. Certains, j'en ai déjà parlé, avaient des "gardes ", indigènes de leur famille ou de leur clientèle, qu'ils employaient à faire exécuter leurs citations on leurs sentences, et ils se montraient assez jaloux de leur autorité.

Aujourd'hui ces moyens radicaux leur sont interdits et, comme ce sont les seuls efficaces, je ne serais pas éloigné ale croire qu'il ne faut pas chercher ailleurs la cause de la diminution du prestige des chefs indigènes.

A présent, quand un palabre a été réglé par un arbitre et qu'il n'a pu faire exécuter sa sentence, le plaignant n'a plus qu'une ressource, c'est de s'adresser à nous. Pour lúi c'est lin pis-aller.

On remarquerasquen examinant la manière indigène de régler les litiges, je n'ai pas distingué entre procès civils ou commerciaux et procès criminels.

C'est qu'en effet nos administrés ignorent cette distinction; ils n'ont aucune notion de ce qui est l'intérêt commun, l'intérêt public, et tout se ramène pour eux à un intérêt particulier lésé par l'adversaire. S'agit-il de vol? On ne punira pas l'acte délictueux en soi, on tâchera de faire rembourser la victime. S'agit-il d'un.. 
iméurtre ? On ne suinquiète pas de protéger la société contre le retour d'actes graves, troublant la sécurité publique; on ne s'occupe que d'une chose: faire payer par le coupable le prix du sang. La coutume indigène ne connaît pas de sanctions, même pas celle du mépris public; elle ne prévoit que des compensations.

De là vient le grand reproche que les indigènes peuvent formuler, et formulent, à l'encontre de notre Justice. Ils ne nous feront pas grief de notre impartialité, pas plus d'ailleurs qu'ils ne nous en sauront gré. Chacun peut avoir successivement à s'en plaindre et à s'en louer. Mais notre justice leur paraît iuutile, puisqu'elle ne rapporte rien.

On me dira, on m'a dit: mais il vous est loisible dinfliger des dommages-intérêts, d'imposer le paicment d'indemnités représentant aux yeux des familles le prix du sang prévu par la coutume. Oui, assurément, de même quiil nous est recommandé de condamner à payer ses dettes un débiteur récalcitrant. Mais le moyen de faire exécuter la sentence?

Je sais bien, nous avons la contrainte par corps; mais si un débiteur est détenu, il ne peut plus solliciter ses propres débiteurs, recouvrer ses propres créances et désintéresser son créancier; et puis l'entretien du prisonnier est aux frais de ce dernier. Comme d'ailleurs la détention ne saurait être rigoureuse et que d'autre part elle ne comporte rien de déshonorant, c'est une mesure inopérante et impraticable.

Notre droit prévoit la saisie des biens du débiteur. La coutume indigène appliquait aussi ce principe; le créancier saisissait et au besoin vendait les biens de celui-ci; il se remboursait et se dédommageait. Le malheur est que les seuls biens liquides, tangibles, saisissables possédés par un indigène, ce sont des personnes, celles de sa famille sur lesquelles il a juridiction: épouses, enfants, neveux, esclaves, frères cadets. Ce moyen nous est donc interdit; c'était le seul efficace. En dehors de lui, nous n'avons plus rien. Comme compensations, nous n'en pouvons offrir à l'indigène que de morales; ce qu'il vient nous demander, en 
somme, ce sont des représailles. Voilà pourquoi je disais que notre intervention est pour lui un pis-aller.

Comme ces représailles ne rapportent rien, les indigènes ne les appliquaient eux-mêmes que dans des cas èxceptionnels. Si elles étaient dans les habitudes, elles ne sont pas, je crois, dans la coutume. Je n'en ai connu qu'un seul exemple: celui du meurtre, par ses maîtres, d'un esclave dont la conduite les désespérait; il ne travaillait pas, volait dans les plantations, empruntait les femmes de son prochain. Lassés de payer ses fredaines, ils le tuèrent.

Il faut dire d'ailleurs que les actes purement et simplement criminels ou délictueux sont assez rares, au moins chez les Bapounou.

Le vol pur et simple serait peut-être un peu plus commun; mais le vol par effraction, d'une case par exemple, est exceptionnel. Le vol dans les plantations est peu fréquent.

Le meurtre, l'assassinat, et, d'une façon générale les crimes de sang, ne le sont pas davantage. Je signalerai, en passant et avec doute, la trace d'une coutume ancienne, suivant laquelle le chef de la terre avait droit à une indemnité en raison du sang versé sur son territoire, trace que j'ai relevée une seule fois.

En revanche, dans les endroits où les palmiers abondent, les rixes à main armée où le sang coule sont assez fréquentes, mais le vin de palme en est la cause; elles n'ont pas en général de suites mortelles. Toutefois, les plaies produites par les longs couteaux bayaka sont émotionnantes. 
CHAPITRE II

\section{Des CRIMES CONTRE les PERSONNES}

\section{$\S 1$ \\ De l'empoisonnement}

Il se produit cependant, et trop nombreux malheureusement, des crimes entraînant mort d'hommes; mais ceux-là sont environnés de mystère. Les indigc̀nes ne sont pas sûrs si leur auteur est un homme ou l'esprit d'un homme, est un homme ou une bête. Je veux parler des envoûtements et des crimes attribués à l'homme-tigre. Sur les uns comme sur les autres, on n'a eu jusqu'à présent que des renseignements bien restreints.

L'obscurité qui les enveloppe est due au peu de connaissance que nous possédons sur les croyances des populations; elles sont, je pense, partout les mêmes dans la Nyanga. Les indigènes font la distinction entre le corps et lâme; mais ils y surajoutent un troisième élément qui pourrait s'appeler l'esprit, le double, le corps astral, élément qui dans la conception des indigènes n'est assurément pas l'àme. Cet esprit, intimement lié au corps en temps normal, peut l'abandonner, par exemple, pendant le sommeil et agir indépendamment de lui; il survit, au moins quelque temps, à la mort du corps, et constituerait alors ce que nous pourrions appeler les mânes des défunts. On lui prête très généralement un rôle malfaisant.

C'est lui qui agissant sur le corps d'autrui, à l'insu ou avec l'assentiment de celui que j'appellerai son propriétaire, c'est lui qui peut causer sa mort en s'attaquant aux organes internes et $y$ provoquant des maladies. Pour nos administrés, on le sait, la mort n'est point un évènement naturel, elle est toujours causée par quelqu'un qui, volontairement ou inconsciemment, a " mangé l'âme " de la victime, disent les indigènes, l'a "empoisonnée ", traduisent les inter- 
prètes, l'a "envoutée ", dirons-nous, par souci de la précision.

Je veux attirer l'attention sur l'expression d'empoisonnement employée par les interprètes; ils n'en connaissent pas d'autre et c'est grand dommage; car elle a ému plus d'un d'entre nous au début de sa carrière; elle a été, et pourra être encore la cause de condamnations tout à fait injustifiées. J'ai vu ainsi infliger 5 et 10 années de prison à deux soi-disant empoisonneurs, parfaitement innocents, au moins de ce crime: leur victime avait succombé à la suite d'un repas, où elle avait eu une demi-douzaine de commensaux restés indemnes, et où tous avaient mangé au même plat, bu au même vase; après enquête, j'ai pu retrouver le médecin qui avait soigné le mourant; il attesta que, celui-ci avait succombé à une maladie dont.les premiers symptômes lui étaient apparus et avaient été traités par lui longtemps aupararant.

Lors donc qu'on nous parlera d'empoisonnement, il conviendra d'insister avec soin pour faire préciser: s'il y a eu, et dans quelles circonstances, des substances ingérées qui pourraient être rénéneuses. L’on a chance d'entendre des réponses singulières, comme celle que jai recueillie un jour d'un plaignant, prétendant que son oncle avait été empoisonné avec des " excréments d'arc-en-ciel ".

Je ne veux pas dire que les empoisonnements sont une légende; ils sont au contraire fréquents à la côte et les Bavili ont la réputation d'être passés maîtres dans cet art. Mais les idées d'empoisonnement et d'envoûtement sont si bien embrouillées, mélangées, qu’il est sourent impossible de faire distinguer les deux actes par les indigènes.

La médecine légale nous prêterait un grand secours, mais sur les poisons du Gabon, elle est dans l'enfance. On sait qu'il y a des Strophanthus, des Strychnos rénéneux; on connaît la fère de Calabar, l'Erythrophlœum guineense. On parle de poisons provenant de la décomposition des substances animales; j'ai entendu parler de poisons ferments. En résumé on ne 
sait à peu près rien; on ignore presque totalement, en tous cas, la manière de retrouver ces poisons dans l'organisme, condition sans laquelle un médecin, requis pour une autopsie, ne conclura jamais à un empoisonnement.

Pour nous, ce que nous devons obtenir, en pareil cas, c'est l'aveu et c'est toujour's difficile.

Il se trouve en effet dans une affaire d'empoisonnement des responsabilités de plusieurs ordres. Il y a bien le coupable principal, l'empoisonneur proprement dit, celui qui a intérêt à faire disparaître la victime. Mais il peut avoir un complice qui a effectivement administré le poison; il y en a, autant dire toujours, un autre, celui qui l'a fourni. Les fabricants de poison sont des spécialistes, souvent des femmes, et qui vendent leur marchandise assez cher. Pour se garder des dénonciations d'ailleurs, elles exigent du solliciteur un crime préalable, un assassinat, en un mot: une vie humaine; leur client la choisit généralement dans sa famille proche et la victime est fréquemment un de ses enfants. Le poison n'est livré qu'à ce prix.

On conçoit facilement, dans ces conditions, combien il est ${ }^{-}$ardu de se faire une certitude. D'une part, on veut ne pas se laisser impressionner par la clameur publique, de lautre on est émotionné par une mort suspecte et l'on voudrait bien en trouver et punir les auteurs. C'est assurément un des débats de conscience les plus pénibles.

\section{$\S 2$}

\section{De l'Homme=Tigre}

La superstition de l'homme-tigre n'est pas moins obscure que celle de l'envoûtement. Elle se présente sous deux formes. Dans un cas le tigre, entendez : léopard ou panthère, le tigre auteur du crime est un animal véritable appartenant à un individu, lui obéissant, exécutant ses ordres; ce tigre passe à ses héri- 
tiers comme un autre bien nobilier. Un tel, dit-on, a un tigre. Dans l'autre cas, l'animal n'est qu'une incarnation, en quelque sorte; on ne sait mène pas bien si c'est un homme qui a pris figure de bète, la bête n'étant alors qu'une apparence, - ou bien s'il y a eu incarnation proprement dite d'un homme dans un animal véritable.

Cette superstition doit ètre très répandue dans l'Afrique bantoue; je l'avais constatée en Zambézie sous les mêmes formes; elle s'appliquait au lion, à la panthère ou léopard et mème au crocodile. Il n'y a là rien d'étommant, lous ces bantou sont de mème souche et ils parlent des dialectes assez voisins pour que certains de nos compatriotes, connaissant des langues du Gabon, arrivent à comprendre d'emblée celles de la Zambézie.

Lidéc que les indigènes se forment de l'hommetigre est extrêmenient obscure; je citerai le cas suivant. Dans les savanes de la Nyanga, une panthère véritable arait fait des victimes; on commençait à parler d'homme-tigre. Un Européen se rendit sur les lieux, examina les blessures, les traces de l'animal, et conclut de toute évidence à un aninal ; il ne pouvait cn aucune manière s'agir d'assassinat. Les indigènes abondaient dans son sens; il les croyait convaincus. L'un d'eux déclara avoir vu la bête, en indiqua les circonstances et la cause paraissait entendue, quand il ajouta: " J'ai vu l'animal, il avait un pagne de guinée et il avait des grosses couilles!" Il fallut arrêter l'affaire d'autorité et c'est une mesure au résultat bien aléatoire.

Qu'y a-t-il au fond de toutes ces histoires d'hommetigre? Il est assez difficile d'élucider la question.

Quelquefois, nous nous trouvons certainement en présence de méfaits qui sont l'œuvre d'un animal véritable. C'est souvent le cas quend il s'agit de massacro ou de disparition danimaux domestiques: chiens, poules, moutons. Ce peut être encore le cas s'il y a des victimes humaines, mais cette dernière hypothèse se réalise, je crois, exceptionnellement. 
Très souvent, je n'ose dire, le plus souvent, il n'y a que vulgaire et làche assassinat, crime d'autant plus épouvantable; quil est la plupart du lemps commis sur des êtres faibles et sans défense: vieillards, enfants et femmes. C'est la rengeance dans ce qu'clle a de plus répugnant.

N'y a-t-il que cela? Il y a autre chose et qu'il est bien difficile d'expliquer. Une remarquable étude a été faite de la question dans la Subdivision de Tchibanga en 1916 par M. H. Charbonnier, Administrateur-Adjoint des Colonies. Après une enquète de plusieurs mois conduite avec unc persévérante sagacité, il a découvert l'existence de véritables sociétés secrètes d'hommes-tigres; elles ont leur hićrarchie, leurs statuls, leurs cérémonies d'initiation.

Mais quel est leur but véritable? Constituent-elles une secte religieuse? Poursuivent-elles seulement la satisfaction d'instincts pervertis? M. Charbonnier n'a pu l'établir. Leur objet immédiat est de se livrer à des sacrifices de vies humaines, en suile desquels on boil le sang et on mange quelques parties de la victime.

Certains articles des statuts règlent la marche de ces sacrifices: on les renouvelle à chaque initiation, à la création de chaque groupe nouveau. Dautres ont lieu au gré des divers membres.

Pour l'établissement et le développement des trois groupes étudiés par M. Charbonnier, qui complaient ensemble 56 adeptes, le calcul indique qu'il a été immolé en 8 ou 9 ans plus de 80 vicțimes, je dirai, victimes statutaires; le nombre des vies humaines sacrifiées pour la seule satisfaction de l'instinct sanguinaire individuel est inconnu; on sait seulement que les victimes règlementaires n'ont pas étć les seules massacrées.

Ce résumé sommaire de l'ćtude en question dispense de tout commentaire tant sur le caractère monstrueux de ces rites que sur l'urgence de leur abolition.

On ignore encore quelle est l'extension de cette secte en pays bayaka; il n'est pas possible de dire si les crimes imputés aux hommes-tigres dans diverses 
parties de la Circonscription doivent être attribués à des sociétés analogues. Toutefois, j'incline à croire que leur développement n'est pas aussi considérable; la fréquence des crimes dans un territoire donné est trop restreinte pcur qu'on puisse l'attribuer partout à une société du genre de celles étudiées par notre confrère.

\section{$\S 3$}

\section{De la procédure en matière criminelle}

Les morts par envoùtement ou du fait de l'hommetigre, et c'est-à-dire à peu près tous les décès, donnent lieu à des procédures très longues sur lesquelles il convient d'insister. Les pratiques fétichistes entrainant mort d'homme, aux yeux des indigènes, relèvent non pas de la religion, mais de la magie. Ils ne font pas très nettement la séparation, la distinction cutre les deux ordres de faits; ils en ont cependant une idée et ils ne s’élèvent jamais contre des érènements auxquels ils attribuent Dieu pour auteur. Ils ne connaissent rien du Créateur, mais ils croient à son existence; quand un vieillard très âgé vient à mourir, il ne viendra à l'idée de personne daccuser. quelqu'un de maléfice. Dieu l'a pris, dit-on; et on s'en tient là.

Dans les autres cas, il en va différemment et il faut à tout prix trouver à la mort un auteur responsable. Ce n'est pas le souci de l'intérêt public qui anime la famille, ce n'est pas davantage le besoin de la vengeance, sentiment qui serait encore fort excusable chez des êtres primitifs. Le mobile qui les conduit est beaucoup moins noble, c'est l'àpreté au gain. L'auteur de la mort doit payer diboumi, le prix du sang. Le taux en est variable, suivant la cupidité des bénéficiaires, suivant aussi peut-être la situation du défunt. Il comportait toujours autrefois un ou deux esclaves, comme si on eût voulu remplacer numériquement la vie qui venait de s'éteindre. Le non-paiement du prix du 
sang entraînait le plus souvent la mise en servitude de l'auteur présumé de la mort, et au besoin d'une partie de ses proches.

Comment le coupable est-il désigné ?

De plusieurs manières.

Il y a d'abord la désignation faite par la victime. Je n'ai jamais eu l'occasion d'assister au décès d'un personnage important; mais, des nombreux palabres qui mont été soumis, j'ai conclu que les derniers instants lucides du moribond devaient être assiégés des questions de la famille. Ses membres veulent connaître le responsable de la mort menaçante; peut-être l'agonisant en a-t-il eu la révélation dans un rêve. Un songe est plus probant qu'un témoignage, et puisqu'il s'agit d'inculper un esprit, quoi de mieux que l'attestation d'un esprit?

Maintenant, les mourants parlent-ils aussi fréquemment qu'on a voulu me le faire croire? J'ai quelques doutes; l'imagination des proches y supplée; l'important est qu'il y ait un coupable désigné et qu'il soit solvable.

A défaut de pareille accusation in extremis, et même conjointement avec elle, un autre procédé est appliqué. On interroge le cadavre lui-même; on en pratique l'ouverture, la nécropsie et les organes sont examinés. Malheureusement, cette tâche est réservée à un féticheur et il opère, sauf erreur de ma part, sans témoins. Il a beau jeu à raconter qu'il a trouvé telle plaie et il la montre: c'est à ne pas s'y tromper un coup de couteau, dans le cœur, dans'les poumons, ou les intestins; il présente des objets qui de toute évidence n'ont pu pénétrer par les voies naturelles: noix de palmes creusées et remplies de substances plus ou moins déterminables, etc., etc. La conclusion de l'autopsie indique done toujours qu'il y a eu crime mystérieux, envoûtement. Reste à désigner un coupable et il n'est pas plus difficile au féticheur, au.nganga d'y parvenir.

Enfin s'il s'agit d'un crime attribué à l'homme-tigre, la disposition des blessures, leur situation, la disper: 
sion des lambeaux du cadarre, ne peuvent laisser aucun doute. Et le nganga n’aura pas plus de peine à désigner le sorcier malfaisant.

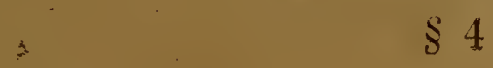

\section{De l'épreuve du poison}

L'auteur ainsi désigné se laissera-t-il condammer sans mot dire? Il s'en faut. Mais il y a lieu de s'attendre à tout avec nos indigènes. Jai entendu un homme ainsi accusé répondre: "Je veux bien payer, parce que, en somme, j'ai bien pu tuer un tel en dormant; mais cn conscience, je n'en sais rien ". Fallait-il conclure à la culpabilité ? Je ne lai pas cru.

D'autres se défendent énergiquement, et, sùrs de leur innocence, offrent de se soumettre au poison d'épreuve. Dans toute notre région, le poison le plus employé, le seul employé, je crois, est le "mboundou". Il est possible que ce soit un Strychnos; je ne l'ai vu ni en fleurs, ni en fruits. Il m'est apparu comme un, arbuste atteignant au plus $1 \mathrm{~m} .50$ à $2 \mathrm{~m}$., n'ayant rien de particulièrement remarquable, si ce n'est sa lrès longue racine pivolante; on peut en arracher sans la briser plus de 0,75 . C'est l'écorce de cette racine qui est employće; ràclée, elle est franchement rougeàtre et amère.

Comment l'administre-t-on? Je n'ai pu me le faire dire avec précision. Le nganga fait de cette écorce râclée de la racine une infusion, ou une macération que boira le patient; il pourrait se faire aussi quon lui fasse absorber des boulettes de cette même substance. Le poison ingurgité, on en attend l'effel; le patient, pour être déclaré innocent, doit, au bout d'un certain temps, avoir uriné; si cela lui est devenu impossible, il est coupable. Le coupable désigné par l'épreuve était-il, autrefois au moins, exécuté à mort sur le champ? Je ne le crois pas. Le mboundou, en effet, ne s'administre pas toujours aux accusés euxmệmes; on peut prendre le mboundou par procura- 
tion; le neveu remplace l'oncle, le cadet son aîné. J'ai appris que, chez les Mitsogho,-on le faisait prendre à des poules. Dans bien des cas, l'épreuve du poison semble avoir le caractère d'un sort jeté entre plusieurs coupables possibles, que le résultat élimine successivement.

- A l'heure actuelle, on administre encore le mboundou aux personnes humainés, à notre insu naturellement, mais on ne manque pas de faire prendre aussitôt après un contre-poison, dans la composition duquel entreraient, paraìt-il, des oufs et de la poudre.

J'ai cependant connu et jugé un cas où le coupable d'une mort attribuée à l'homme-tigre, coupable désigné, sans poison d'épreuve, par un féticheur, a été massacré sur le champ par les proches parents de la défunte, sa propre femme. Mais c'est certainement un cas exceptionnel.

Comme tous les peuples primitifs, les indigènes ont foi dans l'épreuve du poison. Est-elle au moins excusée par l'honnêteté des féticheurs qui l'administrent et qui sont le plus souvent spécialistes de la préparation? J'ai de la peine à les croire scrupuleux; ils doivent, suivant la générosité des parties, augmenter la dose ou la diminuer opportunément. Il va sans dire, d'ailleurs, que c'est une coutume à supprimer.

\section{$\S 5$}

\section{Caractère des sentences et des pénalités}

A la suite de l'épreuve du mboundou, le coupable est désigné; le litige devient un litige ordinaire. Il s'agit de faire payer le prix du sang. C'est une somme d'argent qui est en cause. Jai exposé ailleurs les péripéties de la procédure.

A présent, toutefois, où le poison d'épreuve ne sadministre plus aussi généralement, puisqu'on sait ce moyen d'instruction défendu, j'ai constaté que les procès criminels pouvaient donner lieu à de véritables enquêtes, avec auditions de témoins, confrontations, 
etc. Il se produit alors parfois un incident que je veux indiquer; le prérenu s'est décidé à avouer, mais il lui répugne de le faire en public; en raison de quel sentiment?. Je ne me le figure pas, le chàtiment ne se présentant pour lui que sous la forme d'une indemnité qu'on ne peut guère le contraindre à payer. Il déclare alors avoix a faire à ses juges une déclaration secrète; ceux-ci se retirent à l'écart arec lui, et c'est derant cet aréopage restreint qu'il formule son aveu. Au retour, derant le public, il se contentera de dire qu'il paiera; on ne lui en demandera pas davantage.

Ce conseil secret se nomme en pounou, "foundou". Il est en usage non seulement entre prévenus et juges, mais entre ces derniers eux-mênes; quand les arbitres d'un litige veulent se concerter, ils " vont au foundou ", y délibèrent leur décision et revienment la prononcer devant lauditoire.

On peut encore imaginer le cas oì ni le mourant n'a fait de déclarations, ni le coupable n'a formulć d'aveux, ni l'épreuve du poison n'a donné de résultats. Il reste encore une chance de trouver un coupable et de le punir, c'est de pratiquer l'incantation qu'on appelle chez les Bayaka, Kossi.

Elle est faite par des nganga spéciaux, qu'on appelle nganga Kossi. Ce sont le plus souvent, comme beaucoup de sorciers d'ailleurs, des étrangers: esclaves Banzabi, Masango, Mitsogho. Il semble que leur prestige s'augnente de l'obscurité et de l'éloignement où se perd leur origine.

Le fétiche Kossi est grave en ceci qu'il touche à coup sûr le coupable, cause infailliblement sa mort. Et voici comment on procède à l'opération. Un individu meurt et on ne peut présumer qui peut bien aroir " mangé son àme ". Le nganga Kossi est appelé. Dans une calebasse, il met du vin de palme, de lhuile de palmistes et la suspend dans la case du mort.

Puis, avec des substances d'alimentation courante: bananes pilées, poisson fumé, graines de courges, il forme une boulette à laquelle il ajoute de la chair du défunt, et va l'enterrer superficiellement sur sa tombe, 
Au-dessus, il pose un piège, de ceux qui servent à prendre les petits animaux: oiseaux, tchibissi, etc.

Il annonce alors que dans un délai déterminé, 3 ou 6 mois ou même un an, quelqu'un aura mal à la tête, ou au ventre, ou en quelque endroit du corps qu'il désigne, qu'il parlera alors une langue ćtrangère, nzabi ou itsogho, et qu'il mourra. Ce sera le coupable.

Le nganga doit visiter au bout de 10 jours le piège posé sur la tombe; il le trouvera détendu: un anima! l'a déclenché, ou même une feuille morte. Il saisit l'animal ou la feuille, en un mot ce qui est pris au piège, et le brûle. Le charme est parfait; on n'a plus qu'à attendre son résultat.

Il réussit, paraît-il, toujours, el je ne m'en étonne pas; ce qui semble curieux, c'est la manifestation prévue d'avance que le coupable parlera une langue étrangère; la connaissance en est exceptionnelle. Je n'ai jamais été témoin de ce prodige, mais les indigènes y croient; l'un d'eux m'a affirné avoir ainsi entendu parler nzabi, et il ajoutait: "Le nganga avait dit : Le coupable aura mal à la tête, il parlera nzabi, puis mourra. Pambo Gnyoundou, un mois après la confection du médicament, a eu mal à la tête, il a été malade cinq mois, au début du cinquième mois, il a parlé nzabi, puis il est mort. On l'a ouvert; il avait passé avant de mourir un jour sans manger; pourtant nous avons trouvé dans son estomac ce que le nganga avait mis dans la calebasse et la bouiette, et, entre autres closes, l'huile de palmistes (qui n'est jamais consommée) ! ! !”

Cette coutume du Kossi est à proscrire au moins autant que celle du poison d'épreuve; c'est un prétexte à escroqueries et à assassinats. Elle a, en outre, ce défaut, qu'elle ne termine rien et qu'elle ajoute un palabre aux outres; la famille de la victime tuée par le Kossi au lieu d'accepter de payer le prix du sang pour le premier défunt, sera très disposée à le réclamer pour son parent. Des représailles sont toujours à craindre. 


\section{Quel compte tenir de Ia justice des indigènes ?}

Quelle conduite devons-nous tenir viș-à-vis de la Justice des indigènes? Il y a lieu de distinguer.

L'épreuve du poison, le Kossi sont évidemment des procédés qui doivent être proscrits. De même la prise d'otage, la mise en servitude. Une assemblée indigène ne saurait désormais avoir le droit, sinon d'infliger des peines afflictives, que la coutume ne connaît pas, au moins de porter atteinte à la vie, à la liberté, ou seulement à la santé des personnes.

D'autre part, la coutume ne prévoit que des compensations; celles-ci étant d'un paiement très aléatoire, même quand il est imposé par nous, il convient d'y ajouter des sanctions. C'est d'intérêt public.

Nous devons donc nous réserver absolument le règlement, le jugement de toutes les affaires criminelles.

Il est probable toutefois que la Justice des indigènes en aura été saisie avant nous. Nous ferons donc sagement d'examiner avec soin cette enquête préliminaire; à défaut d'éléments de preuve, nous y trouverons d'utiles renseignements, et propres à diriger notre instruction, à aider à la manifestation de la vérité, à contraindre le coupable aux areux. Car le plus souvent, les indigènes ne savent pas mentir, je veux dire, ne savent pas organiser un mensonge.

Il faut cependant user de cette enquête indigène avec prudence; ce qui est en jeu, ce sont des intérêts particuliers. Les plaignants ont besoin d'un coupable, et solvable; ils s'inquiéteraient peu de faire condamner un innocent.

Dans les affaires civiles, il en va différemment et je serais disposé à laisser aux arbitres indigènes beau= coup plus de liberté.

Il faut d'abord leur abandonner sans exception tous les litiges trop anciens, ceux dont les parties primi- 
tives ont disparu, où les témoins sont morts. Nous ne parviendrions pas à nous faire une certitude. La langue des indigènes comporte des formules dont le sens littéral ne nous dit rien, mais dont l'emploi peut avoir une signification plus étendue. Un arbitre indigène sait ce que parler veut dire. Telle allégation, telle réponse le convaincra qui ne nous apporterait aucune lumière.

La décision d'ailleurs pourra sans difficulté être soumise à notre confirmation.

Je ne verrais pas d'inconvénients à ce que les autres affaires civiles soient soumises à ces mêmes juges, s'ils ne présentent pas a priori des indices évidents de partialité. Je dirai même que je laisserais volontiers aux justiciables la liberté de s'adresser à tel arbitre de leur choix: chef indigène, commerçant, missionnaire. A une condition toutefois, c'est que leur préférence ne fût pas un signe de méfiance ou d'hostilité à notre égard, qu'ils n'obéissent pas aux sollicitations de gens dont le but serait de diminuer notre autorité. Mais si les arbitres européens ou indigènes sont de bonne foi, qüimporte? Ils retireront de leur rôle un supplément d'influence? Tant mieux, leur tâche en sera d'autant facilitée; il n'y a que des avantages à voir augmenter l'autorité d'un chef, la clientèle d'un commerçant, la main-d'œuvre d'un planteur, les fidèles d'une Mission.

Notre autorité à nous n'en sera pas diminuée; îl nous est toujours loisible d'accueillir l'appel qui serait fait de ces décisions, et même d'évoquer l'affaire à notre Tribunal.

Ce dont les indigènes ont le plus besoin, c'est de la paix. Pour la leur procurer, on peut tout sacrifier, même l'équité. Leurs palabres sont souvent si compliqués, qu'il est bien difficile de déterminer qui a tort. et qui a raison. Et le système de la cote mal taillée est peut-être le plus approprié à ce genre de litiges. 


\section{CONCLUSION}

J'arrêterai ici ces commentaires. Le soin revient à unes confrères d'en contrôler les assertions, corriger les erreurs, réparer les omissions. Le travail est loin d'être complet; tel qu'il est cependant, je crois qu'il ne sera pas inutile aux fonctionnaires de l'Administration régionale; en mettant ceux-ci d'emblée au courant des principales coutumes de notre région, il leur évitera les tâtonnements et les hésitations du début, les pertes de temps et les erreurs qui en résultent.

La peinture que j'ai faite de l'état moral de nos indigènes ne les surprendra pas; l'expérience qu'ils ont acquise leur dira que je n'ai rien exagéré. Il n'en sera sans doute pas de même pour un lecteur non initié; pour quiconque viendra de la Métropole, ou même seulement d'une autre Colonie, ma description semblera bien poussée au noir. Avec une organisation telle qu'elle est dépeinte dans ces lignes, pensera-t-il, avec cette absence de cohésion dans la population, cet abaissement, cette suppression de l'autorité natuirelle, il paraît bien difficile d'obtenir de ces races une érolution, un progrès quelconques.

J'en suis bien d'aris; le problème est difficile. Je crois que mieux vaut le reconnaître en toute franchise; nier une difficulté ou la passer sous silence n'est pas la résoudre. En se mettant courageusement en face d'elle, en l'examinant sous ses divers aspects, on a chance d'en découvrir, au moins d'en préparer la solution. Et le travail que j'achève, outre le but d'enseignement que je me suis proposé, avait aussi celui de rendre éridents les obstacles auxquels se heurte notre ouvre de civilisation. L'état actuel des indigènes est la conséquence, la résultante d'un ensemble de croyances superstitieuses. C'est elles qu'il faut faire disparaître, c'est avant tout cet état d'esprit 
quil faut modifier; et pareil changement ne se produit pas au commandement. Il ne saurait être obtenu par la vertu, ex opere operato, d'un règlement.

Mais nous pouvons y contribuer puissamment par notre influence personnelle. L'indigène est foncièrement versatile; toutefois, de tous nos enseignements, de tous les conseils qui paraissent le laisser indifférent, il reste toujours une trace, infinitésimale, je le veux bien, mais certaine. De ces traces accumulées, un ordre de pensées différent naîtra dans ces esprits enfantins; aux sentiments férocement individualistes succéderont à la longue des sentiments plus charitables. Et quand un noir commencera à s'occuper de son voisin, il ne sera pas éloigné de la notion de l'intérêt commun.

Une comparaison se présente fréquemment à mǫ̣ esprit.

Les grands fleuves ne manquent pas de charrier dans leurs eaux des quantités de matières étrangères; ils les abandonnent à leur embouchure. Lapport annuel est mince, à peine appréciable; mais avec le temps ces dépôts accumulés feront reculer la mer. Notre action ressemblera en quelque manière à celle de ces cours d'eau.

La tàche sera donc très longue; ce n'est l'ocurre ni d'un fonctionnaire, ni d'une génération. A peine la première partie en est-elle accomplie; je veux dire lapprivoisement de la population. A présent doit commencer le dressage. On pourrait croire, à me lire, que j'ai les noirs en grand mépris; ce serait une erreur. J'ai pour eux la plus profonde pitié; mais je les prends pour ce que je crois qu'ils sont: des enfants particulièrement mal doués au point de vue du caractère, de l'intelligence, pourvus, par contre, d'un bel assortiment de vices. Je ne vois à leur usage que cinq péchés capitaux, mais ils les possèdent au degré héroïque.

L'évolution sera lente; le progrès, difficile, ne sera constaté quaprès plusieurs générations. Mais que sont 25,50 années au regard de la vie d'un peuple?

Soyons seulement persuadés que ce progrès est 
possible: si la race noire est actuellement inférieure à la nòtre, je ne veux pas croire qu'elle le soit par nature, ni surtout qu'elle doive l'être toujours. "Il ne faut pas consentir à mettre des inégalités fatales et ćternelles entre les honmes ".

Tehibanga 1914 -. Sindara 1918

FIN.

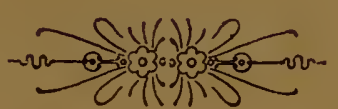





\section{TABLE DES MATIÈRES}

Sur la manière d'appliqu si les coutumes indigènes. - Conseils préliminaires aux Chefs de Subdivision

\section{PREMIERE PARTIE}

\section{Des Personnes}

Chapitre I. - De l'Etat des Personnes.

$\$ 1 .-$ De la Servitude.............. 6

$\$ 2$. - De l'origine ethnique des esclaves et spécialement des Babongo.......... 16

Chapitre II. - De. la famille ou tribu........ 21

Chapitre III. — De la filiation............ 25

Chapitre IV. — Du nom............... 27

Chapitre V. - Des devoirs réciproques des parents et des enfants, des maîtres et des esclaves.

Chapitre VI. - De la tutelle et de l'adoption... 38

Chapitre VII. - Du Mariage.

$\$ 1$. - Des conditions requises pour contracter mariage ...................

$\S 2$. - Solutions proposées aux litiges occasionnés par les mariages............

$\S 3$. - Des droits et devoirs respectifs des époux.

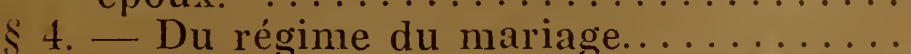

5. - De la dissolution du mariage...... 57

6. - Du mariage entre femmes......... 69

$\$ 7$. - De l'adultère................. 70

Chapitre VIII. - De la répartition territoriale des indigènes. .................. 82

$\$ 1 .-$ Du village....................... 83

2. Du nom des villages................

$\S 3$. - De la terre.................. 93

Chapitre IX. - De l'autorité indigène.

\$ 1. - Existence de l'autorité........... 96

2. - Attributions de l'autorité indigène.. 103

3. - Transmission de l'autorité......... 107

$\S 4$. - Des titres indigènes............. 110 


\section{DEUXIẼAE PAR'TIE \\ Des Biens}

Chapitre I. - Des biens immobiliers et mobiliers 113

Chapitre II. - De la propriété.............. 126

$\S$ 1. - Propriété des biens immobiliers...... 127

$\S 2$. - Propriété des biens mobiliers...... 128

$\$ 3$. - Des différentes manières dont on acquiert la propriété................. 133

Chapitre III. - Des successions............. 134

$\$ 1$. - Des qualités requises pour succéder. 135

$\$$ 2. - De l'ordre successoral............ 136

3. - De la prise de possession et de la répartition des héritages. ........................ 136

$\S$ 4. - Des testaments.............. 140

Chapitre IV. - Des contrats et des obligations.

$\$ 1$. Considérations générales.......... 142

$\$ 2$. - Des différentes espèces de contrats: De la vente ou de l'échange. _. Du paiement. ..................... 154

\$3. - Du contrat de louage d'ouvrage.... 163

$\$$ 4. - Du contrat de gardiennage de bétail. 169

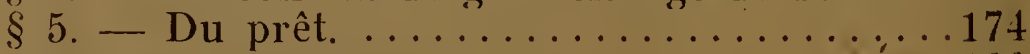

$\S$ 6. - Du mandat. . . . . . . . . . . . . 180

$\S$ 7. - Du cautionnement. ........... 183 TROISIÈME PARTIE

\section{De l'Administration de la Justice entre les indigènes}

Chapitre $\overline{1}$. - De la procédure en matière civile. Caractère des 'sentences...............

Chapitre II. - Des crimes contre les personnes.

\& 1. - De l'empoisonnement. ........... 194

$\S 2$. - De l'homme-tigre. ............. 196

$\S 3$. _. De la procédure en matière criminelle. .................... 199

$\S$ 4. - De l'épreuve du poison............ 201

$\$ 5$. - Caractère des sentences et des pénalités.

202

$\S$ 6. - Quel compte tenir de la justice des

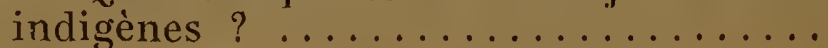

Conclusion. 



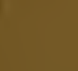

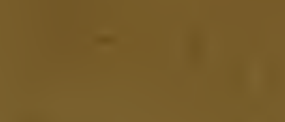

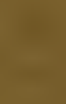

Y

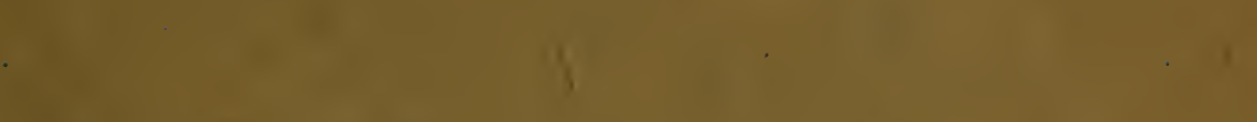

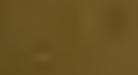

$-$

$=$

.

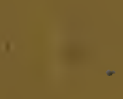

1

$+$

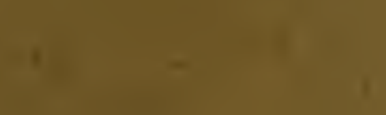
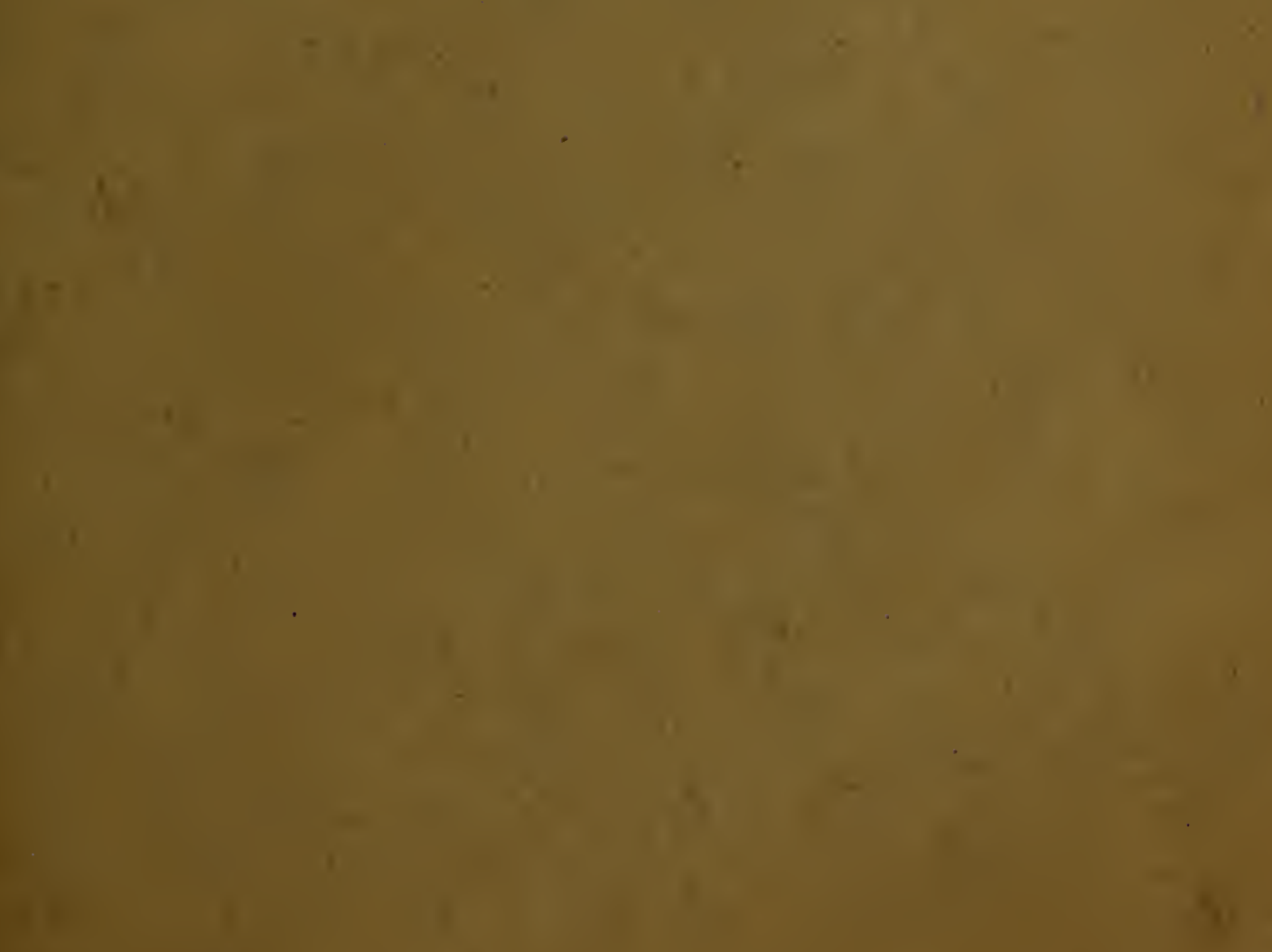
